\title{
Pleasure and Dread: The Paradox of Travel
}

by

Jo ANKOR

BACHELOR OF CUlTural TOURISM (HONS)

This thesis is submitted to the Graduate School of the University of Technology, Sydney in fulfilment of the requirements for the degree of Doctor of Philosophy.

December 2009 


\section{TABLE OF CONTENTS}

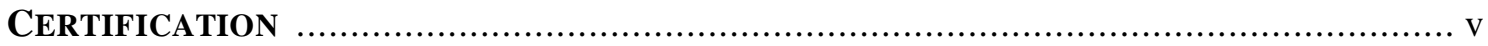

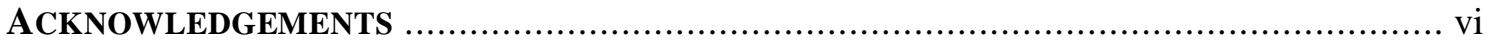

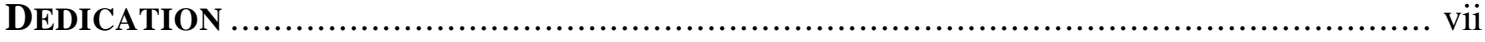

ABSTRACT

INTRODUCTION

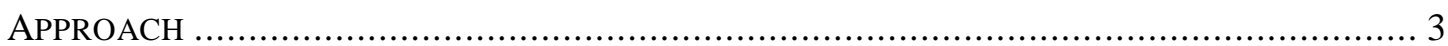

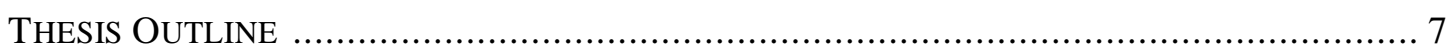

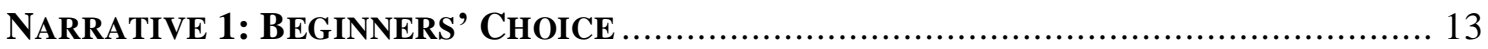

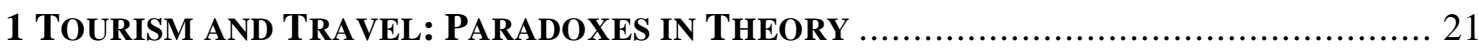

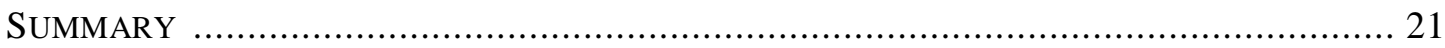

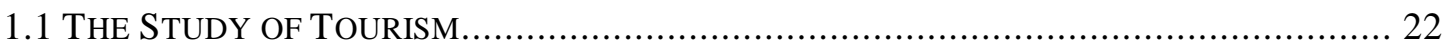

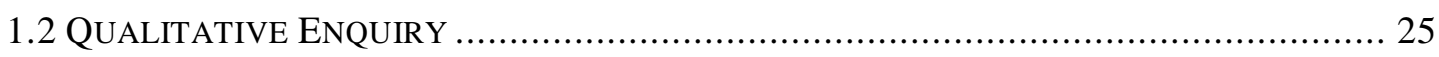

1.2.1 COMPLEXITY AND QUALITATIVE ENQUIRY ........................................... 26

1.3 THE SEARCH FOR MEANING ............................................................................ 30

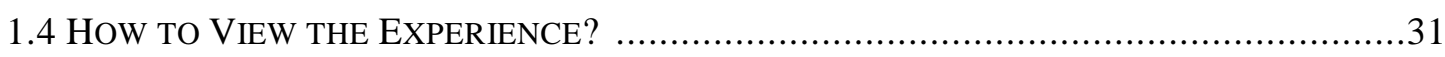

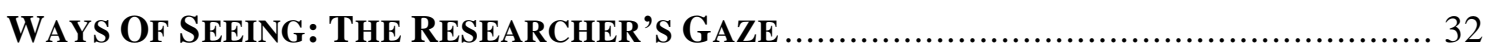

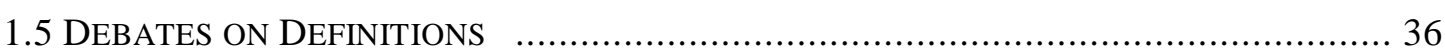

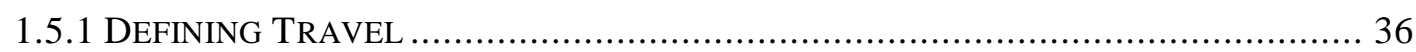

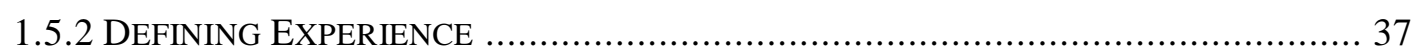

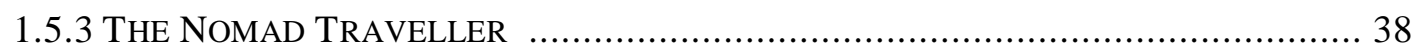

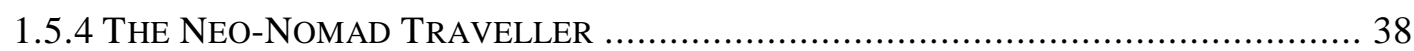

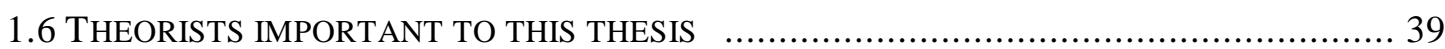

1.7 REVIEWING TOURISM THEORY DEVELOPMENT .................................................. 41

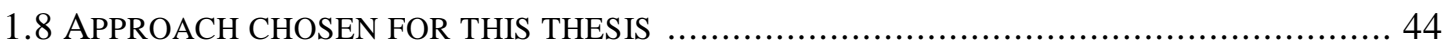

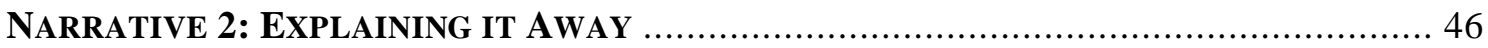

2 Choosing the UnKnown: Paradoxical Nomads ............................................. 53

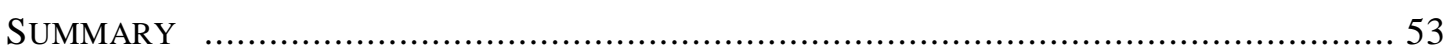

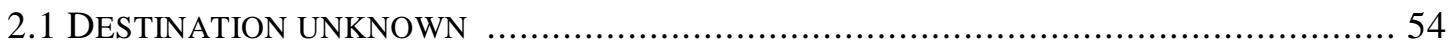

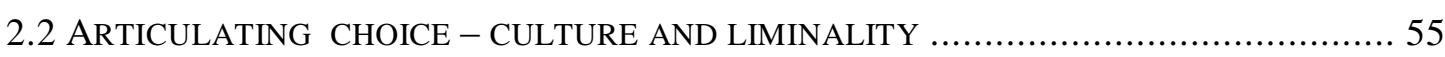

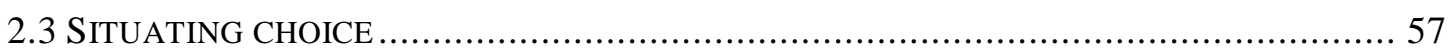


2.4 LIMITS IN LANGUAGE AND DISCOURSE. 59

2.5 TRAVEL - HOME, DISCOVERY AND PRIVILEGE ............................................... 61

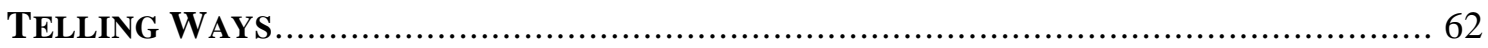

2.6 KINDS OF UNKNOWN - WILDERNESS, ADVENTURE, BACKPACKER ....................... 67

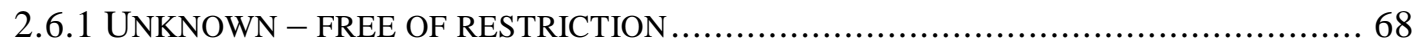

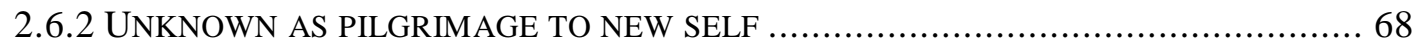

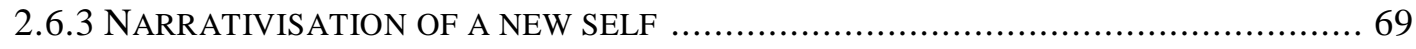

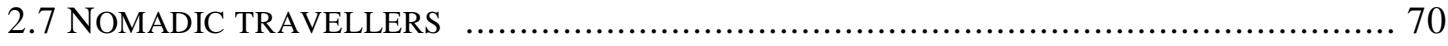

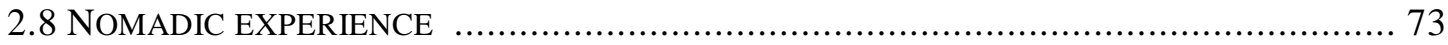

NARRATIVE 3: THE SAILING BODY - THERE'S NO MIDDLE GROUND AT SEA！.............. 76

3 ENCOUNTERING DIFFERENCE: THE OFFER IN THE MOMENT .............................. 89

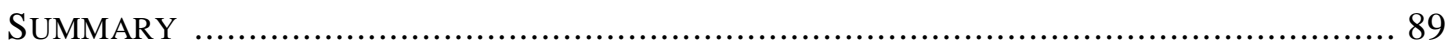

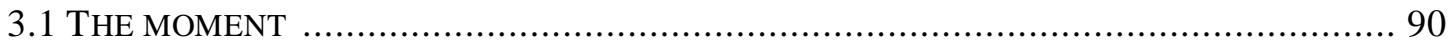

3.2 CREATIVITY - MOMENT, SPACE AND PRESENCE .............................................. 93

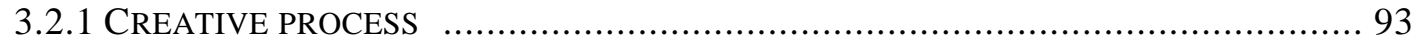

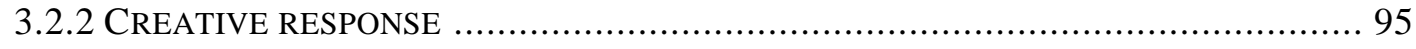

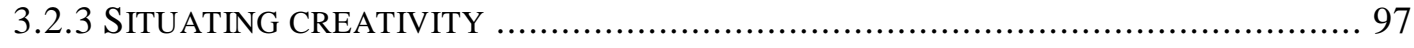

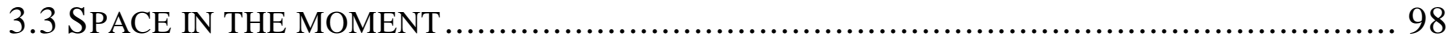

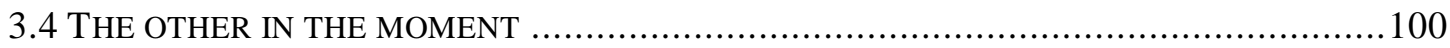

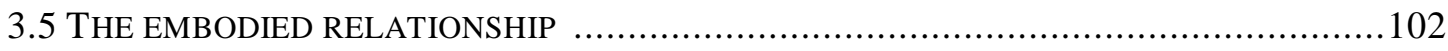

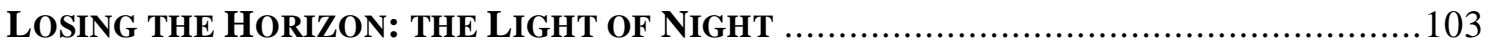

3.6 THE REFLECTIVE SUBJECT - NARRATIVISATION AS CREATIVE SUBJECTIVITY? .........108

NARRATIVE 4: THE EXOTIC LIMINAL-THOSE OTHERS, BEING OTHER, BECOMING OTHER 111

4 Other ANd Event: Philosophy of Possibilities .............................................. 121

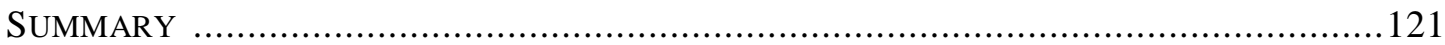

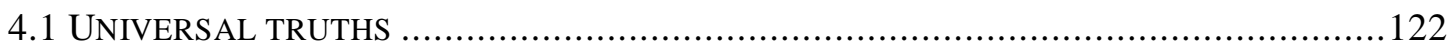

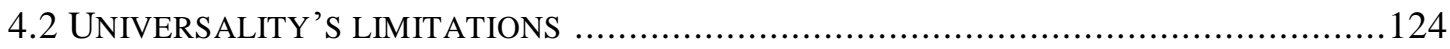

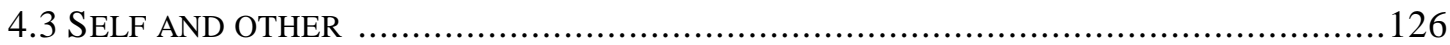

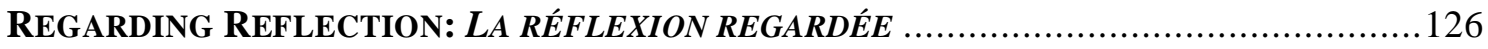

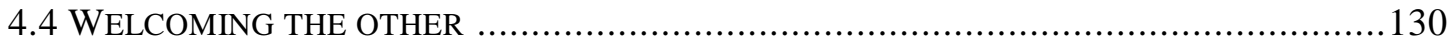

4.5 LEVINAS' PHILOSOPHY OF THE ENCOUNTER …............................................. 132

4.6 RESPONSIBILITY - THE FACE OF THE OTHER …..........................................134

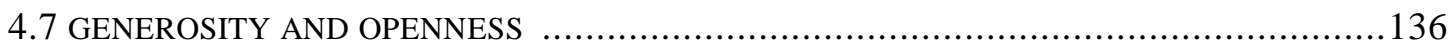




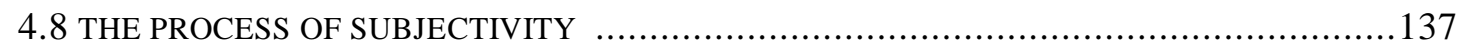

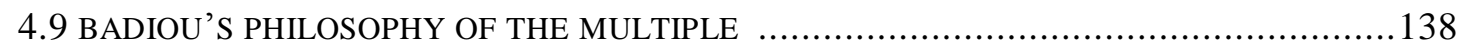

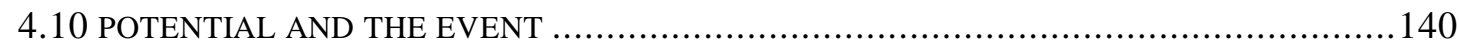

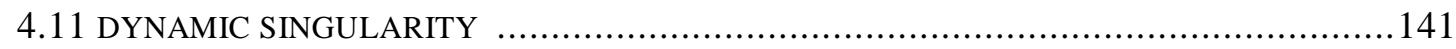

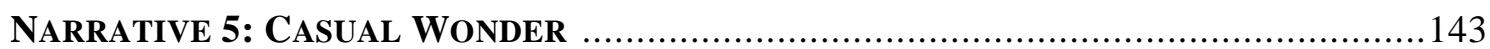

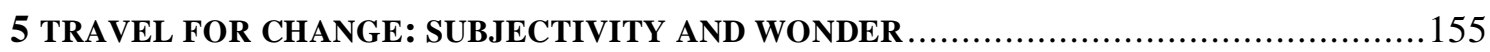

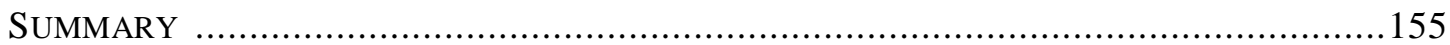

5.1 ALTERITY AND MULTIPLICITIES - BEING IN THE WORLD ....................................156

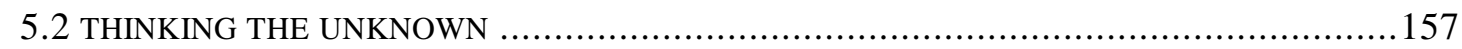

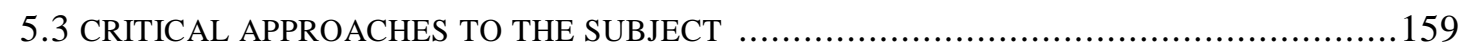

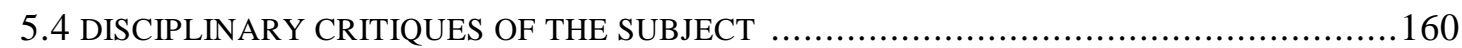

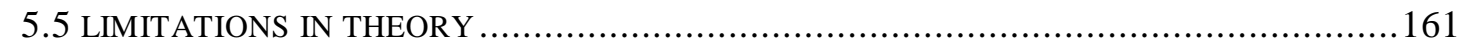

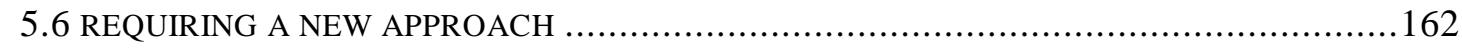

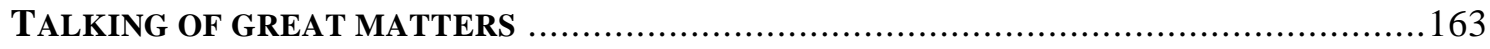

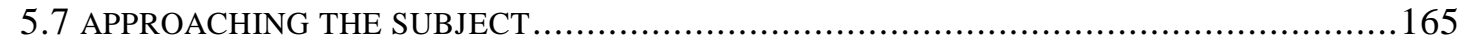

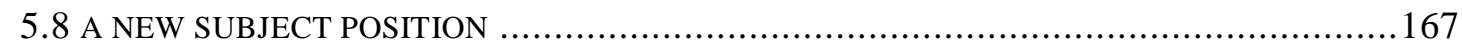

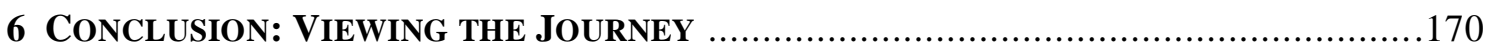

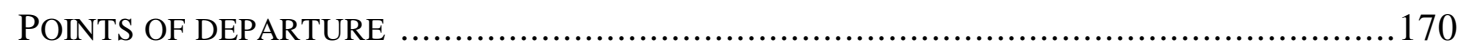

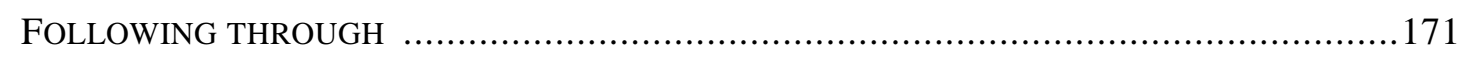

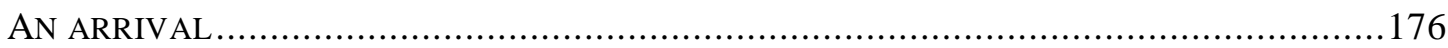

NARRATIVE 6: EPILOGUE - RETURN TO KNOWN ............................................... 178

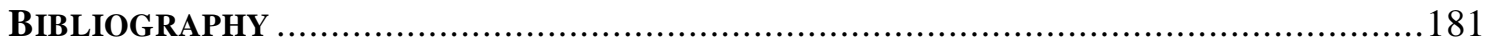




\section{CERTIFICATION}

I certify that the work in this thesis has not previously been submitted for a degree.

I also certify that the thesis has been written by me. Any help that I have received in my research work and the preparation of the thesis itself has been acknowledged. In addition, I certify that all information sources and literature used are indicated in the thesis.

Date

Signature of Student

Jo Ankor

16 December 2009 


\section{ACKNOWLEDGEMENTS}

I would like to acknowledge that the work presented in this thesis was made possible by the contributions of many people.

At University of Technology Sydney: my supervisor, Dr Stephen Wearing, for constant, positive, effective and invaluable guidance and support; the warm and willing help from all staff for a scholar who lived thousands of kilometres away; the financial support of an Australian Postgraduate Award scholarship.

And always there: my daughters Liz and Ali; John; Norman and Ian; and many wonderful friends. 


\section{DEDICATION}

To all the partners of Doctoral candidates who survived incremental loss and sudden reappearance - may they be bountifully rewarded for tenacity, endurance and always seeing the long view. 


\section{ABSTRACT}

Both pleasure and dread lie in wait for the traveller. The willingness to embrace whichever of these may arise shapes the experience of travel. This thesis offers a multi-voiced exploration of this paradoxical relationship and seeks to develop a philosophical understanding of why we travel. Its intention is to expand the boundaries of tourism research methodologies and to suggest new ways of approaching the study of tourism.

This thesis begins in an observation of a personal experience of travelling by yacht, which brought contact with a group of people who had chosen to travel not because of what was known to be there, but precisely the opposite. This 'unknown' as destination was chosen because it was not known what may be found or what might happen. These travellers had set out, willingly accepting whatever may occur, seeking to meet face-to-face with the people and places that may arise an acceptance of the paradoxical presence of both pleasure and dread. The focus of tourism research, on attractions, sights and services for example, does not appear to include travel which has no framework or specified purpose and which is specifically open to the surprise of the unexpected and the potential of the unpredictable.

Drawing on cultural studies, creativity studies and philosophy, an exploration is made of the unexpected and unpredictable moments of travel. Emmanuel Levinas' (1969) philosophical analysis of the face-to-face encounter with the unknown 'other' offers an understanding of this encounter as where we can develop new meanings of our human position as subjects through a nonreductive relationship with difference. This leads to a consideration of the embodied and emplaced situation of the encounter in the experience of travel and a consideration that this encounter is critical to the development of new understanding of our relationship to the world and our own subjectivity.

Through the juxtaposition of narrative, academic and critical-creative writing, the contested nature of the relationship with difference is opened up in a manner usually restricted by tourism studies' reliance on limited, dominant, 
research approaches. This multi-vocal technique offers a fresh dimension to tourism studies research on the complex nature of the travel experience.

I suggest that the relationship of the individual and the 'other' lies at the heart of all travel and that the nexus of traveller, space and difference - self, context and other - is a key to understanding the travel choice to experience the unknown as destination. 


\section{INTRODUCTION}

Dean MacCannell, somewhat wryly, notes that 'factors that motivate tourist desire are mysterious and illusive, even to the tourists themselves' (2002, p. 146). Travel and tourism to sites of memorialisation - such as geographic areas from which families had migrated, sites of historical significance (from war memorials to palaces to archaeological remains), sites of cultural significance (from movie settings to cities to wilderness nature) and sites of religious significance - means going to places that have been identified and chosen for the known content they offer. Such travel provides the traveller with a framework, an expectation for confirmation of prior knowledge, a purpose - and an end that is integral to its beginning. In this, therefore, the focus of tourism studies on attractions, authenticity, motivations, expectations, sights and the provision of the many services that assist in getting to and accessing such sites, has been addressing the tourism spectrum.

However, my personal experience of getting aboard a yacht and 'heading out' brought contact with a group of travellers who had chosen - as I had - to be there, travelling that way, not because of what their destination was known to offer and contain, but precisely the opposite. They had set out into the unknown, willingly accepting whatever may occur, seeking to meet face-to-face with the people and places that may arise. This 'unknown' as destination was chosen because they (indeed, we) did not know what they would find, what it would be like, what was there, what might happen. A 'mysterious' motivation, rather as MacCannell suggested.

What does it mean to choose the 'unknown' as a destination when, contrary to travel and tourism involving sites of memorialisation, it obviously does not provide any framework, nor the expectation for confirmation of prior knowledge, nor even a specified purpose, and the end is, well, open-ended? This travelling could hardly be said to be linked with attractions, authenticity, expectations, sights and the provision of tourism services. Is it reflected in tourism studies? What can be learned from examining travel that is specifically open to the singularity of what may happen, to the surprise of the unexpected, where choosing a destination and mode of travel is to deliberately open up to the potential of the unpredictable? 
This thesis attempts to answer these questions and, in doing so, to see if examining the choice of the 'unknown' may extend current understanding of postmodern subjectivity through understanding the traveller subject. While there is continuing debate about definitions of 'postmodern', it will be understood in this thesis as the development in the latter part of the twentieth century of a criticism of the modernist homogenising practices in art, industry and theory.

The postmodern world acknowledges interconnectedness, complexity, multiplicity and context to be integral to ways of living and also to ways of understanding the world. The attributes of working outside frameworks, being openended, challenging the definitiveness of knowledge and privileging play over purpose, are applied to describe postmodern attitudes. These descriptions also delineate a postmodern establishment of the subject - an interactive recognition of difference that may change the self is accepted; it may even be expected. To expect that the self may, and can, change is to accept the effect of any of the multiplicities of possibilities that engagement with the world engenders. To expect that the self may change accepts the unpredictable, the unexpected. In short, it allows for those conditions that support and encourage a creative interaction with the world. It is predicated on allowing difference; it requires a respect for the other ${ }^{1}$ - the different, the unknown - that does not explain away - that is, 'reduce' or confine - difference.

Examining the non-reducing relationship of self and other has been a significant development in western ${ }^{2}$ philosophy in the latter half of the twentieth century. The relationship of self and other is not yet widely addressed in tourism studies. However, the personal travel experience predicated in the unknown, I suggest, is closely akin to this non-reductive relationship with the other. While there is acknowledgment in tourism theory that travel experiences are 'highly personal - subjectively perceived, intangible, ever fleeting and continuously on-going' (O'Dell, 2005, p. 15), the experience as a potential for the unexpected has not been addressed in depth. Jamal \& Everett (2004) note the way 'experience' is a contested concept itself with multiple meanings and interpretations within both tourism studies and the global tourism industry. There is a need to link the experience and its interpretation in a manner that

\footnotetext{
${ }^{1}$ Since I consider using a capital $\mathrm{O}$ is still predicated in metaphysic's subtle use of the other as needed for the self, rather than fully realising the other as separate, I have chosen to use the lower-case spelling in the thesis.

${ }^{2}$ The choice in this thesis is to not capitalise 'western' as using the capital retains a subtle privileging of one cultural development over others.
} 
brings the traveller's reading of place and interaction to the fore. Diprose points specifically to the role of the other where 'existing ideas are opened to new paths of thinking' through 'a generous response provoked by the other's alterity' as the other's difference inspires and moves us (2002, p. 127); the travel experience, with its nature as interactive, inseparable, unrepeatable and unpredictable, offers the moment when generosity can be enacted. And I really don't mean tipping, I mean those moments of aperçu, of connection, that provide insights - unexpected and un-plannable - and that change our understanding of our selves and the world around us.

\section{APPROACH}

Such questions of experience and the formation of the subject touch some of the most profound concerns of being human. As such, I consider that there is the need to allow a variety of voices into the discussion; research into such depth of humanness surely cannot be encapsulated in a single voice or style. This is a de-stabilisation of the traditional placement of the subject in research. Like placing a sculpture within beams of light of differing colours, angles and intensities, where the object is not reduced or changed but various aspects are revealed, the conscious use of differing voices offers a greater depth of insight to this research. I consider this multi-vocal presentation as a valuable contribution to tourism studies and, further, that introducing strong criticalcreative writing into tourism studies offers great potential for exploring the nature of experience and the relationship of the individual and the other. The ephemeral and creative nature of the experience is difficult to communicate but lies at the very heart of travel and tourism for the individual.

A flexible and creative style of scholarly writing is attracting increased critical attention; although it originated in literary studies, there is a growing application of what I will name critical-creative research writing in the Social Sciences and the Humanities. Sartre's writing on Flaubert, Levi Strauss using travelogue as treatise, Foucault exploring ideology as historiography, Said's essay on Orientalism and Deleuze and Guattari's seminal A Thousand Plateaus are exemplary examples of the application of critical-creative writing. Within academia, the use of alternative voices is more often read as rival or contradictory opinions, Beverley notes, contending that such

dichotomous positioning illustrates the limits of that writing 'because we have no words for multiplicities even in our criticism'; and when there is conflict and complexity, it is 
taken to negate (2003, p. 325). Approaching the experience and the unknown in travel raises the discursive and theoretical difficulties, to which Beverly refers, of analysing an open concept within a scholarly tradition that tends toward closure. The sense of the wonder, enchantment and involvement that is common in the travel experience is not easily expressed through the authoritative academic voice. Recent developments in approaches to research have challenged the notion of the single unified voice that tourism studies writing has privileged, and relied upon.

To deconstruct this position of authority, which I consider on its own is not fully able to address the questions under consideration, I have used three voices within my thesis writing - analytical, narrative and critical-creative. Through this dismantling of an established approach, it is anticipated that concepts of the unknown and the other in travel can be re-examined with unexpected insights. Employing three voices highlights the distances between different narrative modes in exploring travel. It also demonstrates the importance of different expressions of travel - theoretical, imaginative, narrative. This incorporation of reflexive writing specifically explores the multiple threads without justifying any; it incorporates responsiveness and places voice and reader in relation to each other. The conscious placement of the reader within the exploration is contested as an academic writing style. However, it's effectiveness has been realised in, for example, cultural studies and feminist writing where institutional analysis, ideology critique, textual explication and personal response have been used to bring forward alternative, previously silenced, stories into the main arena of scholarly debate.

My own exposure to critical-creative writing began while undertaking undergraduate studies in creative writing and cultural studies. 'Ficto-criticism' is a somewhat marginalised terminology in Australia, however the need for expressive research writing techniques is becoming increasingly apparent (for example, applications in social sciences such as ethnomethodology) and these are being described in a range of terms. In this thesis - and for the purpose of introducing this style of research writing into tourism studies - I am using the more generalised term of criticalcreative research writing to describe the use of a multi-vocality in research. One of the challenges mounted against critical-creative research is that it lacks intellectual rigour. Fullagar and Fleming (2007) counter this: it is very specifically written with great rigour as it is working without boundaries (refer to 1.2 for further discussion). To creatively put across a theoretical paradigm in localised or imaginative language does not reduce 
that theorisation in any way. It does require responsive reading however; the reader is drawn in, not allowed to remain an impassive observer. They may laugh, they may sigh - linking the theory with the emotional experience it is describing and recognising the inseparability of thought, emotion and experience. And this, of course, is particularly relevant to travel.

This rationale for the approach chosen for this thesis is also based on the ongoing discussions of the relationship between narrative, writing and the travel experience, of how writing travel reconfigures the travel experience in the effort of representation. This is an issue that is present in tourism studies, from the configuration of travel brochure writing, the claims made in travel advertising, tourism journalism in weekly newspapers and dedicated travel magazines, to the prolific publication of travel narratives. Jamal and Hollinshead consider that:

much of the currency in tourism literature has tended to focus on the tourist gaze and the surveillance of the tourism industry, drawing upon discourse analysis, critical theory, social constructionism. The omission of studies and narratives which locate the situated particularity of 'body' and 'emotion' in tourism, whether that of the tourist or the host, is a problem which has been noted and addressed by very few scholars. (2001, p. 67)

Dann, in his sociolinguistic analysis of tourist destination promotional material, considers it is 'discourse which delineates the sight, language which informs the tourist ... in other words, phrase precedes gaze' (1996, p. 21). Jamal and Hollinshead note the contribution of Feminist theorists such as Butler's $(1990,1992)$ focus on 'the linguistic and socio-political construction of the subject which are subject to the same criticism on the loss of the situated participant ... as embodied and embedded in a perceptual, sensual world' (2001, p. 67). They further highlight Veijola and Jokinen's (1994) depiction of 'the loss of situated body in tourism scholarship' through their article which 'plays with a dialogic narrative approach that is in stark contrast to the 'objective', impersonal writing style of a "scientific" claimant' (ibid). Tourism studies have tended to follow a positivist tradition, limiting attempts to address the postmodern, particular and interactive, intersubjective space between individual and society in the construction of the tourist experience, notes Ryan (1996). Todd (2005) contends that embodied categories carry an emotional charge, but analytically the formation of shared 
experiences and the sense of group belonging and solidarity is often explained in terms of core social variables, thus never completely representing the individual 'real' experience.

While much of tourism studies' research is based within the research parameters and paradigms of the social sciences, the field also benefits from research undertaken in other disciplines. This thesis has developed within the Humanities' disciplines of cultural studies and creative writing. Both areas are interested in the phenomenon of tourism - one through the cultural relationships and impacts of tourism practices and the other through the representation of travel within literature, in its many forms. Both draw on long-established disciplines of language; as such they bring a different perspective to tourism research through the employment of paradigms that are less focussed on applied research but, rather, work into the exploration of conceptual ideas through strongly qualitative approaches.

The aims and objectives of hypothesis-based research, more familiar in tourism research, are not consistent with an exploratory, language-orientated approach. However, the statement could be made in more traditional tourism studies terms that this thesis employs an approach that consists of a literature review and content analysis with a reflexive component. An alternative description is that theory from tourism studies, cultural studies, creativity studies and philosophy provide conceptual bases for the thesis, while creative analysis techniques have been employed to illustrate and expand the theory and, as a triangulation for understanding the individual travel experience, a personal manuscript of travel provides a naïve first-hand account of encountering difference and facing the unknown.

It presents an interweaving of three threads - theory, creative and narrative - to express the complexities of the individual travel experience, which leads seamlessly into the understanding of the making of meaning as discussed in twentieth-century philosophies of the relationship with difference that are particularly relevant to the travel and tourism experience. Tribe describes this approach as a 'fusion of grounded theory, content analysis and researcher artistry' (2008, p. 926).

It could also be stated that the aims of this thesis are to contribute to understanding the travel experience and what it may tell us about motivation, choice in travel and how the travel experience may affect or contribute to gaining new understandings of the world that affect our ways of being in the world. For this thesis, 
using three different approaches to understanding the question reflects its central proposition, that the meeting of subject, object and context in a never-before configuration is where new meaning can develop for the individual.

This thesis does not presume to offer an answer to the debate of reconfiguring the travel experience through representation, nor that of locating the situated particularity of body and emotion in tourism research; instead it offers a particular view that can be argued, for or against. In the tradition of creative writing practice, the author offers alternative voices in an attempt to represent the multifarious layers that are discerned within the travel experience. These voices are designed to serve as an illumination (while never considered to be the illumination) for academic tourism research, reminding all researchers of the complexity of the phenomenon of travel.

This thesis, then, draws attention to the critical and theoretical implications of the defining lines between the creative, the critical and the theoretical in the dominant paradigm of objectivity that is familiar to tourism research. Through the use of creative narrative intervention into the spaces of critical knowledge production, it remains aware of the tension between the open nature of critical-creative practice and the tradition in research writing of a clear proposition and outcomes. In order to explore the formation of the subject through the active practices of encountering difference in travel, this writing allows lines of flight (Deleuze \& Guattari, 1987) in the engagement of criticalcreative writing. The ephemerality of the moment of encounter and the responsiveness required in the face-to-face meeting with the other that occurs in these moments require a paradigm as elusive as the concepts are themselves: the critical-creative is one possibility.

\section{THESIS OUTLINE}

Five Sections provide the theoretical argument of the thesis. Each contains a critical-creative passage reflecting on the theory addressed in that Section. These Sections are linked through narrativisations of the travel experience. This narrative draws on an experience of sailing a 10-metre steel ketch with my family in the ocean waters off southern and eastern Australia in the late 1990s. [The full story of this experience is in preparation for publication as a travel narrative.] In this way, these are not referred to as 'chapters' but as Sections and Narratives respectively, and numbered sequentially. 
In the first Section, 1 Tourism and Travel: Paradoxes in Theory, tourism is recognised as a dynamic phenomenon that draws interest from a range of established academic disciplines. As such, tourism is an area of study that often finds itself situated between disciplines (Jamal \& Everett, 2004) where a range of theoretical understandings, paradigms and methodologies may be applied. The choice that initiated this thesis, of a destination where it was not known what might be found or what may occur, is situated against the more familiar tourism research focus on the established practices of organised travel. Examining this choice means examining the expectations and experiences of travel, and this requires methodologies that can reflect the ambiguities and often un-voiced complexities of the travel experience, echoing the currently expressed need for reflexive methodologies in tourism studies (Hollinshead, 2004). It is suggested that qualitative methodologies, such as have been developed in the social sciences, are appropriate to begin examining the travel experience. While this thesis hopes to demonstrate the applicability and usefulness of critical-creative research writing and the narrative voice as methods of writing about tourism and travel, it also draws on a range of disciplines to examine what travel toward the unknown may mean. These are cultural studies, tourism studies, creative studies and philosophy. Further to this, travel, tourism and tourist are inconsistently interpreted and applied terminologies and their definition for the purposes of this thesis are established at this point.

The observation of the choice of the unknown as destination brings attention to Levinas' powerful case for the 'other', as difference, being critical to our understanding of self. 'Radical alterity' is the term Levinas uses for the complete separateness of this other - radical, as the root, and alterity, as difference. Meeting the other - meeting difference through a face-to-face encounter - is where we develop new meanings. The question that initiated this thesis - that of choosing the unknown - can also be seen as coming into a relation with radical alterity, an engagement with the unknowable. However, a search within the tourism literature for radical alterity in travel reveals very little. It does show a number of, less direct, references to 'something happens' in the spaces of travel, that can change the individual. The work of MacCannell (1992, 2000), Clifford (1997) and Horne (1992) contribute through the suggestion of a postmodern, nomadic traveller, who is interested in the unknown and the unexpected in travel. These theorists provide an initial framework to investigate what travel that consciously seeks the surprise of the unexpected may offer. 
What is meant by the 'unknown' is the question that begins the second Section, 2 Choosing the Unknown: Paradoxical Nomads. While meanings of the word 'unknown' are discussed, I suggest that the unknown as destination can mean any place in the world - urban, remote, populated - where the unexpected is allowed to unfold. Articulating the choice to travel in this open-ended way encounters two difficulties; firstly, it is not easy to express, as the underlying motivations are conceptual rather than practical, and secondly, as an explanation, it makes people uncomfortable. The choice to travel is examined through reference to typologies of needs and motivations (Cohen 1973, Maslow 1962, Plog 1991), while the response of feeling uncomfortable is examined in relation to cultural expectations and the limitations of language and discourse. Discourses establish cultural expectations (Foucault, 1992); through the expression of ideas, discourses can establish what is acceptable to say or not say, and can establish the powerful dominance of certain ideas. This also applies to the discourse of tourism.

Alternative travel such as adventure, wilderness and back-packer travel are situated as travel where the individual is freed from restriction and can find a 'new self' through enactment of retreat or pilgrimage (Baumann, 1996). It is suggested that these are inwardly-focussed relationships which are not so much predicated on an engagement with the unknown of the world as on an inner search that is divorced from the surrounding world. MacCannell's (1992) nomadic traveller, however, is one who wishes to engage with the places and people met along the way. This outward orientation that is supported by Syed Islam's (1996) delineation of two types of travel sedentary and nomadic. The nomadic traveller, for Islam, undertakes travel that is to do with encounters with otherness that fracture a boundary. Both MacCannell's and Islam's reference to the nomadic are used to examine the experience of travel as interactive. I suggest that the nexus of traveller, space and difference - self, context and other - is a key to understanding the travel choice to experience the unknown as destination.

There are moments in travel where a shift in awareness occurs (Suvantola, 2002) and a new understanding or perception results. In Section 3 Encountering Difference: The Offer in the Moment it is what constitutes these moments that becomes the focus for examination. Suvantola suggests that there are meeting points in travel - a convergence of understanding, things known yet unknown, and context - where the 
relationships between these elements is challenged. I suggest that travel offers the possibility of such moments of sudden insight if the traveller is responsive in the encounter with the difference of the other. Before this concept of the other is more fully explored, however, there is a body of research into moments of awareness and change that offers understanding of their importance. This is found in the study of creativity. Through theories of creativity, we gain a conception of how new ideas, that is, insightful perceptions and connections, are developed in the juxtaposition of existing knowledge, new elements and an openness to the possible combinations available (Csikszentmihalyi, 1990). This leads to an investigation of the relationship of space and embodied awareness in the travel experience, for the self-aware de-centrality of the visitor means that they inhabit a space differently and they are aware of context and connections they may not normally be able to access. More importantly, at this point the role of the other - of difference and the unknown - becomes a focus as part of this moment of encounter.

Here Levinas' (1969) philosophy of the face-to-face encounter with the other provides a conceptual framework for understanding the responsive relation to difference. The face-to-face encounter with the other demands that the self open to the other in response, through the recognition of radical difference. This moment of encounter in travel has the unpredictable potential of pleasure or dread, excitement or challenge, wonder or even fear. The traveller is situated for a change of the self. This Section concludes that travelling is an activity that provides the opportunity to question the traveller's place in the world and perhaps to reveal possibilities of existence which were previously concealed (Garlick, 2002b). If so, then it is an activity that enables the individual negotiation of identity and subjectivity through a non-reductive relation with the other.

The relationship of the self and the other, that is critical in the travel experience of encounter, is a contested one in philosophy. In the fourth Section, 4 Other and Event: Philosophy of Possibilities, this relationship is explored. The historical position is that what is other and unknown is seen as a problem to be investigated and resolved. The other has also been viewed as simply a mirrored self, a reversed figure only presented as a reflection and made available for the use of the self. However, Levinas (1969) holds that the other is not the simple reversal of identity and is not formed out of resistance but is prior to every initiative. Levinas' work is explored to further 
understand the moment of encounter because he offers a conceptualisation of the relationship with the other that is not reductive of the other, but allows a space for accepting what the other may offer. This suggests that the creative moment can only occur in the presence of the other, and that the key to this encounter is the response of the self to the difference of the other.

An understanding of how the moment itself can offer multiple possibilities is gained through an examination of Badiou's (2003) philosophical account of the multiple events present as possibility within a situation such as the moment of encounter. Badiou's work on multiplicities provides an analysis of how the creative moment of encounter contains the potential for new ideas. The movement of the traveller into the unknown is an act that positions the self in a situation which holds the elements of a potential event, one that may change the self through the development of new ideas and conceptualisations. It is suggested, then, that the self is constituted through the relation to the unknown engendered in the moment of encounter. There is an active positioning of the self for change.

It is realised here that Badiou's approach makes use of an ontological philosophy while at the same time recognising the element of what he terms 'poetry' that is also required for a full understanding of the experience of the moment of encounter. Levinas' account of the relationship that is non-reductive is based in a phenomenological philosophy. Here are two contrasting, indeed opposing, philosophical approaches that each contribute a critical element for understanding the traveller's moment of encounter. They are both relevant to the construction of individual subjectivity that is evidenced in the sought encounter with the unknown. The next theory Section considers how this contributes to contemporary theories of the subject.

In 5 Travel for Change: Subjectivity and Wonder, the moment of encounter as forming the subject is taken further. If the conjunction of alterity, the event and the responsive self has the capacity to change the individual's relationship to the world through the development of new meanings for her/his being in the world, then I suggest that the other (alterity) and the event (multiple in the situation) are formative of the subject and that there is, therefore, a need for a new theory of the subject - one that reflects the role of alterity and multiplicities. Differing critical approaches to understanding the subject/self are discussed as well as the differing disciplinary approaches of cultural studies, sociology, literary studies and philosophy (already 
contributors to examining the travelling subject in this thesis). Here, it is suggested that, because both the other and the multiple are required in concepts of the subject and understandings of subjectivity, both phenomenological and ontological understanding of the subject are required to contribute to a theory of the subject that is contemporary. Finally, a new model of the subject, that is commensurate with the travelling subject we have been following throughout this thesis, is proposed, one that draws on the subject as situated in, woven through, and developing from, joyfully embraced multiplicities.

To lead into these theoretical discussions, the narrative voice offers a description of that choice to engage with the unpredictable possibilities of the unknown, in the first of the Narrative sections, Beginners' Choice. 


\section{- Narrative 1: Beginners' Choice •}

Going cruising has always exerted a strong, almost romantic, appeal. There was nothing nautical in my background, being brought up on a forest plantation reserve in rural South Australia. My father, however, had nurtured in his children a curiosity for 'what's around the next corner'. He also passed on his fascination with the earth's long geological history, quietly displayed to those who might want to read it in the rocks and formations shaping the land. My brother had grown up to become a speleologist and scuba-diving instructor, leading expeditions to water-filled cave systems under the Nullarbor Plain and writing books. I dreamt of living in different places.

Stuart and I met when I was learning to sail: by then I was living by the sea in South Australia's capital city, Adelaide. Stuart had grown up spending his Australian summers on Adelaide's beaches, racing sailing dinghies with one of the many local yacht clubs. You can see them every Saturday, the fifteen kilometres of Adelaide beachfront sprinkled with a confetti of little white sails and shimmering with competitive intensities. Stuart was keen to show off his sailing abilities - and trophies and a whirlwind romance ensued, then nine months in the USA and back to Australia to establish career and family.

But curiosity and dreams are unmanageable things. The question hovered in the background; was there a way to combine Stuart's sailing, my curiosity for new places, our young family? It was when our daughters, Elizabeth and Alison, were three and one years old that Stuart and I discussed the possibility of fitting us all into a small boat and meeting the world at sea-level. This was the solution surely - going cruising! We made a firm commitment to work to attain our dream, although we had no money, no yacht and no cruising experience. 'Not a problem - mere details ...'

I enrolled in the Volunteer Coastguard Basic Seamanship course, the sole female in a class of fishing-mad, motorboat-owning fellas. I missed topping the class by half a mark and departed knowing all about left- and right-handed propellers, the best fishing spots for miles around Adelaide and how to wield a gutting knife. This was encouraging, if short on the sailing knowledge front. The Port Adelaide Technical and Further Education College offered Australian Yachting Federation Yachtmaster studies. These courses, recognised worldwide, have theory and practical exams at three certificate levels: Inshore Skipper, Offshore Skipper and Ocean-going (Master Class 2). 
I began at the beginning. On the first sailing 'Practical' I only felt a tiny bit seasick as we rolled our way back through the sea's confused chop at the marina entrance: this was a good sign for our proposed trip, I was sure. With the Inshore Skipper's Certificate successfully completed, I could drop words like 'tack downhaul' and 'clew' with studied nonchalance into the after-race conversation at the Cruising Yacht Club, where Stuart now sailed on Saturdays. Occasionally I would be offered a crew position too: sailing experience was increasing.

Stuart wanted to learn more of navigation and we enrolled to do the Offshore Certificate together. With a babysitter for our two daughters organised, Monday nights saw us driving the forty kilometres to lectures. Here was a class full of dreamers. Some already owned their boat, some (like us) were still looking. Some had their dream on a cradle in the back yard. We studied passage planning, weather, emergency procedures, navigation, radio skills and fitting out. We did night sailing on a two-day Practical. We made a complete passage plan for the major assignment, victualling and equipping an imaginary yacht to sail from Adelaide to Sydney. We kept building up our sailing hours, crewing on the three-day Tripolis Race, renting a yacht and taking the girls sailing for a week on Lake Alexandrina, accepting any opportunity of time aboard that was offered. We sat the exam. We passed.

I had been borrowing every book on sailing I could find in the library, including all the books on maritime disasters - the 120 Days Adrift At Sea type of story - thinking to maybe learn something from them too. Details of the yachts we inspected, notes from the books, tips from sailing friends and lists of suggestions were all written into a little green notebook labelled Shipbook. I noted the advice of Lyn Pardy (a well-known sailing writer) - 'Just go!' We could finance an initial two years of cruising; perhaps after that we would find work. Perhaps we might find one of the girls got terribly seasick and the whole trip be curtailed. One author laid down the challenge: 'Many dream of sailing away. A few buy the yacht. But only a very few actually do it'. I was determined to be one of that 'very few'.

The world holds a wide variety of ways humans live and relate to it, to each other, as individuals and as communities. One thing I really wanted my daughters to experience was a sense of the arbitrariness of our particular culture. We speak one language and believe a certain set of things but other people speak in languages that are incomprehensible to us and work within the certainty of very different beliefs. I wanted 
my girls to begin to grasp that validity of alternative ways of living. I wanted this so that they could understand there is choice - for example, their society may believe that women must shave their armpits to be acceptable but it is another thing to conform while at the same time understanding that your reason for conforming is not a belief that herein lies beauty, but herein lies my culture's norms. These, of course, are formidably complex conceptual understandings, but the raw material of exposure to alternatives will remain available to thinking as a person goes through life. I hoped to give the girls the gift of immersion in another language, of playing under palm trees with children who wore different clothes, of seeing other ways of living.

I also wanted the girls to live close to the natural world for a while, probably reflecting my own childhood in the country. Stuart was a city boy all the way through so this was not his dream. This also would be gaining an understanding of relationships; the smallness of 'man' against the forces of nature may be a bit of a hang-over from the Romantic poets, but through taking the girls out of the urban environment so they could experience the sun, the sea, the wind, the land with an immediacy not previously available to them, I hoped they could develop an appreciation of the natural environment and 'man's place as just a small part of it. It is too easy to believe that we are all-powerful and all-deserving of the products of the earth from inside the confines of the televised city.

We arranged to have Oblion, a yacht we were interested in, raised out of the water so it could be inspected ('surveyed' in nautical parlance). Unexpectedly, the original (not current) owner of the yacht arrived at the boatyard, a flamboyant character well known in the Adelaide sailing scene. He had built Oblion for his family of four with the intention of sailing to England. And then a story we were to hear time and again: 'My wife got terribly seasick. We couldn't go.' Oblion had been sold. I had wondered about the yacht's name and, with an idea of its origin, phrased my question carefully; 'Is there any point to Oblion's name?'

A huge grin was offered in return. 'So you know the story? Yes, I wanted to call her Oblio but when I went to the Australian Register of Shipping, there was already an Oblio. So, I put the 'n' on the end.'

Oblio was a character from the 1960s musical, The Land of Point. The story is that everyone in the land of Point has, well, a point - on the top of their heads actually. All the trees, bushes, and houses are also pointed, but the young Oblio - you guessed it 
- has no point at all. So he sets out with his best friend, a dog called Arrow, to ask the Great Wizard in the Forest for the Point of it all. All very appropriate to cruising, but the most magical part of the show was the puppet dog Arrow who was so engaging that the puppeteer simply ceased to exist for the audience. Magic indeed ...

We bought Oblion and moved aboard on a roasting hot Adelaide summer day when the northerly desert-heated wind has the city cowed and motionless. Inside, with most of the living area below the waterline, it was surprisingly cool. I was now to discover a world I had no idea existed, but as work and school filled the passing weeks, preparations for the trip seemed to be coming a poor second to daily living. I wondered if we would ever be able to make the break to actually go. There were alterations - buy a yacht and then change it seems to be an immutable reality - and learning how to handle this new addition to the family while out on the water. Practising anchoring took a number of hilarious Saturday afternoons, including being rescued from sandbanks by passing, fortunately friendly, powerboats.

One March morning, the marina office gave me a message to ring Stuart at his office. I called from the phonebox at the end of the pontoon: yachts rocked gently at their moorings in the fresh breeze and the sunlight danced on the ripples. 'My project is finished,' he informed me. 'We can plan to leave at Easter.'

Friends realised suddenly that we were really going. A constant stream of visitors came. Friends from my choir performed a farewell song, specially written in four-part harmony. We were still trying to finish jobs and stow last minute gear. Fruit and vegetables were hanging in plastic bags from curtain hooks all around the cabin. A friend brought a bag of fresh onions from his farm which I hung up above the table. Salami and pickled ham (for long term meat since we had no fridge or freezer) swung from hooks above the galley. The place smelt like a corner deli.

Elizabeth's godmother arrived with a flowerpress as a farewell gift. On a boat? I chuckled to myself and found a bit more space in an unsquare locker. Martin, our nephew, was sailing with us to Kangaroo Island for his fourteenth birthday present. He also arrived, with three fishing rods, and the family, and more friends. Someone went off to buy take-away Chinese food for dinner while Elizabeth and Alison added to their 
collection of chocolate Easter eggs. They had been given eggs as farewell presents from their classmates as well as friends, including one huge egg nearly half a metre long for Elizabeth. These now hung in more plastic bags from extra pegs opposite their bunks, where we also hung the wet weather gear.

The girls were excited but not sad. As far as they were concerned, this was the same as other weekend trips. Extended travelling had no reality for them: the concept of days at sea without landfall meant nothing. The idea that when we did stop somewhere it would be all new, day after day - well, they couldn't begin to imagine it. Alison, at eight years old, was hesitant because she didn't like sailing very much; I had sat with her earlier, understanding her reluctance but saying that in this she would have to trust us.

The day before Departure Day and my diary notes: Today is exciting and scary at the same time: we may never return, we don't know how far we will go, or where we will end up, or if the girls will take to long-term sailing, or anything really. I tell myself that we are just sailing the sixty miles to Kangaroo Island, which we have done before, and then Ifeel okay. What will tomorrow's goodbyes be like? Lots of tears? We 'll see.

Easter Saturday - planned departure. The wind hadn't suddenly blown up, none of us were ill, the sun was shining - 'Guess we have no excuse not to go, eh?'

Family and friends arrived. Sailing friends came alongside in their yachts, festively armed with streamers to throw. The girls and Martin filled spare water containers, someone went off for extra kerosene, people came onboard for a look; I made myself a cup of tea, and shifted more things from my 'To Do' list to the 'Do While Under Way' list.

Finally visitors were shoo-ed ashore, Martin and I stood by with warps in hand. The girls waved madly to the assembled group on the shore and we cast off to motor gently out past the commercial Outer Harbour wharves, accompanied by our small escort of friends on their yachts. The wind was very light: I went right for'ard to clip the lighter genoa sail onto the forestay. This departure was under control - everything had gone smoothly, no tearful outbursts from the girls (or grandmothers, for that), we would be fine. Then I looked down at the sail to realise that, for the first time in my life, I was busy clipping it on upside down ... 
The escort of yachts prepared to turn back for home. Streamers and jokes flew across the water in farewell - but that was all that was travelling over the water for the wind had died to almost nothing and Oblion was barely moving. The genoa and mainsail were set, we were on our own - if emotional energy could have effect we would have been flying down the Gulf St Vincent. Instead speed was one and a half knots. Immediate destination - the town of Kingscote on Kangaroo Island; estimated time of arrival - who knew? Boat speed is measured in knots (nautical miles per hour) and, according to my research, the average cruising yacht speed was four knots. That was about equivalent to walking. Well, we were barely strolling right now; at less than two knots we would be a while getting to Kangaroo Island.

We discussed starting the engine. We didn't yet know that the two tanks held enough fuel for some hundreds of miles and the motor could run quite happily for long periods; at the moment, somehow, it seemed to be cheating to use it at all. But it was mid afternoon, Kingscote was still fifty miles away and not likely to be reached before tomorrow. Elizabeth lay along the side deck reading, and Alison slept on the double berth below. Martin set all three fishing rods to trail hopefully over the stern. The bags of vegetables and sticks of salami swung gently in the cabin, Stuart was snoozing and what did it matter if we took two days, five days even, to get to Kingscote? My diary: Will be overnight to Kangaroo Island. Frustrating (though only partly) as no deadline of any sort: what a strange world, cruising.

Time would have a different meaning at sea. How long would it take us to adjust to a slow travelling speed and no fixed timeline? We were curious to observe the change. I was still going, mentally at least, at full pace, following the last hectic weeks of preparation. Physically I could have overtaken Oblion easily on foot, though I had no pretention to Jesus' reported abilities. Instead, I made a list of what we had to do at Kingscote then set about cooking dinner, remembering to use the lock-on rods which fix the saucepan or kettle in position and which go by the unlikely name of 'fiddles'. Dinner was a tuna mornay, cooked in the new pressure cooker, using the kerosene stove, at sea; no-one was hungry so this feat went under-appreciated. By everyone else, anyway - I was privately very pleased with my first achievement of The Trip. 
Three days at Kangaroo Island had given practice at anchoring, lowering and using the ship's dinghy, and learning how Oblion swung to the tide. It is an odd thing to have one view of the bay from your bunk on going to bed and the opposite side of the bay on view when you wake up. We had bought some last minute things and visited a well-known sea-lion sanctuary. Nephew Martin had been put on the ferry back to the mainland, reluctant, and still clutching his fishing rods. We were ready to move on.

Some 350 miles away from Adelaide, past the inhospitable South Australian coast and around eastward, lies Bass Strait. Every sailor of the southern waters of Australia can tell tales of Bass Strait, where half the Southern Ocean tries to squeeze through the gap between Tasmania and the Australian mainland.

'If you get through Bass Strait, you can sail anywhere,' we had been told.

'The worst weather we experienced on our world cruise was Bass Strait,' encouraged a returned sailor. Oh great. We wanted to get to the other end of this troublesome stretch of water.

From our anchorage in the protected bay at Kangaroo Island, Stuart radioed for an update on the weather from the marine service of Melbourne Radio, based 700 miles away. The next leg of our journey would take us toward Melbourne, which lies by Bass Strait. The weather forecast was not very clear; I was all prepared to leave but the next stretch would be at least four days at sea and Stuart made the decision to wait. I was impatient, still being in city mode, but my diary reads: Teatime [the Australian vernacular for the evening meal]. The wind has strengthened and we are bobbing up and down madly. NOT what Melbourne Radio said. We will stay put and watch the white-caps outside the bay from here.

By 0830 next morning, we had cleared the bay and were on our way. Everything was stowed. The specially-bought steel thermos was full of hot soup for the day's sailing - easy and nourishing food in a non-breakable container had been recommended to me. Stuart had set out the snook line with its floating paravane to troll behind Oblion's wake - he was hoping for a fresh dinner. The fruit and veg still hung around the cabin; there was nowhere else to store them and anyway, they were out of the way suspended from the roof. The Easter egg bags had not noticeably decreased and still bulged on the hooks by the bunks. Stuart wore his best jeans and shirt, dressing to boost his morale as he took us out to face the ocean. The responsibility must have been sitting 
heavily on his shoulders for he was not talking much. My confidence in him was not necessarily matched by his own, or did his greater experience make him more aware of what he didn't know?

Sailing close to the eastern end of Kangaroo Island, we entered Backstairs Passage, at the end of which we would emerge into the Southern Ocean. I was so excited: this was not day-sailor stuff, this was the real thing. Only yachts embarking on long trips sailed through here.

For me this was the true beginning of our trip and all my love of adventure and fascination for the unknown came back to me from wherever it had been hiding during the last busy weeks. This is what I wanted to share with my daughters, this other side of life. 


\section{Tourism And Travel: Paradoxes in Theory}

\section{- Summary}

In this first theory Section, tourism studies is recognised as an area of study that often finds itself situated between disciplines (Jamal \& Everett, 2004). Tourism is a dynamic phenomenon and draws interest from a range of academic disciplines, all of which contribute to different facets of the research. The study of tourism falls into two main groups - study of the business of tourism and study of the experience (Jamal and Everett, 2004). Tourism research is therefore often situated where a range of theoretical understandings, paradigms and methodologies intersect.

The choice of travel that initiated this research, that of choosing a destination where it was not known what might be found or what might occur, is situated against much of tourism research's focus on the more established practices of organised travel. Examining this choice means examining the expectations and experiences of travel, and this requires appropriate methodologies. The need for reflexive methodologies in tourism studies (Hollinshead, 2006) is explored and it is suggested that qualitative methodologies, such as have been developed in the social sciences, are appropriate to begin examining the travel experience. Critical-creative research writing, as noted in the Introduction, is one approach that is applied. The narrative voice has already established its presence.

The ambivalent position of the researcher who is examining human experience remains problematic in qualitative enquiry (Denzin 1997, Hutchinson \& Samdahl 2000). This is explored in Ways of seeing: the Researcher's Gaze, the first of the critical-creative research writing contributions. Further to this, travel, tourism and tourist are inconsistently interpreted and applied terminologies and their definition for the purposes of this thesis are established at this point.

References to a new orientation in travel by MacCannell (1992, 2000), Clifford (1997) and Horne (1992) offer interesting insights toward understanding a postmodern, nomadic traveller, who is interested in the unknown and the unexpected in travel. Their work is examined to provide an initial framework to investigate what travel that consciously seeks the surprise of the unexpected may offer. 
I suggest that such travel offers those moments of sudden insight or aperçu that can affect our personal meanings and understandings of the world. But these are not easily discussed or expressed; in Explaining It Away, the Narrative talks of reactions to the choice of the unknown.

\subsection{THE STUDY OF TOURISM}

The academic research interest in studying the phenomenon that is called 'tourism' has developed with recognition that it is a major global economic activity. In westernised nations particularly, increasing economic return within an activity will invariably attract scholarly interest: increasing activity of a global scale will be examined for potential economic return. Tourism studies, then, reflect the economic complexity of the activity that is tourism: the movement of people, management of sites, supporting services and measurement of impacts can readily be seen as the province of economics, commerce, marketing and management studies. Theoretical perspectives of tourism are similarly disparate in tourism studies, again reflecting the complex nature of tourism itself. A careful interrogation of the phenomenon of tourism, according to Jamal and Everett (2004), identify two main lines of theoretical development - the business of tourism and the experience of tourism. Understanding the motivations, desires and experiences of tourists, as the contributing participants in this global activity, has become the province of sociology, geography, anthropology and psychology. After all, why do we - people who choose to travel - want to spend time and money being displaced from home and our supporting networks? The examination of travel and tourism experiences as representations of cultural and philosophical frameworks has been the province of literature and cultural studies, attempting through analysis and expression to identify the influences and impacts of movement.

While identifying these two broad areas of enquiry, it still needs to be recognised that they are integrated one into the other, that they are inseparable in their co-existence within the tourism phenomenon. At the same time, it can also be recognised that the research output from each is enormously disparate in methodological approaches. Models for measuring capacity-carrying or economic input from hotel bed-night statistics for example are complex mathematical formulae, and 
quite different from exploring the quality of individual experience within travel through interviews, personal journals and travel writing. Yet all these aspects of tourism are inextricably entwined, rather than separable into definitive areas, such that tourism researchers often find themselves situated in liminal zones between disciplines (Jamal \& Everett, 2004, p. 1).

The observation of a group of travellers who had chosen to go where it was not known what might be found or what might occur raised the initiating question for this thesis: What does it mean to choose the 'unknown'? This thesis is interested in what it is that the unknown in travel - both the social unknown of cultural difference and the physical unknown of geographical space - offers, as a chosen travel goal. Its focus is on understanding personal experience and subjectivity in travel. The role of curiosity and dreams in making a travel choice was apparent in the first Narrative, highlighting the very personal and subjective meanings of travel for the individual. Two academic areas have a focus of study on the construction of 'meaning', that is, the ways in which we conceptualise ourselves, our being in the world and our relationship to the world around us. These areas are sociology and philosophy. Sociology, as the study of societies and the relationship between humans and the world, has struggled with finding acceptable methodologies that reflect the ambiguities and the interpretive limits in describing living and working in the world. The study of behaviours, beliefs, institutions and change undertaken within sociology (Gieryn, 2000) is highly relevant to tourism research. The social relations that belong to, influence, and are shaped by, the behaviours, beliefs and institutions of any society underpin the individual's relationship to the world. 'No social relations are carried out in the absence of either thought or emotion', Tenhouten notes, and therefore analyses need to consciously address these aspects 'if meaning is to be found in any system, any social process, or in any social relation of the everyday world' (1996, p. 2). All tourism activity occurs within social contexts; it follows that the tourism experience is integrated with the thought and emotion present, as described by Tenhouten, and that these must therefore be acknowledged and incorporated into analysis of the travel experience. Leisure studies, which have contributed to tourism research as representing one aspect of leisure activities, have also been seeking and developing methodologies that can reflect the interrelationship of activity, emotion and the sense of self that is crucial to our understanding of our place in the world as human beings. 
Analysis of the 'self' - its constitution, its situation, its relation to other selves attracts various descriptors, practised by various observers, from those awarded an authorised voice to personal introspection, and include psychoanalysis, intuition, habitus, ideology - indeed, 'navel-gazing' in the Australian vernacular. Literary studies have contributed through analysis of the self as 'subject' and the constitution of signs and signification, connotation and authoring in the placement of that subject. In cultural studies, subjectivity is considered at three levels: the unconscious, the effects of surrounding sociohistorical forces and the multiple subject positions that each individual occupies (Leith, 2001, p. 28). Cultural studies have contributed to a widening examination of the self through analysis of representation and discourse, such that issues of power, control and voice in the construction of the self, and, consequentially, that which is not the self - the 'other' - have been foregrounded.

Broader understanding of how we as human beings make meaning of our being in the world, how we develop the physical data we receive from our sensory input into conceptual understanding of the processes of living and being, has been the province of philosophy. While psychology has mapped brain areas and a physiology of thought, and sociology has assessed patterns of behaviour of groups of people, philosophy considers the ways we put meaning together, the way ideas are handled, the way thought is organised into conceptual understanding. Philosophy proposes to think about how we find meaning in our world and our place in the world (Badiou, 2003); it seeks to express our position as subjects. Western philosophical thought still retains a Platonic approach to our understanding of the nature of being and the question of how we come to 'know', demonstrated in the questioning of the senses and of language. Philosophy seeks to reflect, and reflect upon, the relationship between individuals, individuals and their society, and the personal understanding of ourselves in the world, that is, our subjectivity. French philosopher Alain Badiou (2003) describes philosophy as having the dimensions of a 'discontent' of thought, of humans as thinking beings, and of the importance of risking new points of view. We now live in a world, he contends, where the multiple complexities that make up 'being' require a philosophy that reflects the way any event or situation in which we find ourselves engaged is unique - what Badiou describes as the 'irreducible singularity' of events (2003, p. 55). At the same time it also needs to be able to embrace 'the surprise of the unexpected' - the unpredictable outcomes of such events (ibid). 
Such a philosophy would provide an understanding of how we establish meaning in a complex postmodern world. It also offers a different method to examine travel as a movement for positioning the traveller for learning and experiencing. A philosophical analysis applied to tourism, then, has the potential to bring some very different aspects of the experience of travel into discussion.

\subsection{QUALITATIVE ENQUIRY}

The phenomenon of tourism demands a plethora of critical analysis techniques. Tourism research struggles with the tension between the privileging of scientific databased analysis, which is founded on the repeatability of research, and trying to account for the construction and activity of social life and experience, which changes constantly and whose gathered evidence can never be repeated. Not only is there debate on the expediency of various methodologies but the integration of the findings resultant from this range of methods is often impossibly difficult. The compatibility and comparability of the plethora of approaches, methodologies and analytic tools between qualitative and quantitative research is a problem for tourism studies.

The diversity of research methodologies that are applied in examining the experiential dimension of travel and tourism are a challenge to accept and manage. In order to capture the individual tourist's construction of experience, Wearing and Wearing (1996) suggest, qualitative methods allow for recording, presentation and analysis of a greater variety in response, as well as being able to tap into the impacts on the self. Qualitative enquiry must necessarily rely on the human being as primary tool in research - through interview, discussion, conversation. This is then analysed in writing, interpretations and representations by the researcher, her/himself a person and participant in the data-gathering. The researcher therefore is situated as part of the research process, not outside this process. 'One's stance and gaze as researcher, whether directed to the subjects or objects of inquiry, become a matter of politics, ethics, attitude, method and epistemology', Hutchinson and Samdahl note (2000, p. 238). The researcher's own cultural position cannot be divorced from the gathering, interpretation and reporting of research. For Foucault (1992), this informing of the analysis means it is necessary to understand the critique itself as an affirmed power; who does the speaking, from what position and viewpoint, the institutions that prompt people to speak and which store and distribute the things said - these shape knowledge in political and 
powerful ways. The design and focus of the research, even the initiating question itself, must be recognised as emanating from a particular politico-cultural position; this is of particular relevance in tourism studies where the inter-engagement of different cultures, which is the basis of travel and tourism, is being examined. Jamal and Everett (2004) compellingly note that while research is undertaken, we as ourselves - the individual human person of the researcher - are interwoven into the life-world we are studying, being simultaneously researchers, residents, societal members and, indeed, tourists.

It is important that the different styles of analysis offered by qualitative techniques be recognised as no 'soft' option in research, but rather demand considerable sensitivity to the 'un-fixities of meaning, affiliation and identity' (K Hollinshead, 2007, pers. comm.). In regard to tourism research, the flexible interpretive approaches of qualitative methodologies are particularly valuable, Hollinshead believes; they demand the use of intuitive and creative capacities as perceptual diagnostic tools, and because these can reflect the shaded meanings, affiliations and identities that tourists experience in travel, exploration of the travel and tourism experience is expanded (2007, pers. comm.). The reporting and display of this kind of nuanced findings, however, draws challenges in scholarly debate within institutions. Parry and Johnson (2007) suggest the use of creative analytical techniques that not only offer a way to work through the process of qualitative research but also that reflect the ambiguity of the researcher's position. Creative analytical techniques reflect experiences in ways that represent 'personal and social meanings rather than simplifying and reducing' through the 'purposeful engagement' of issues connected to subjectivity, authority, authorship, reflexivity, and representational form (Parry \& Johnson, 2007, p. 119).

\subsection{1 · COMPleXity AND Qualitative ENQUiRY}

The qualitative paradigm places emphasis on complexity and diversity (Mace, 1997, p. 268), and therefore is a research approach that can reflect the multifaceted nature of experience. Part of the challenge in analysing individual experiences is that while an experience is an isolated - as in singular and individual - effect, it is also contextualised by the physical and social environment in which it occurs. Separating experience from the context of its occurrence for the purposes of research is problematic and requires, at least, an acknowledgement of the limits this places on the application of results. Parry and Johnson (2007) suggest that for studies of leisure activities, such as 
tourism, utilising methods that reflect the personal and social meanings of experiences make better use of material than abstracting elements, removing them from their contextual embeddedness, and working with these in isolation. Take a look at the informal tourism 'research' overflowing the travel-writing section of the local bookshop: it is clear that travel and tourism activity takes place in a social context and produces personal responses, it is not an activity reported in isolation (even though feeling isolated may be part of the experience). The argument for the use of expressive elements in tourism research, such as autoethnography, creative non-fiction, visual images and story-telling, is that these are better able to illustrate the socialised and personal dimensions of the tourism experience.

Texts 'that seek to portray ... the contradiction and truth of human experience ... showing, even partially, how real human beings cope with both the eternal verities of human existence and the daily irritations and tragedies of living that existence' (Lincoln \& Guba, 2005, p. 211), offer the possibility of more adequately representing the travel and tourism experience. Creative analytical techniques are critical, conversational and multivocal representations of research (Richardson, 2000, p. 253) and may include the use of poetry, autobiography, autoethnography, narrative expression, artistic and literary genres, and visual techniques including photography (Parry \& Johnson, 2007, p. 119). Such techniques' imaginative and evocative ability allow the complex contexts of social accounting to be better demonstrated (ibid).

Critical thinking does not equate to rhetorical skill, disembodied-ness and the merely adversarial (Alston, 2001, p. 38) but to establishing a connection between information, context and opinion. Similarly to the travel experience, current research in the process of creative practices identifies the difficulty in both describing, and accepting descriptions of, the subjective nature of that creativity itself, for purposes of developing theory (Phillips, accessed 18 August 2008). ${ }^{3}$ Not being able to embed such descriptions in a factual base has generated criticism of such research as being 'conciliatory, analgesic and without a critical edge' (Gablik, 1991, p. 60). Rather than repudiating the critical edge, creative analytical techniques within research can act to deconstruct the data collected and the writing of theory. This insertion of illustration,

\footnotetext{
${ }^{3}$ The applicability of creative process theory to the examination of the experience in travel is elaborated later in this thesis (refer 3.2 Creativity - moment, space and presence).
} 
poetics or critical-creative writing can break through the autonomous space of western scholarly research and theory construction.

Feminist studies have worked to make effective use of mixed methodologies, weaving autobiography and personal journals into criticism and analysis (Tedlock, 2003). This inclusion of creative analytical techniques can also be seen in Muecke's (1997) No Road: bitumen all the way where observation and reflection on theory are interwoven with a record of journeying. Clifford (1997) interleaves the analytical chapters in Routes: Travel and Translation in the Late Twentieth Century with descriptive written passages of his own reflective travel observations. He describes this mixed approach as collage, as does Carter (1992) in his writing of the migrant travel experience and discussion of ways of recording these experiences. Collage is a useful descriptor toward understanding the benefits of inserting a variety of textual mediums into the writing of research, if collage is considered as a technique that 'asserts a relationship among heterogeneous elements in a meaningful ensemble' and which allows a 'bringing together' of viewpoints of experiences (Clifford, 1997, p. 11). Scholarly discourse, Clifford continues, condenses thought and feeling; applying a collage approach in reporting research facilitates the accessibility of both these aspects, providing a less restricted view than the purportedly disengaged stance (ibid). In the field of tourism studies, the methodological challenge has been to find a way of expressing the complexity and layered nature of the situated yet individual travel experience in research writing. Tribe indentifies a lack of methodological innovation in tourism studies as problematic for examining the phenomenon of tourism but also as a concern for the discipline itself; 'Tourism has to develop new methodological insights to advance the field,' he warns (2008, p. 925).

Some models are available from feminist studies, as already mentioned. Humanities and Social Science researchers have been experimenting with research writing that seeks to express the emotional experience rather than the factual experience; this expressive and reflective writing attempts to both acknowledge and articulate the reciprocity that exists in the examination of experience. A number of models have emerged under a number of names, including ethnomethodology and fictocriticism. These employ a creative analytical component as a way both of expressing the complexities of theory, and of reporting the interactive, embodied and experiential nature of the activities that the theory is seeking to encapsulate. 
Fictocriticism has been described as criticism without an argument, using an interplay of writing positions (Brook 2002, Gibbs 1997, Robb 2001). It seeks to deconstruct established relationships through the juxtaposition of ideas and thoughts which then allows contrasting ideas and knowledges to interact in ways they could not do when handled separately. Through such interaction, questions can be raised that facilitate greater insight. For this thesis, I refer to this methodology as critical-creative research writing. Using critical-creative research writing draws on postmodernist models of subjectivity, which recognise the subject as temporal and fragmented; the writing is an acknowledged composition, positioned between rhetorical and subject positions (Cary 2004, Robb 2001, Rose 1997). Significant applications of creative analytical techniques are found in the works of Barthes and Derrida, where each take an approach in their writing analysis that is structured as speaking from the inside, a position that enacts a withdrawal from the masterful stance and is instead a de-centring of the subject that offers new insight into the research material (Brook, 2002). It is a valuable space for difficult-to-enunciate knowledges such as the writing of performativity, identity and cultural production, which are all implicit in travel and tourism experiences.

Collage, ethnomethodology and fictocriticism all employ critical-creative research writing styles that owe something to the concept of the narrative in literature studies. The narrative, if taken as themed story-telling, is integral to the production of the travel/tourist experience by the tourist her/himself and returns us once more to the full shelves of the bookshop's travel-writing section. The narrative has work to do in expounding, exploring, determining and expressing the many complex inflections of the other and of becoming part of the other (Sidone Smith, 2006, pers. comm.), making it especially relevant for this thesis. Critical-creative research writing is not, Fleming and Fullagar note, an easy form of research to produce; it is not a matter of an 'anything goes' kind of writing nor 'a naive form of reminiscence' but requires constant reflection on style and levels of disclosure 'while working between conceptual and everyday registers' (2007, p. 17). Any creative analysis technique applied in tourism studies requires particular discipline. It is critical-creative writing and different from the reflexive writing up of field work, which can often be found in the form of journals and diaries where the researcher is considering their personal position within the environment of the research activity. Rather, the critical-creative element works as a way of expressing ideas outside rigid academic language in order to bring out subtleties 
in meaning, inference and interaction of the theory and ideas under consideration.

\subsection{THE SEARCH FOR MEANING}

From the outset, western travel writing has been considered transparent (Khair et al, 2006). When travel writing first began to be published and made available to a general readership, it was confidently assumed that what was written precisely described what was there. One could follow the pathway and experience exactly the same thing - travel writing was factual and accurate and reliable. Moreover, the judgements implicit in the writing would, if attention had been drawn to them, have been considered only reasonable and rational. The demand for descriptions, diagrams, illustrations and measurements by the funding bodies of the eighteenth and nineteenth century travel expeditions, such as the Royal Geographic Society, was embedded in an assumption of impersonal observation. These reports, and the diaries written up and published for general readerships, were taken to simply describe a place and people as they were; no interrogation of either the description or the position of its enunciation was considered, other than as a record of 'truth' (Khair et al, 2006, p. 9). However, such writings, as a source of understanding the practice of tourism and travel, remain sites where meaning must be contested and where context and positioned discourse continue to be examined and debated.

How we, as human beings, understand 'meaning' and 'reality' forms the base of all philosophical discussion. The western search for 'fact' and 'truth' - really, the western determination for absolute 'truth' and 'fact' - collides with the interpretation of lived experience that constitutes our understanding and conceptualisation of the world. 'Western epistemology was shaped by the belief that emotion needed to be cut out of the process of knowledge production' but rather, this needs to be heard, 'for without it we hold onto a unified voice' (Tierny, 2003, p. 310). The unified voice is not so much one voice representing a homologous many, but more of a single voice shouting down all others, often magnified by an association with an authorised position. In this sense, mono-vocality reduces that which is different by defying the multiplicity of the world with which we are, paradoxically, familiar on a daily basis. Jamal and Hollinshead suggest a conception of travel and tourism as 'highly reconstructive practices' involved in a range of 'matters of enlightenment and knowing' which 'can contribute to the study of being, identity and possibility' (2001, p. 64). 
One of the reasons travel and tourism research can contribute to philosophical questions of meaning, being and identity is that tourism is not a one-way action of the tourist upon the host culture but the subjective experience of a two-way interaction between tourist and host (Wearing \& Wearing, 1996). 'Two-way interaction' implies not only the presence of two separate parties and some reaction between them but the importance of that other party. One could go so far as to say that interaction cannot occur without this 'other'. I further suggest that the presence of the other is integral to the travel and tourism experience. Moreover, the presence of the other is integral to how we, as human beings, structure meaning - of our place in the world, of our experiences in the world, the meaning, indeed, of ourselves, of being. Philosophy, as suggested earlier, would seem to offer something to the study of travel and tourism; certainly, an examination can be found in philosophy of the structure of the other and of the self that leads to the development of concepts and conceptualised understanding of the world, as well as the role of reflection and narrative in considering experience. The examination of those matters of 'being, identity and possibility' that Jamal and Hollinshead identify as potential in tourism research, may reveal a depth of intention in the reasons for undertaking of travel that has not been considered previously and to which philosophy may contribute. The traditional assumption, Levinas writes in Totality and Infinity, has been that 'reason has no plural', that there is always one truth, one answer (1969, p. 208). However, he continues, consideration of our lived experience shows us that reason 'has many centres and approaches the truth in many ways' (ibid); the travel experience likewise has many approaches, realities and truths. MacCannell's (2002) note can be reiterated - that the motivations of tourist desire are mysterious and illusive, even to tourists.

\subsection{HOW TO VIEW THE EXPERIENCE?}

The intentions individuals hold in undertaking travel are complex and often inadequately expressed (refer to 2.3 for more detailed discussion). That travel can transform the individual is a common theme in autobiographical travel narratives, television shows, film and indeed in tourism promotional materials. The potential exists, even on protected group travel to familiar or known destinations - destinations of small enough difference that perceived threat is minimal - for chance events to occur that unequivocally and irrevocably change the individual. Such change may be a reinforcement of held cultural beliefs, however biased - the sought-for reassurance of 
already-held values that affirms the traveller's prior convictions. Or a personal challenge may occur, such that the returning traveller is aware that they will never be able to go back to where they came from, that they 'do not now fit into the space [they] occupied previously' (S Henry-Edwards 2008, pers. comm.), because previously held values and beliefs have been confronted and, consequently, altered. While mediabeloved calamities such as transport crashes and man-made disasters - especially ones that invoke 'an Australian among the missing, presumed dead, we await further information' cliff-hanger headlines - are immediately recognisable as events that will change any traveller involved in them, other less publicly acknowledged experiences can also be significant. For example, the immersive experience of racial discrimination (even in the position of the privileged); a communication difficulty that could not be overcome; an epiphanous moment of revelation: the profound effects of such incidents are often a struggle to verbalise. They do not make media headlines yet such experiences shift our ways of 'being in the world', that is, how the individual understands her/himself as an individual and in relation to the world in which she/he lives.

In order to open up understanding of the complex nature of this interaction, I turn to critical-creative writing. This first foray is an interpretive contemplation of how the researcher's reflexive awareness of observing yet at the same time being immersed in the context of their observation requires a multi-focal sight that constantly slides between many positions of viewing. The blinkers and filters, the ambivalent reflections of ourselves as researchers, is part of the research experience. The immersive, immediate and subjective nature of travel is part of the travel experience that tourism research attempts to address. The limitations and revelations of observation are equal parts of the journey of both researcher and traveller.

\section{- WAys OF SEEING: THE RESEARChER's GAZE •}

The primacy of the ocular in Western discourse would seem a statement of everyday knowledge. Such is the power of discourse. The visible detail portends the invisible principle.

Observe, and you shall know. 
And the observer behind you observes you. See, the visiting President walks along the beach, smiling; we know because we see it on the news. We know because the President walks along the beach encircled by a snapping-lensed reporter crowd. And each photograph is framed to be exclusive; see, the President walks along the beach - just for you to see, just for you to know. The tabloid sells millions but the photograph is intimate, personal, insider.

But look, widen the lens - the President walks, the crowding cameras can jostle, because the beach is cordoned off for the paparazzi crowd's exclusive visual capture, the capital-return recording of a moment. Beware this, the camera's cinematic pull-back take that widens and opens the vista - it impinges on ocularist observational neutrality. Use it carefully: it may disturb.

Disturbence unsettles; disruption causes discontinuities. Lenses disturb the act of observation by reframing the framing. But do we want to know? Leave me with my fragile and inaccurate reading - it makes me feel special, happy, I have the inside take. Let me believe the President walks for me, knows me, greets me from the tabloid, alone on the beach.

The researcher likewise can disturb by observation. Disturb assumptions, disturb knowledge. Disturb their own concept of self. The lens shifts to include the observer in the view - who is recording whom? The lens turns to frame the observer, illuminating context.

A marine researcher reaches for polaroid sunglass lenses to pierce the water surface's refractory illusions. And now we have the coral, the sand-screened stingray, where before there was only beach and inscrutable shore-lapping sea. Lenses that filter providing greater insight - ah, there is a paradox for the philosopher.

But sunglasses also disrupt. Their opacity, Droit observes, brings the glance to a stumbling halt (2005). Check back: the President is walking along the beach - without sunglasses. The lensed gaze of the reporting crowd is reciprocated with the naked eye. 
Enigmatic black-wrapped eyes, on the other hand, refuse engagement. Instead, the observer is faced by their own self, mirrored in polished surface, badged with branded cool. The self is now an object of selfgaze, inserted into the dialectic of object-subject observation. The image of self distracts the already-thwarted gaze. Lacking the sought object, double rebuff reduced to self alone, knowledge can only be recycled in a continual looping back of self to self. Focus is sliced between attempt to penetrate and distracting insertion of myself re-presented to myself. The narcissistic mirrored self exercises a seductive obsessive possession of the observer; Sartre's self making itself.

But an insistent thought taps, breaking the spell of self-perpetuation - to observe is to know, they taught us. The power of the occluded glance wrests privilege from the observer. The opaqueness of sunglasses obscures forthcoming response; anger, dismissal or loved embrace resides equally in unreadable potential. The observer's gaze is denied; knowledge collapses within failed contact. Ironic that sunglasses protect the enigma of gaze while the sightless wear sunglasses as signification of lack.

Offer, then, the touch, the equaliser handshake, for a retry at mastery. Or the secondary constructive, language. Its acknowledged position as a consequent to encounter makes this a hazardous gesture; lacking reciprocal encounter, too many possible offences muddy the self's assessed clarity of intent.

And there it is: 'the self's assessed clarity of intent' which in research can blind the observer. Clarity of intent is necessarily framed in paradigms that may render the gaze incompetent. Wyndham's (1951) blind man was the solitary competent in a suddenly sightless world; the belief-blinded researcher has no such luck. Research relies on received information but must be self-deprecating in statements of method. The mode of reception, the ability to receive, are barely under our control Foucault tells us. The skills to use knowledge, indeed knowledge itself, comes to us within frames of power. 
And the context, the source of information received - these are rarely under our control, for doesn't research take us out specifically to spaces where we don't know? Surely that is the point - the accessing of what we don't know. But how to access something not known becomes a tautology, for something must be known about it, in some form, in order for it to be identified as duly receiving attention.

Call for the philosopher again ...

But the dominant ocular is disrupted by sound. There is a pub adjacent the President's beach. Laughter, pulses of percussion rhythm, voices, all rise into the day's shimmering summer heat. Verandahed shade does not preclude the protective second-screen of sunglasses; through the wide open doors, barstools cluster in the inside cool - here sunglasses are pushed up to gaze ceiling-ward, protecting hair from alien overhead observation but allowing eyes to engage barman, mate, beerglass. Revealed glance is available for contact. Outside, the sun's strength strikes indiscriminately, loosening ties, rolling sleeves - obliterating eyes behind darkened glass. Here voices beckon, call out to friends, hands reach to pull inward, embrace, create personal space into inclusion; the heard invitation accepted and enacted in the body's touch. Sunglasses divert the gaze, to the use of other senses, and we barely break stride in our living.

Information is received through all senses, mitigated through held beliefs to form a choice of action. Information is offered to the researcher at formalised encounters framed by intent purportedly understood by all participants, but intent should never be assured to be the same for all. For beware - sunglasses speak. The very blankness is a statement. Badged kudos waits to be recognised; stylistic enunciations of belonging and identification. And they remain. The sun drops below our horizon but sunglasses are retained, a night-time accompaniment of studied ease worn crown-high.

From contemplating the research gaze, a consideration of the literary expression of research is required and it is appropriate to begin with definitions. 


\subsection{DEBATES ON DEFINITIONS}

The terms 'travel' and 'tourism' are often used interchangeably, as are traveller and tourist. There is also a familiar existing prejudice which preferences 'travel' terms over 'tour' terminology; for example, White and White (2004) explain that they chose to use the terms 'travel' and 'traveller' in their research with long-term Australian Outback travellers because these terms better represented the internal and external elements of the journey. It was also because the term 'tourist' is one that these longterm travellers felt as implying short-term, disengaged and often disinterested interaction with place, and was something which they were keen to be situated against. The origins and convolutions of the associations which privilege travel over touring would make a thesis on their own. Here, I will take travel to be the broader category of movement between places. It does not have a set linearity or self-closing loop of movement embedded in this, just movement. Tourism is one aspect of travel; it contains an economic supporting sector as well as the making and maintenance of sites and activities and the movement required to access them. Tourism thus intersects with travel but neither includes the whole of the other.

\subsubsection{DEFINING TRAVEL}

Chadwick (1994), in his summary of tourism concepts and definitions used in the gathering of travel and tourism statistics, suggests the use of 'travel and tourism' as a single phrase in research because this is inclusive of both the movement of people as well as the economic and social sectors that support movement. He defines 'traveller' as 'any persons who travel', and within the scope of travel and tourism research, further defines travellers as those who return to their local community $(1994, \text { p. } 77)^{4}$. Ghosh (in Khair at al, 2006) draws attention to the bias within the Oxford Dictionary's (2005) definition of travel: travel: (1) go from one place to another; make a journey esp. of some length or abroad; (2) journey along or through a country. Using terms such as 'abroad' and 'country' predicates the definition itself in a western discourse: 'abroad' is a particularly British expression used to indicate everywhere else than Britain, while 'country' is based in the concept of nation-states which is itself a relatively recent western development of models of the political unit. Travel has been occurring for much

\footnotetext{
${ }^{4}$ Interestingly, the word 'tourist' is not mentioned at all.
} 
longer than either of these terms indicate and to use such terms in defining travel excludes other origins, purposes, practicalities and expressions of travel, especially by non-westerners.

That leaves us with the rest of the definition - 'going from one place to another' - which aligns with the understanding that travel is the broad activity within which tourism takes place and with which the tourism industry intersects. Syed Islam considers that, at its simplest definition, travel is movement between spatial locations; while travel writing is narration that unfolds the events of trekking in space, he continues, it is in the process of negotiating the between of those spatial locations that a person makes themself a traveller (I996, p. 5). Clifford defines travel as 'practices of crossing and interaction' (1997, p. 2). Such a definition is inclusive of the issues of 'diaspora, immigration, migrancy, tourism, pilgrimage and exile' (ibid, p. 11) that also resonate within discourses of human movement and reiterate that tourism is only one part of travel. Mongia, speaking from a non-western perspective, takes travel as a 'figure for ... modes of movement, stasis and knowledge', a mode that is a combination of movement and non-movement rather than movement defined against a fixed 'home' that is returned to - which is the dominant discourse in studies of tourism (in Khair et al, 2006, p. 5). Mongia also understands imagination, reflection and receptivity, that is, the realm of thought, as integral to travel. Western discourses of tourism place little emphasis on 'thought' as a dimension of touring and certainly predicate return-to-home movement as the only movement involved. Although writings and viewpoints of nonwestern travellers are very slowly becoming available to a wider academic readership (Khair, Leer, Edwards \& Ziadeh's Other Routes: 1500 years of African and Asian travel writing (2006) is one example), most English-language travel writing is embedded in the 'distinctive cultural and historical experience' of the European 'age of expansion and colonisation', with human mobility taken as a predominantly European practice (Khair et al., 2006, p. 5). Interestingly, the Oxford Dictionary's (2005) definition illustrates precisely this embedded Eurocentricity.

\subsubsection{DEFINING EXPERIENCE}

Two other terms require attention in order to examine the choice of open-ended travel that initiated this research: 'experience' and 'nomad'. Experience is more than passively received sense impressions, according to American philosopher Mark 
Johnson; it is a complex interaction of perceptual, emotional, bodily, historical, social and linguistically-dimensioned elements that work to make up our understanding of the world (1987, p. xvi). Taking Johnson's description, experience can then be understood as an inseparable combination of the physical and conceptual, that is, the sensory input received through the body that is subsequently reflected upon and thoughtfully considered.

\subsubsection{THE NOMAD TRAVELLER}

The term 'nomad' has come into tourism studies quite recently as a descriptor of travellers whose attitude differs from that of the (imagined?) mass tourist (Feifer 1985, MacCannell 1992). However, the nomad is specifically delineated as not being part of travel and tourism in Chadwick's (1994) definitions used in tourism statistics and analysis; here nomads are typologised as people who are planning to stay away for more than one year and/or on a one-way journey, that is, not returning to a fixed 'home'. This is a curious division - length of journey and direction of journey set nomads apart as travellers. The implication is that travel is properly less than a year long and returns the traveller to their starting place. Further, the exclusion of nomad travellers from being real (statistically justified) travellers is based on defining nomad travel as being travel 'not affected by travel promotion' (Chadwick, 1994, p. 69). Here the definitions of travel and tourism, and of traveller, are clearly linked to the economic aspect of tourism as business.

\subsubsection{THE NEO-NOMAD TRAVELLER}

Using the above definition, these nomad travellers are not part of travel and tourism. MacCannell (1992) suggests there is a new kind of traveller, the neo-nomad, who wants to create experiences and seeks encounters that embrace difference. However, MacCannell's new tourist/traveller is not necessarily on one-way or longterm travel but, rather, shares attitudes that are associated with nomadic movement outside the mainstream of established tourism practice. The nomad traveller, MacCannell suggests, does not travel 'as an invader conquering territory' but in the belief that their experience will be 'made of dialogue with those they meet along the way'; they leave home 'not knowing where they will end up' in terms of the experiences that may arise (1992, p. 4). 
The choice of travel that initiated this research, that of choosing to go to a place or in a direction because of not knowing anything about it or what might come out of it, offers a point of departure for discussion of attitudes and receptivities that are becoming visible in the twenty-first century, postmodern world. Such travel is not the quest of mythic stories, nor pilgrimage, it is not exploration in the nineteenth century idea of 'discovery' of place, though couching it in such words has occurred. It is not participation in mass tourism, although it may engage in group tourism activity if chosen from time to time; it could be described as journeying, such as is part of 'life's journey'. But it is being open to possibilities while simultaneously accepting that nothing may happen at all.

Travel that is movement which seeks the unknown as destination could be postulated as one particular manifestation of a postmodern way of being in the world. MacCannell's neo-nomads may simply be a demonstration of how, in the late twentieth and early twenty-first century, the way people engage with the world has changed and is changing. Even though the consequent terrorism hyperbole erupting from the events in New York early in this century has had heavy-handed influence at points of entry and exit to nation-states, the postmodern relationship to the world and ways of being will continue to exert a presence and influence. The attributes associated with postmodern being - interest, fascination, play, inventiveness and creativity - resist containment.

\subsection{THEORISTS IMPORTANT TO THIS THESIS}

The pre-occupation of late twentieth century tourism studies research with the 'tourist gaze' (Urry, 1990) at objects, sights and attractions produced exciting and interesting research directions but has also in some ways blinkered researchers by focussing on the 'already-constituted' as the principle constituent of tourism practice and experience (Boothroyd, in Simms, 1997). Three particular theorists of travel and tourism have suggested that a new kind of traveller is appearing in the twenty-first century, as earlier modernist frames of meaning-making are discarded and newer engagements, more reflective of how we, as human beings, live in the contemporary world, are being tried out and conceptualised. For such travellers, the visual is not a focus at all, rather there is a strongly experiential element. Dean MacCannell, James Clifford and Donald Horne each write of this, and each end their texts at a point which this thesis has taken as a place to begin. 
MacCannell (1992) suggests that the postmodern traveller, the neo-nomad, is an imaginative traveller who enjoys a displacement of self-understanding, that is, embraces the moments when self is contested or disturbed by difference. The neo nomad, MacCannell believes, benefits from the freedom to go beyond the limits that frontiers present and knows that chance meetings and conversations will hold the gains of travelling.

In The Intelligent Tourist, Horne reflects the influence of theories of the gaze in his focus on museums and sight-seeing. However, he believes that research needs to allow for the 'paradoxes and fiascos and spiritual perils' of tourism - to 'contemplate the possibilities for enlightenment' (1992, p. x). Instead of focussing on sights and sites, he writes, we should consider travel as a 'great question-raiser'; from what is told to us, if we listen, and from what we experience ourselves, we travel in order to 'build up our own particular criticism of existence' (ibid, p. 361). Horne suggests we 'give up sightseeing for sight-experiencing' as the new way to engage in travel [emphasis in original] (1992, p. 375).

\section{Clifford, in Routes: Travel and Translation in the Late Twentieth Century,} pleads for travel knowledges to be taken seriously (1997, p. 31). Travel is a condition of living, one that is inseparable from dwelling, he contends. If travel is a search for 'difference, wisdom, power, adventure and an altered perspective' that offers no guaranteed results but instead 'often lets uncontrollable, unexpected things happen', then such happenings are crucial sites where being human is constituted by displacement as much as by stasis (Clifford, 1997, p. 90). That is, movement is a constant in the formation of subjectivity, requiring the 'untethering' of travel from its constitution in a dichotomous oppositional relationship with 'dwelling' (ibid, p. 44). Clifford suggests a concept of 'dwelling-in-travel' (close to that of Mongia's travel as a composite of both movement and non-movement) that can show displacement as constitutive of our cultural meaning, our subjectivity (ibid, p. 2). The traveller who accepts the open-ended nature of movement brings attitudes of tact, receptivity and selfirony that are conducive to non-reductive understandings, and relationships that are non-reducing of the other (ibid, p. 11). 


\subsection{REVIEWING TOURISM THEORY DEVELOPMENT}

As noted earlier, theoretical interest in tourism has increased proportionally with the global growth of tourism activity. Tourism theory has developed slowly, acquiring input from a range of academic disciplines that is itself problematic due to the disparity of paradigms and methodologies evinced. It doesn't help when the phenomenon of tourism is complex and wide enough that all these various applications are, in themselves, quite valid. It is the development of theory that can be applied across a range of aspects and used within a range of disciplines that is both needed and hampered. The international nature of tourism means, in addition, an increasing language and cultural diversity in research input: amongst many examples, research from Finland and Norway contributes to that coming out of American and British universities; New Zealand and Australia have developed strong leisure studies input; Chinese tourism research tries to keep up with its vast, fast tourism expansion. Academic studies began with a desire to understand group tourism practices in the mid twentieth-century. With the development of cultural studies came a more critical analysis of tourism in regards to impacts on host cultures, ranging from environmental impacts to cultural impacts and examining implicit power imbalances.

By the 1990s, tourism researchers could be working anywhere within the range from micro-social psychological explanations of tourist choice to macro-social explorations of the globalisation of tourist venues (Wearing \& Wearing, 1996). Several theorists have attracted wide interest. Cohen (1973) worked with the concept that holidaying was an escape from work and every-day life and that tourism activity was to be understood through a dichotomy of home/away. The implicit sense of looking over one's shoulder that this carries, that the value of holidaying lies in not being somewhere rather than celebrating where one is and what one is meeting with, is problematic. Cohen's theory focuses on the individual, the attitudes that are brought along and the outcomes of the tourist activity undertaken in terms of self-satisfaction. While an important contribution, it does not address the presence of the other in the tourism experience. The tourist in Cohen's theory is working in a closed world of the self.

Urry (1990) contributed the theory of the tourist gaze which has had a major impact on tourism studies, being multifariously taken into understanding the role and interaction with knowledge sites such as museums, debates on authenticity and the importance put on sight-seeing in tourism activities. In some ways, Urry's theory was 
seized upon as the answer to everything, but it is heavily weighted toward western privileging of 'gaze' in knowledge formation and was challenged by feminist studies of the masculinity of this gaze and by cultural studies of the gaze as consuming and reductive. MacCannell's (1979) theory of the tourist as a new leisure class also explored the role of authenticity and attractions in tourism practice. The importance of the demand for authenticity became a major theme in tourism studies but, similarly to the gaze, has been challenged in the questioning of who establishes the grounds on which anything is deemed authentic. Morris' (1995) taut observations on the objectification, inherent in both the gaze and the practices of cultural consumption that impose a valuation of authenticity by an outside dominant culture, have influenced tourism critique. The examination of authenticity in tourism has also been influenced by Barthes' deconstruction of myths, landscapes and texts, both written and pictorial, and Foucault's theory of the relationship of power and knowledge. These have led to an interest in the change of ways of living in a technology-enhanced postmodern world and a focus on the tourist's role. MacCannell (1992) challenged his own previous work by proposing the postmodern neo-nomad traveller as representing a new travel and tourism orientation. The interplay of changing social constructions of work and home, alongside globalisation and the continued undertaking of travel and tourism activities, challenges tourism studies to free the understanding of travel 'from a history of European, literary, male, bourgeois, scientific, heroic and recreational meanings' (Clifford, 1997, p. 31). Current theory needs to recognise the importance of how humans make systems of meaning and difference, and the influence of travel on these - and indeed of these on travel.

A number of challenges present themselves for tourism studies. Already mentioned is the complexity of the phenomenon of tourism itself, which leads to multiple academic disciplinary relevance and multiple methodological approaches. Depth of knowledge within such a complex field is difficult; while isolating and examining a single factor has been a successful approach for in-depth research, for tourism the isolating of one factor will render it almost impossible to understand since its existence lies within its situational interactivity. What remains is the requirement to have depth of knowledge in a range of disciplinary complexities brought simultaneously to bear on the question - quite a challenge. These difficulties for research are reflections of the newness of tourism as an academic field of study, and indicate that theory should 
be expected to be highly changeable as it goes through rapid growth - and equally rapid critique.

Definitions of key terms, as discussed earlier, are also problematic, again relating to the many areas contributing to tourism studies and the particular disciplinary orientation of each, including language and directional focus of research. Typologies of styles of travel, such as long-haul, back-packer and adventure, are debated, as are typologies of people who travel. (Further discussion of travel typologies is presented in 2.3.) The discourse of tourism and travel research extends across a wide range of subject areas, with Hollinshead citing the need for broadening the research base of tourism studies to use more reflective methodologies and for the development of a strong critical tourism element (pers. comm., 2006). The orientation of tourism studies toward a strongly westernised perspective also needs to be examined. Self-initiated appropriation of First World tourism practices by marginalised groups in Third World countries, in order to make a successful living from tourists to their country, has been noted (Doron, 2005); these adaptations and hybridisations should not be disregarded within tourism studies.

Two other particular aspects of tourism present difficulties: firstly the study of the individual versus the study of group tourism activity and practices. Can these be related to each other or must they remain separated bodies of understanding? How much can they give to each other in developing tourism theory? Secondly, the world is a changing place and the labels of 'modern' and 'postmodern' on theory, on social life, on technology, and on human activity, are hotly debated, highly charged and suitably muddied. Yet there are different influences on tourism and travel in the twenty-first century. By understanding postmodernism as a palimpsest where new forms of cultural consciousness are slowly being rewritten over modernist forms of cultural consciousness (Fife, 2004, p. 165), these differences may be more able to be enunciated, and this will help tourism theory's development.

The urge to travel has been variously ascribed to a range of conceptual paradigms - curiosity, discontent, ecological survival traits, displacement, trade, boredom and desire, to name a few. It has also been considered against its antithesis those who don't travel. Tourism research has examined personal aspects of the travel experience such as motivation, purchase patterns, repeat visitation patterns, expectations, sightseeing, collection of souvenirs and image-taking such as 
photographs. Boudieu's $(1987,1990,1991)$ theories of social and cultural capital have been applied. Research has also explored the individual as traveller through aspects of self-identity, memory and satisfaction. However, there is less research into what it means to undertake an experience or choose a destination that has the potential to effect profound change, to shift the individual's way of being and knowing the world.

Wearing and Wearing (1996) suggest that the travel experience contains a higher degree of co-creation than previously considered and that, further to understanding this, destination needs to be examined as an interactive space. Considering the interactivity of the encounter as integral to the travel experience begins to provide a shift in conceptualisation that allows for the role of the other to come into closer account within the travel experience, something that earlier focus of theory on the gaze and the escape did not.

While much travel literature situates the tourist to view the local people of the destination as either the exotic other or the service other, tourism authorities, including in wealthy western locations, are aware that the cultural positioning of those local tourism providers is that the tourist is well and truly 'other' (P Cahalan, pers. comm., 2008). If the postmodern traveller is more aware of the transferability of the 'tourist gaze' as directed toward their self, they are aware of becoming the exotic object within the space they are visiting (Huggan, 2001, p. 201). Feifer noted that the traveller 'cannot evade their condition of outsider' $(1985$, p. 271$)$ but I suggest that this is not a problem for this conceptualised postmodern traveller, rather an ironical acceptance of outsider status is expected, which offers greater respect for the agency of the host. Travel is interactive - and therefore the other must be fully present in theories of travel and tourism.

\subsection{APPROACH CHOSEN FOR THIS THESIS}

Across tourism research there are many references to travel, journeying and being a tourist as passages to new ways of life, as spaces where identities evolve, or as impacting on the self in some way (White \& White 2004, Wearing \& Wearing 1996, Suvantola 2002, amongst others). In travel 'we change places to achieve the experience of variety that we desire' writes Suvantola (2002, p. 44) but why do we desire variety? What are 'new ways of life'? How do identities 'evolve' in travel? With such temptingly undefined phrases and the questions that arise from them, further research is 
irresistible - and required. These observations do however indicate that there is development of the self, in some way, that is consciously being sought, and that travel holds the possibility of providing. The sailing travellers I met, who had chosen the unknown as destination, fit this description.

Humans think, and therefore play around with information received - turning, sorting, aligning - to make sense of and to have an understanding of purpose, relevance, consequence and thereby make their choices to participate. Travel is an important undertaking in the continual search to understand and make meaning. Through an application of Levinas' philosophy of the responsive relationship to the other as enacted in the face-to-face encounter (certainly available in the practice of travel in a literal sense, but also applicable to the construction of conceptual understanding that results from travel experiences), the role of the other in this making of meaning can be examined. Explorations of the relationship of art and creative practices to travel and tourism are beginning to be published in travel and tourism research. Linking creativity with theories of travel in the area of tourism studies, through a detailed philosophical examination of what happens in the moment of aperçu when new conceptual understanding is generated, is situated in an area of research that is just starting to generate interest. The juxtaposition of philosophy and creativity with travel experience will take tourism studies in a fresh direction.

I suggest that travel offers those moments of aperçu, of sudden insight and new understanding, that can affect our personal meanings and understandings of the world. The central situation of this thesis, then, is that travel offers the potential for moments that generate new ideas and therefore new meanings, altering the subjectivity of the traveller.

Everyday words for such conceptual premises, however, are hard to come by. Profound aspects of life struggle for expression, as the narrative voice can demonstrate. 


\section{- NARRATIVE 2: EXPLAINING IT AWAY}

Even before we left, there had been mixed responses and moments of incomprehension - 'why exactly are you doing this?' From close family to friends to passing yachtsmen at the Squadron marina where our yacht 'Oblion' was being prepared, we received questions, comment and advice.

To start with: 'Where are all our books?' Stuart had asked in surprise when, arriving home from an interstate conference soon after we had bought Oblion, he had found a bare living room.

'I’ve started packing. We're moving aboard aren't we?' I replied.

'Where are all your books?' Stuart's mother had arrived to visit right at this moment. She looked at us suspiciously.

'Well, Mum, we haven't told you yet, but- !' My lovely mother-in-law was not happy with our plans. Her primary knowledge of ocean sailing came from spectacularised 'I Survived...' stories in her regular dose of Reader's Digest. She said nothing to stop us, though her heart must have quailed inside her; no words of caution or advice or remonstrance, just offers of meals at her home (getting us off the boat?) and to take in the family dog (now you will have to come back to Adelaide?). She dwelt in practical everyday dealings, using words familiar and reliable, addressing issues of the world she inhabited and was quite happy to remain within.

As our families and friends began to realise we were seriously intending to set out to sea for an indefinite time and an indefinite goal, a range of other conversations ensued.

'Jo's got this wild idea of an adventure,' my father announced to his friends when we were visiting one afternoon, en route to delivering a load to Oblion. 'Sailing around Australia. Or the world. Don't know where she got such an idea.'

'Oh?' was the reply. 'And how was the desert trek you got back from last week? And that Antarctic trip last January was pretty enjoyable, wasn't it?' They laughed; 'We could tell you where she'd get such ideas from!'

My father was very quiet for a moment and I could see on his face a realisation of a certain ownership of our 'wild idea' though he limited his response to 'humph'. 
He was not entirely happy that his grandchildren, our daughters Elizabeth and Alison, were to be exposed to a risky undertaking. My mother just smiled. Previously highly articulate, she chafed under the constraint a stroke had put on her speech. There were no words at her disposal to attest to her own sense of adventure and love of the new. Her keen interest in the wide world around her had not been dimmed by her illness: the sparkle in her eyes attested to that. Given the chance, she would probably have hitched a ride with us.

Surprisingly, Elizabeth and Alison's Uncle Ian, who had led underwater cave exploration expeditions and scuba-dived in oceans around the world, told us that attempting to sail those oceans to be a much braver affair than he cared to engage in. Here was a respect for the medium tightly curled around a passionate love of the underwater world that produced an odd tension.

Friends' reactions varied. 'I wouldn't spoil my children's education by taking them out of school!' (Obviously only one form of education is valid or 'proper'.)

'It's just a midlife crisis.' (Dismissiveness asserts the position of the speaker as 'more' knowledgeable.) How we could spend six years actually planning a crisis I found an interesting sub-question to contemplate.

'I would love to do what you are doing but ...' Here a long story would usually start. Whether couched as reasons, explanations, excuses or justifications, here was the parade of life's and society's limitations - imposed, accepted, sought even. These were the words that build our walls and mark our boundaries of safety and risk. 'Here be Dragons!' declare the old maps, in the places of emptiness from which drifts of strange scents, guessed forms, hinted colours are sensed. Oh, and I so wanted to go there!

'I'm scared of the water. I can't even imagine how you can contemplate this!' This response was far more common than I had expected. Such a very real fear of the sea is not an affectation nor is it the result of a frightening experience, though that can be the case: it simply seems to be within some people. Perhaps it is the potential of the environment, sensed as dangerous - the movement of the dinghy as you step into it signals a shift in understanding balance, something previously familiar and under control. The awareness of depth beneath the hull challenges the established relationship of foot and firm earth, similarly familiar and under control. Some courageously battled 
to put this fear aside and visit Oblion in the marina, or share in rowing to the mooring. It was a severe test, usually not repeated.

But we also were greeted from an unexpected direction by 'Oh yes, my brother and his wife have been cruising for three years!', followed by the most wonderful support along with advice, understanding and enthusiasm for our plans.

When Oblion was taken out of the water so we could work on painting her hull with anti-fouling in the Squadron's slipyard, I found that to work on a boat up on the hard, as it is called, makes one public property. Everyone stops to chat, to tell you what they did with their hull/propeller/topsides and what you ought to be doing with yours. I learnt to smile, answer and listen while still painting and scraping when interested members of the Squadron came by. Visitors were always generous in enthusiasm for our project and offered charts, advice, details of places 'not to be missed' and much encouragement but we heard again 'I would love to do what you're doing, but the wife gets really seasick'. We also heard 'When I've finished the boat, I'll be going too'. But yachts are never finished; Oblion certainly never was. It could be a trap, an acceptable reason to never make that final move.

My father went to Antarctica again, this time on an icebreaker. For one who gets incredibly sea-sick he had an extensive knowledge of treatments which he practised determinedly on his trips to the Antarctic - never let small issues get in the way of a goal - and offered a written explanatory list of remedies, prescribed and otherwise. He did warn us, however, of ten-metre waves and Force 9 gales in the Southern Ocean.

'It's okay Dad! We plan to turn left and head for the Pacific Ocean.'

And I didn't get seasick anyway, did I?

Finding words to describe our own experiences of the unknown we had chosen to sail toward was also hard. And who would possibly understand anyway? Moreover, did we want to know how scared the other family members were?

We had been sailing for two weeks, only to experience being encased for 24 hours in a Force 8 gale. Finding the sheltered calm of Apollo Bay on Victoria's southwestern coast had provided a solid night's sleep, moored securely to the town's strong jetty. The next day, we decided to continue on; a short day of sailing would put us close 
to Melbourne's Western Port, where the town of Hastings offered a large marina. No reason, then, to stay; it would be just a few hours straight-forward sailing. In a manner of speaking, that is.

The day began well but two hours after Oblion had left the shelter of Apollo Bay, the wind had gradually swung to the south-east and was now beginning to build waves angled against the tossing remnants of last night's storm-swell.

Should we turn back? Stuart posed the question.

'No, I don't want to go back. It's not that far.' I had my mental sights fixed squarely on Hastings.

Conditions deteriorated and by evening we were slogging against increasing, messy cross-seas and a contrary wind, ploughing directly across the busy Melbournebound shipping lanes that converge on the narrow entrance to Port Phillip Bay, accurately known as 'The Rip'. To turn and attempt the run through that dangerous narrow passageway was not an option with night close by; we were even hesitant to do it by day. So, sailing close to the wind, Oblion held course and crashed and punched her way towards the lighthouse on Cape Schanck, which marks the port-hand entrance to neighbouring Western Port bay.

In the darkness at ship's time of 2000 hours [the twenty-four hour clock is used at sea; 2000 hours is $8 \mathrm{pm}$ ] Cape Schanck light shone off the starboard side. Starboard? - it should be to port, otherwise we were sailing directly into the east-west lying coast! We were being set well off-course by wind, wave and tide, in toward the shore and an inhospitable lee shore at that. The lights of large cargo vessels ploughed past the stern. I felt myself beginning to panic: not again, not another awful night! I was no good at this - why had I ever wanted to come sailing?

'Ready about.' Stuart tacked, setting us south. Cape Schanck now lay to port and the tankers steamed, a mile away, across our bow. Still close-hauled, the motion on Oblion was dreadful; 'washing-machine sailing' we came to call it. I tried to shut out the jerk and slam of the motion.

'I'll keep going for a while, okay?' Stuart asked to continue on watch, to see Oblion clear of the Cape. He didn't say it, but it was better to be holding on to the wheel in the wind than being tossed around in the sealed air of below-decks. I, however, was grateful to hide away below - the recent frightening experience of the gale was 
unsorted, raw, a brush away from returning to engulf body, mind and soul. Now I lay, tensed to rigidity, resisting every lurch and roll. I couldn't escape even for a second from the crashing motion; there was no chance to clear my mind, take a deep breath, regain some semblance of control. I felt myself slowly shattering to little pieces, each screaming at me to be released. I can't handle another night like this, it isn't fair, the weather forecast hadn't indicated these conditions, oh when would we get there? - and why couldn't this wretched washing machine of a boat be STILL?

Cape Schanck remained just off the port bow. In the black night, with only the lighthouse's regular beam, it seemed to Stuart that we were fixed to one spot. Hours seemed to pass on the same tight, choppy, uncomfortable course. Stuart stayed at the wheel, I below: I couldn't face being on deck. I couldn't face being on the boat at all. Guilty, but unable to pull myself together enough even to offer to take the wheel, I didn't tell Stuart how I felt.

Needless to say, once safely moored in Western Port's marina, the week was one of lovely weather. Sunny days with gentle breezes were grand for drying washing, and Oblion's bilges. But my diary told the inside story: This week has been a week of tears and questions.

In a yacht at sea you are in immediate contact with the elements. The power of wind and ocean are beyond your command. I knew all that. You have to know and trust your boat: I knew that too. You have to accept total personal responsibility for decisions made and do the best with the situation you find yourself in. This is what I wanted my daughters to experience: it was what I wanted to face, this challenge. Yet now I was full of trepidation at the thought of going out to sea again, a sort of frozen knot in my stomach. What had happened? I had hoped that the personal development we would all go through, as individuals and as a family unit, by facing difficult situations together and having to accept this very immediate responsibility would benefit all of us. Now I was blubbering into my macaroni like a three year old. And getting a blistering headache as well. My diary wails: Why am I doing this? Why didn't we DRIVE around Australia?

Fine days at sea were no problem; it was the bad weather I feared. Would we meet more? Three times we had coped; would I find it easier next time or would it be 
the end of me? Could I face even the possibility of more? We could put Oblion up for sale and go back to Adelaide. It would be easy. My diary: Everyone says how wonderful the Whitsundays are and cruising in the tropics. Bad weather is NOT FUN. This sailing is supposed to be FUN.

Stuart had learnt in his outdoor education studies the theory of adventure activities. The fine line lies between being at the cutting edge of your skills, where the adrenalin runs but you still have some grasp of what is occurring and your place within it, and being that tiny bit past that point, where the situation and the activity overwhelm and it becomes misadventure. If that was close to where I was, what to do about it? I may have been nearly overwhelmed by situations beyond my capability, but, between us, Stuart and I had managed. I recalled the comments about Bass Strait and that after the Strait lay a new ocean, a change in coast direction, different weather patterns and many places of sheltered anchorage. It MUST get better than this, otherwise why does everyone do it? Whoever 'everyone' was.

I enjoyed shore life while I could, telling myself I would be fine.

Relying on advice that it is best to get through Bass Strait by the end of April, and following a week of trips to the museum and zoo in Melbourne, Oblion joined the early morning tide back down the channel. Stuart was below, tinkering with something in the engine and the girls were on their bunks. I held Oblion steady under full sail in a gentlemanly beam reach with the water chuckling sweetly under the bow. The channel swept us down and round to head westward along Phillip Island and out to sea. Around the bend now, and the wind was blowing in from the open sea. From coping confidently on a beam reach, Oblion faced into a steep chop with a head wind. As I pulled the sails in to close-hauled, I was talking out loud to myself again. Despite my constant (desperate?) internal reassurances to myself all week that everything would be fine, suddenly everything was not. I called to Stuart. He, too, was aware of the changed motion below and was trying to pack up his engine work.

'What's the matter?' he snapped from the cabin.

'Just tell me what to do!' The fragile confidence I had managed to build up in port was fast dissipating.

'What do you expect me to do?'

'This is awful. I can't cope! Can't we go the other way?' I cried. 
'Well, change course!'

'But we can't get out round the other end of Phillip Island, there's a bridge!' I was near to tears, shouting.

'Well, do you want to go back to Hastings?' Stuart stuck his head up the companionway.

'No I don't! I just want to stop this horrible slamming into waves!' I suddenly, decisively, swung the wheel right over and we gybed. With a bang and whoosh the main and mizzen booms crashed wildly across, snapping the sails furiously as Oblion found herself on the reciprocal course, pointing back the way she had just come.

'What are you doing?' Stuart too was shouting.

'I DON'T KNOW!' I howled. That was it. I stood holding the wheel and must surely have looked like a cartoon character with my mouth wide open and tears cannoning in little arcs from my eyes. Stuart flung himself back down the companionway in total frustration and Elizabeth, tearfully, shouted at us to stop. Alison hid in her bunk.

But strangely, it was a turning point. When I had finished crying, I had come to a decision. To hell with it all, THERE IS NO WAY I AM GOING TO LET THIS BEAT ME. I AM SAILING THIS BLASTED BOAT OUT THERE. I gently swung Oblion round once more and trimmed the sails for a westward course, close hauled, out of Western Port. Stuart popped his head up again.

'The chart says it is always uncomfortable in this patch of Western Port.'

'You could have told me.'

'You didn’t ask.' 


\section{Choosing the UnKnown: Paradoxical nomads}

\section{- Summary}

What is meant by the 'unknown' is the question that begins this Section. While the meanings of the word 'unknown' are discussed, I suggest that the unknown as destination is where the unexpected is allowed to unfold.

Articulating such a travel choice encounters two difficulties; firstly it is not easy to express, as the underlying motivations are conceptual rather than practical, and secondly, as an explanation, it makes people uncomfortable. The choice to travel is examined through reference to typologies of needs and motivations (Cohen 1973, Maslow 1962, Plog 1991). The response of feeling uncomfortable is examined in relation to cultural expectations and the limitations of language.

Discourses establish cultural expectations and norms, Foucault (1992) reminds us. Through the expression of ideas, discourses can establish what is acceptable to say and not say, and can establish the powerful dominance of certain ideas. Discourses of travel are no exception. The critical-creative research piece Telling Ways explores how words, including those from travel brochures, can take on different meanings depending on context.

Travel involving the unknown is also discussed in relation to alternative travel such as adventure and wilderness travel, and back-packer travel. These situate themselves as explorative spaces where the individual is freed from restriction and can find a 'new self' through enactment of retreat or pilgrimage (Baumann, 1996). It is suggested that these are inwardly-focussed relationships which are not so much predicated on an engagement with the unknown of the world as on an inner search that is divorced from the surrounding world.

However, MacCannell's (1992) nomadic traveller, introduced in 1.5, is one who wishes to engage with the places and people met along the way. This outward orientation is supported by Syed Islam's (1996) delineation of two different types of travel - sedentary and nomadic. The nomadic traveller, for Islam, undertakes travel that is to do with encounters with otherness that fracture a boundary. Both MacCannell's and Islam's reference to the nomadic are used to examine the experience of travel as interactive. I suggest that the nexus of traveller, space and difference - self, context and 
other - is a key to understanding the travel choice to experience something previously unknown.

The Narrative offers an exploration of these interactions of body, difference and environment in The Sailing Body - 'all' is it, there's no middle ground at sea!

\subsection{DESTINATION UNKNOWN}

The observation of travellers who had chosen to be travelling not because of what their destination was known to offer and contain, but instead because what it might offer and contain was not known, initiated a series of questions about how people travel in different ways. This 'unknown' as destination, chosen because what might be found, what it may be like, what may happen, is the both daunting and exciting equivalent of being the writer's blank page - what will write itself upon me? It can be described as unfixed or open-ended travel, a mode of travel that is not provided with a pre-planned framework (such as a set itinerary of places or times), nor the expectation for confirmation of prior knowledge, nor even a specified purpose, and for which the end is, well, open-ended. The decision to embark on travel for which the motivation for choice is an identified lack of knowledge and for which the attraction is quite specifically the unpredictable possibility of the experience, is not well-represented in tourism studies. ${ }^{5}$

Before examining travel that identifies the unknown as destination, it needs to be recognised that the term itself presents a problem as a somewhat awkward word to use in describing a destination choice. The Oxford Dictionary (2005) defines 'unknown' solely in terms of lacking something - not known, unfamiliar. The term 'unknown' here is not construed as 'differing from' or 'new', nor does it carry references to 'potential', where choosing the unknown as destination would seem to be situated. Some of this ambiguity may be because, as Jensen notes, 'known/unknown is not a pure dichotomy' (2005, p 151). What is known/unknown varies for each individual. Even in the choice to

\footnotetext{
${ }^{5}$ An initial search for 'unknown + destination' for this thesis produced a single response - Destination Unknown by Agatha Christie. For 'unknown + travel' returned tales of discovery such as How I crossed Africa: from the Atlantic to the Indian Ocean, through unknown countries: discovery of the great Zambesi affluents, etc, by Alexandre Alberto da Rocha de Serpa Pinto, 1881; Through unknown Tibet, by M.S. Wellby, 1898; Across unknown Australia, by Michael Terry, 1925; even, intriguingly, an Empire-reflexive Unknown London, by Walter George Bell, F.R.A.S., 'with seventeen illustrations', 1920, indicating that the choice to access the unknown is accepted within western tropes of 'discovery' in earlier travel writing.
} 
set out to sea, some knowledge of how a yacht sails, for example, is already present. (Though there was one family I met while sailing who had bought a yacht in Sydney and immediately set out to sail to Holland, without any prior nautical knowledge or experience, albeit with strong confidence in their learning abilities.) So, finding a description for choosing a destination because it is unknown presents a challenge: 'personally undiscovered' (I don't know what I'll find), 'guided ignorance' (it's because I don't know that I want to go)? Each becomes clumsier than the last. Further to this, Roget's Thesaurus (Dutch, 1969) associates 'unknown' with 'secret', giving overtones of withholding and privilege. It also links unknown to 'sealed', similarly suggesting barriers and withholding, but with more strongly associated connotations of power and privilege. Lastly, it links unknown with 'ignorance', with all the implicit shades of power imbalance between the one who 'knows' and the one who does not. In line with MacCannell's (1989) consideration that, no matter the style of travel, a basic component of the motivation to travel is the desire for a deeper involvement with society and culture, then I suggest that the 'unknown' destination can mean any place in the world urban, remote, populated - where the unexpected is allowed to unfold.

\subsection{ARTICULATING CHOICE - CULTURAL LIMITATIONS AND LIMINALITY}

When a decision to travel is announced to family and friends, there is usually a response. This will vary across the range of social familiarity with the concept of travel by both announcer and audience. There are a number of, possibly familiar, responses: the envious comment, the respectful, the congratulatory and the dismissive. But announcing that there is no destination or that the destination is the unknown is likely to be met with silence, or at least a pause. And, while the normal responses are then offered, there is a persistent undercurrent of discomfort. An implication seems to hover, unspoken: What, then, is the purpose? Why is all this effort (and expense) being expended? There are two issues that make talking about this kind of travel decision difficult - it is not easily expressed and it disturbs. The audience is bereft of an appropriate pigeon-hole of purpose and are left, metaphorically, holding an incomprehensible baby. How can 'allowing the unexpected to unfold' as the attraction of a travel choice be expressed simply? While having to justify choice against a range of responses was illustrated in the second Narrative, White and White, in their research with long-term around-Australia travellers, note that when this travel mode was 
announced 'the reported responses of others to the decision to undertake long-term travel were generally of three types: horror, bemusement, or envy' (2004, p. 206). They also noted that the comments of friends and family 'illustrated a deeply held anxiety about the isolation and potential dangers' of this form of travel (ibid).

Some of this reaction is also a response to the challenge that such a choice poses: by going, those who stay are questioned in their choice to remain. In staying, they are prioritising other ways of living and being, and holding on to a 'moral advantage' is one way to validate those choices to themselves. Lacking a language for potentialities, other cultural expectations become visible in the response, in an attempt to force the decision into recognisable relevance and place. If it doesn't fit, condemnation provides an easy alternative. Subtle accusations or implications of the irresponsibility, foolishness, foolhardiness, danger and monetary wastage inherent in such a (poor) choice are presented. (And interestingly, in the second Narrative, these were used in the attempt to articulate coping with the unexpected that occurred.) Lacking a category that provides a socially acceptable, socially understood, ready-made response provokes a defensive loading with moral implications of going outside the accepted.

Yet there are strong connotations in the Australian reading of 'going into the unknown' of bravery, daring and adventure, and of that (highly prized) larrikinism in the breaking of boundaries. Australia has a colonial heritage of men (only) being paid to go off to name and record what the continent 'had to offer', with such activity labelled as discovery and such men typified as heroic individuals (Ryan, 1996), if perhaps slightly mad. The resultant tension between being seen as daring and delightfully incorrigible (both acceptable) as against irresponsible, irresolute and indecisive (all unacceptable) can be resolved by the departing person providing a named destination or an identified purpose or indeed a plan of any sort. Disturbing randomness is then dismissible and 'risk assessment' can be comfortably assigned in its place.

White and White note that the potential for long periods of absence from a permanent home challenged social norms and expectations of stability (2004, p. 206). The articulation of this choice of travel therefore is problematic, as it is outside the parameters of 'regular' society. Expectations of permanence work to privilege emplacement and predictability over constant change, while the liminality of openended travel places this as movement with, for, and in, constant and unpredictable 
change. Liminality is defined as being that which lies between alternatives. The intertidal part of the beach, for example, is liminal - sometimes under water, at other times uncovered - and as such it is difficult to predict what can be found or done in this space at any one time because there is constant change. Bhabha (1994) refers to sites of cultural and social liminality as places of hybridity where new formations of identity develop. Sites of change, whether social or physical, defy prediction and therefore description. They can be exciting to engage with, addictive even, and Cohen identifies a feature of long-term travellers as their 'unwillingness to settle into a sedate, routine and urban way of life' (1973, p. 91). I consider that the choice of the unknown as destination is a choice to access diversity and change, such as is found in liminal zones, but that such liminality is identified by the traveller individually.

The origin of liminality is the Latin word limen, meaning threshold; the traveller's perception of being positioned between understandings, in the doorway to a different viewpoint, or poised where there is a possibility of seeing both ways at once, is an important clue to the choice of the unknown. How is this reflected in understanding the decision to travel?

\subsection{SITUATING CHOICE - MOTIVATION AND NEED AS INITIATORS OF TRAVEL}

In examining choice and motivation in travel, two analyses influential in tourism studies are Plog's psychographic tourists' personality typology and Maslow's structure of human needs. A number of studies have suggested further typologies, for example of tourists' interests and levels of risk-taking ${ }^{6}$. Plog proposed a typology of tourists in which personality types range along a continuum from 'allocentric' tourists, who display attributes of being curious, intelligent and willing to accept risk, to 'psychocentric' tourists, who display attributes of being hedonistic and self-absorbed, preferring places and experiences that are familiar, via a midcentric personality type (Weaver \& Oppermann, 2000). Here, travellers who are prepared to go to destinations about which they know little could be described as fitting into the allocentric category. Cohen developed a typology of tourists that included drifter, explorer, individual mass and organised mass; these were understood as a range of types without any linearity or hierarchy (Weaver \& Oppermann, 2000). The focus of Cohen's analysis, however, is in regard to the tourist's individual self-focussed needs. There is no consideration of the

${ }^{6}$ see Cohen 1972; Pearce 1982; Krippendorf 1989; Page 2003. 
traveller's interest and focus to engage with the external, which is important to the choice made to access something unknown. Here, the traveller's intention is to be deliberately open to the place and people of the destination, and the possible engagements that may ensue.

While Cohen further developed a typology of tourist experiences that range from the quest for mere pleasure to the search for meanings (Uriely, 2005, p. 204), this is still predicated in an exclusive inward focus on the development of the individual. It also establishes a 'range': by placing different experience typologies at either end of a line, they are situated as oppositional and excluded from any possibility of overlap. Finding meaning in life can be pleasurable - pleasure travel can be meaningful: Cohen's typologies need careful de-lineation.

The exposition of the range of human needs most applied in tourism studies, is that developed by Maslow, and which is structured as a hierarchical and predetermined order of importance. Maslow proposed a five-level pyramid, starting with physiological needs such as shelter, food and clothing at the base level and followed by: safety needs - a predictable, orderly world under control, with the familiar frequent and the unfamiliar rare; social needs - emotionally-based relationships such as friends and family; esteem, which is addressed at two levels - respect from others, such as status and attention, and self-esteem, for example competence and independence; and finally self-actualisation - creativity, spontaneity, problem solving and lack of prejudice (Page, 2003). Maslow later added a sixth level of need satisfaction, that of self-transcendence, which he described as to have one or more peak experiences with illuminations or insights that change the individual's view of the world and of their self (Ventegodt, Merrick \& Andersen, 2003). In this approach, Maslow believed that 'higher' needs only come into focus when the lower needs in the pyramid are met. However, it can be argued that fundamental human needs are non-hierarchical, and that relationships are integral to the provision of physiological needs, for example. ${ }^{7}$ In tourism studies, Maslow's hierarchy would place the tourist at the level of self-actualisation. The traveller, however, could be placed at any level, depending on the motivation and circumstances of the travel being undertaken.

\footnotetext{
${ }^{7}$ See, for example, economist and philosopher Manfred Max-Neef's (1991) discussion on poverty in Human scale development: conception, application and further reflections, The Apex Press, New York.
} 
The question of motivation in the choice to travel can be articulated on two levels, according to Weaver and Oppermann - the theoretical and the pragmatic (2002, p. 196). That is, the motivation to travel can be expressed as intrinsic reason or explicit purpose. The difficulty in verbalising a choice to travel simply for the unknown opportunities it may offer is related to the tension and gap between these two articulations because they are not necessarily separable. A defined purpose may not express the complexity of the aspiration which lies behind it; intrinsic reason may only be a potential, not a certainty in any way. Bruner notes the discrepancy between articulated expression and experience, 'for only the discourse makes the claim that the tourist self is transformed', how events are received by the person 'is different from the expectations derived from the discourse' (1991, p. 242). Arnould and Price note that, contrary to pre-trip articulated expectations of mastering skills, participants' experience of wilderness river-rafting produced emotional outcomes, and that their experiences were retrospectively described in terms of these outcomes rather than in terms of the stated expectations (1993, p. 37). Prior articulation of motivation and need is considerably different from post-experience assessment. The question is - was that prior articulation accurately expressing the intrinsic motivation and need, or was it an acceptable 'purpose' that was a safer description of intention?

\subsection{LIMITS IN LANGUAGE AND DISCOURSE}

The dominant western discourse of goals, plans and linear forward motion, framed in expectations and results, requires identifiable 'reasons' in a choice of action. Not having a specific destination in travel plans, situates one's actions and decisions outside this dominant discourse. Discourse, including language, defines experience and performance and naturalises social relations (Jaworski \& Pritchard, 2005, p. 2). As a result, the motivations and aspirations behind the choice of unfixed or open-ended travel direction are not easily or fluently expressed by the traveller ${ }^{8}$. Whether there is a lack in English of words that adequately identify or describe the motivations and needs that have informed the choice, or whether such expression is culturally constrained, is an interesting question that lies outside the scope of this thesis, but it is relevant to why this type of travel is not represented in tourism research. There are well-established tropes

\footnotetext{
${ }^{8}$ Refer Holland \& Huggan 1998, Pratt 1992, Clifford 1997, Khair et al 2006, Desforges 2000, Trinh T. Minh-Ha 1994, Jaworski \& Pritchard 2005 for example.
} 
(that is, accepted figurative textual representations) of this going into the unknown, however, in other applications of experimentation and exploration; take, for example, the well-established and easily recognised trope in the pervasive media representation of the scientist, randomly experimenting in the laboratory, as a someone who is mad, and similarly dismissive representations of the artist or musician 'wasting time', not 'working' for a living while they experiment with sound and colour. The automatic responses to these recognised tropes are equally well-established and dismissive. The potential in curiosity (again, 'curiosity killed the cat' has been reiterated to generations of exploratory children) is only slowly gaining validity and even more slowly gaining a language in which it can be discussed.

Research into innovation is itself restricted by the language of innovation (Dodgson, 2007). One of the paradoxes of innovation and seeking the potential in the unknown is the debated association of success and failure. Achieving a 'successful' outcome is not necessarily proportional to the amount of 'unsuccessful' time of the processes of innovation or creativity. Indeed, definitions of success and what is considered not a success are either problematical or limiting. Not only the unpredictable possibility of success, but also the changes that will be effected by the results of any success are equally challenging to predict, explain or justify effectively, even though they are integral to the process. Phillips writes of exploratory research that:

The vexed issue is that imagination [is] devoid of proof or obvious function, thereby, ostensibly, unconcerned with the betterment of human society. At best, these kinds of research posit notions of perceptual variation, at worst they offer red herrings that may question but never achieve any resolution. Simply put, no thing may be resolved, no precise conventional knowledge may be accumulated and documented - but the action of pursuit may have significance. (2008, accessed 18 August)

In regard to travel and tourism theory, while Holland and Huggan (referencing Said and, Clifford) hold that travel is now used as 'an epistemological category for resisting [both] normative values and homogenising essentialist views' (1998, p. ix), travel attitudes of curiosity and openness are still treated as mere 'strategies of innocence' (Pratt, 1992, p. 7) and 'delaying the transition into responsibilities associated with adulthood in western society' (Riley, in White \& White, 2004, p. 206). Language, notes Trinh, may not withstand the mobility of the journey for 'language is a site of 
home' (1994, p. 9). Discourses of developing new ideas and willingness for change are hard to come by.

Foucault (1992) suggests that discourses develop within particular times and places which determine what it is possible to speak, write, or otherwise communicate. His exploration of society's discussion of sexual matters in The Archaeology of Knowledge examined the change in what is sayable now, as opposed to a century ago, on the subject of sex. He argues that it is not a simple liberation of discussion but a legitimisation of certain aspects of knowledge that are established through institutional authorisation (1992). The validating power of discourses is such that:

[t]heir effect is to make it virtually impossible to think outside them. To think outside them is, by definition, to be mad, to be beyond comprehension and therefore reason. (Foucault, 1981, p. 48).

Stepping outside established discursive practices is difficult to achieve (Voase, 2007, p. 541) due to two factors: the limits imposed by what we know, that is, what knowledge is taught, distributed and sanctioned by knowledge-management institutions including schools and the media, and the limits imposed by a threatened social marginalisation. The structure of discourses, Tribe notes, has an 'including and excluding function, legitimising what counts as knowledge and what does not, so that the ideas and interests of some groups are given authority while those of others are not supported' (2006, p. 367). It would seem that western discourse on movement does not yet contain the ability to describe unpredictable travel that contains an openness to chance events.

\subsection{TRAVEL - HOME, DISCOVERY AND PRIVILEGE}

While discourse shapes travel and the travel experience (Jaworski \& Pritchard, 2005, p. 2), the discussions amongst the sailing travellers I met were most often articulated around the practicalities of the mode of travel while also containing reflective comments about places accessed and interactions with people that had occurred. Hall notes there is an essentially personal nature to adventurous travel that makes such travel experiences extremely difficult to define (2003, p. 375). Tropes of discovery and knowledge-gathering were not present in discussions with sailing travellers, a reflection of the different purpose behind this travelling, that is, there was not a newspaper article to be written, an investment report to be delivered or book to be published on a return to 'home'. Discourses that are predicated in a reporting-to-home 
highlight the situation that there is not necessarily an identified return to home in this travel: indeed, for many of these sailing people, home is where they are. While one particular society and geographic location may have been their point of departure, there was not necessarily any physical space held over there that could be taken to be 'home'. There was no guarantee or fixed expectation that that particular location would be returned to at some time in the future, nor a society or culture. It was a link and reference to the past but not to the future.

It is easier to express and discuss travel choices in the context of extremes, to map the 'exorbitant differences ignited by nothing less than the spectacular', notes Islam (1996, p. 157). That is, it is easier to rely on tropes of exoticism and adventure. Tourism discourse shapes our systems of signification of peoples and places; words are the interpreters of thought and experience but are never free from the subtle (and not so subtle) motives for expression. In the attempt to express the complex relationships within the travel experience, writers of travel literature shift their positions continuously between the pedagogic honorary insider's privilege, the clown/eccentric's lack of responsibility, the foreigner's convenient incomprehension, and touristic euphoria (Holland \& Huggan, 1998, p. 7). These positions are influenced by the mixture of narrative, interview, recollection, reporting and memory used in the writing. Indeed, it seems to be more common for travel writers who use their travels for a livelihood to use out-of-the-way places as a blank canvas to brandish their personal exploration of selfhood which have less to do with travel than suggested. Whether the shifting positions within travel writing are an unconscious positioning or a form of ironic awareness on the part of the writer is not always clear. But words manipulate both reader and writer of travel material into a relationship with the place of the destination and with the host culture. A critical-creative exploration of the influence of words can illustrate the complexity of this subtle effect.

\section{- Telling Ways •}

How is it that words are so personal? How is it that an essay can act like superman's x-ray eyes, according a view of the intimate layers we believe hidden from public view? This is not talking of the specifics of diary-ed words that obsess on the self. Rather it is the way the self - that is purportedly not present - is revealed in writing. How is it that these 
things - words - that are uttered, emailed, typed, printed, reported, shouted, flashed, scattered carelessly or laboured over, in their billions everyday around the world (and here I am limiting to English language words), that these billions of words, while telling the news or the story, also speak the person?

In the travel brochure on my table, the faceless, formless, nameless writer has put self on full view: 'With a nod to local custom, your trip to New Caledonia will be unforgettable.' A nod?

The nod - a minimised greeting. A passing gesture. Surface recognition dismissed instantly, employed when trajectories never destined to cross or engage are reluctantly brought into compulsory-acknowledgment proximity. Indicative of a primary focus elsewhere.

And the non-present writer establishes the visitor's privilege through a subtle display of this orientation, this minimal gesture. Don't go to any trouble, keep your personal priorities in mind. Glaze your sight over the presence of the other whose home you are appropriating, continue on your [merry] way. Oh, throw a nod, of course, to keep them from baying too loudly - after all, we are civilised, worldly travellers. You and I, writer and reader, co-producers of this brochure's effect ...

Words reflect thought, thought shapes word. Consider the contextualisation achieved through a single leading word: 'However, ...' 'Naturally ...' The reader is placed within the frame of the writer, a single word drawing an intimate irredeemable relationship. However 'Of course, you and I know otherwise ...' Naturally - 'You and I agree on the norm ...' A single word establishes a complicity, locks in a commonality which may not ever be present. How then to read otherwise, how to resist the enticement of inclusiveness?

And the brochure is blithely and culturally certain; 'Captain Cook discovered the island ...' This word of exploration and knowledgegathering established solely in a western knowledge system of consumption, of privileged position. It (whatever 'it' happens to be) is there, waiting to be found, waiting to come into existence, passively 
situated for the moment of coming-into-being which is totally reliant on being formulated into western discourse, given a place, a category, a position relative to other discovered 'it's. Tidied, cleaned up; filed into the bowels of the Royal Navy or the Royal Geographic Society basement. And then - bypassed? Forgotten? Left to remain fixed in its now-sameness of grouped referent - all life frozen, seasons stilled, waves immobilised against the [foreign] shore? The inhabited island of Kanaka met Cook on his arrival; Cook's ignorance was being overturned. A new word is required here for the English language does not provide us with an accurate rendition of the occurrence. 'Discovery'? Here were people, faces, language, knowledge outside Cook's previous awareness. From the collection of words, is there one to capture the de-ignorance-ing of Cook? Could we be bold enough to suggest 'education'? Teaching? Why not 'epiphany'? Surely Cook would not be the same from this encounter - new knowledge changes understanding, we are given to believe. Yet on receiving knowledge of the island, Cook appropriated it into a self-instigated trope of discovery, confident in the ignorance of the Indigene.

How much of the person is revealed in words: not a diary this time but the Ship's Log, that scientific recording of events and data, annotated by the captain, Master of the vessel. Reaching another island, appropriating it to the British crown and labelling it Australia, Cook's log announces:

We found ten small fires still burning but the people were gone ... as we saw no house, nor any remains of a house, we were inclined to believe these people had no clothes ... no dwelling, they spent their nights among the other commoners of nature. Mr Banks found his way obstructed by a swamp ... [later] the country in general appeared sandy and barren, and being destitute of water, it cannot be supposed to have any settled inhabitants. This point I find to lie directly under the Tropic of Capricorn; and for that reason I called it Cape Capricorn. (in Patrick, 1990)

On return to the Home of Britain, this Log then reports to an authority for articulation of its authenticity. What a set of words conjoin here: 
'authority' - to allocate the realness of your personal hand-written notes. What do they judge - the soundness of your mind at the time? The accuracy of your senses to see and hear? That what you have noted as experienced falls inside someone else's regard as possible?

'Articulation' - permission to reproduce these words you have meticulously scribed in disciplined confinement on a tossing vessel? The funding body's release of the textual product of its investment, rescribed to an acceptable tale, to what is desired to be read?

And 'authenticity' - that elusive declaration of veracity, without which the public will shun the words so carefully chronicled and laboured over.

But words shift and change of their own volition, chameleon-like they shade and blend to different neighbours, visualising in relationships:

Ocean - light ... ships, lighthouse, entrance ways;

Curtain - light ... interior, home, warmth, intimacy;

Stage - light ... excitement, attention, applause.

Bright images simply by setting in juxtaposition. Shifting in colour, intensity, mood, horizon - words ignite imagination's creative capacity. Limited and expanded through the reader's supply of imagery, experience - knowledge, perhaps.

Note that this is the essence of comedy, to establish the noun 'light' as a source of illumination, then '- beer', propelling the listener/reader into another dimension of image. For context pinches, shapes, shades words live in a state of always becoming. Let us agree with Droit (2005) and consider working with words an activity wholly vested in relations; words are the bearers of our thoughts, releasing them, accompanying them, diverting them from their course.

Comedy, spinning association and dissembling before our eyes/ears, is a twirler of meaning. Yet, strangely, to enable or establish the twirl, the spin, the dissembling, a fixed point is required - the reference without which association is reduced to meaninglessness, twirling becomes a 
mere blur. And here the referent is: the straight guy. (Please pardon the gendered nomenclature but even if otherwise embodied, the position is referred to in the masculine.) Who does the straight guy represent? The unimaginative? The repressed? The uneducated? The socially correct? The standard - but whose standard? The straight guy is predicated in stillness - or is that rigidity? The straight guy remains fixed to the same spot on-stage or on-set - physically, and metaphorically. Except when he is cued to stomp off in annoyance/anger/frustration, trailing an aggrieved suspicion of humiliation. The straight guy is the frame - and becomes framed. The straight guy behaves - and becomes ridiculous. The straight guy works in language which is returned to mock his earnest utterances. The straight guy is the pawn, the prop, established for discarding, a narrative technique of language delivery, a device. He is mainstream: our everyday acceptance, the familiar train, the same work, the address we have always had. He anchors meaning in the naturalised 'of course'. It is only from such surety that departing points can be set to stream out. Though they may split and diverge as they travel, it is the ever-widening, tautly stretched, increasingly tenuous intensity of the connection to that figurative surety that makes humour. Cue words are seated in the mainstream; positioned words are re-set. One word shifted makes us shout with laughter, but there is still the strong dichotomy -

know / ignorant;

inner / outside;

cool / straight.

The straight guy indeed. A reflection of our society's priority of straight-ahead linearity, the uni-directional, goal-orientated focus, regardless of influences, prioritised in order to proceed - where? Further along the line, it would seem. 
Comedy's power is in breaking taboos and silences, in putting our human and cultural inconsistencies in the spotlight and in challenging the myths we comfortably and easily accept. Myths of journeying pervade our literature of travel, too.

\subsection{KINDS OF UNKNOWN - WILDERNESS, ADVENTURE, BACKPACKER}

Mythologies of journeying to meet and know the self have an inward focus on the self and the home society; departure, return and impact remain the framework. The traditional imagining of the small-boat sailor pitting the self (predictably a him-self) against the implacable sea has almost mythological status. It is another myth of the western privileging of fight, domination and conquering. The active choice of travelling the unknown of the ocean as a place of possible change, opposes this discourse of conquering difference. Similarly, in Sallis' Hiam (1998), the main character drives off into the unknown of central Australia through a need to become invisible. In doing this she breaks a cultural taboo of her [immigrant] community, though she sees it as the only way to create a space in which she may find what else there is to be. Here, choosing the unknown is a framework for opening to new possibilities, fed and suggested by the outside.

Tropes are the figurative use of words, and their power lies in their ability to undermine determinate language texts (De Man, in Leith, 2001, p. 1509). The tourism industry appropriates adventure and going into the unknown in promotional material of wilderness and adventure travel through the use of tropes of discovery and conquering: 'unlock the hidden secrets' (Real life experience, Intrepid travel brochure 2009); 'places you've only dreamed of' (Epic Overland Journeys, Dragoman travel brochure, 2009); 'beyond the tourist facade ... into the heart' (Explore!, Adventure World brochure, 2009); 'ascend a peak only a handful of climbers have reached' (The Spirit of Adventure, Peregrine brochure, 2009). In adventure tourism marketing, a sense of pioneering and physical effort is established for tackling a challenge (Hall, 2003, p. 374). Where such phrases undermine concepts of discovery is that this advertised travel is in fact situated within an organised context that includes preparation and information sessions, established routes and other strategies that work toward an identified [safe] outcome. It can still be put into a calendar as 'going from here to here with this group, in this identified area, and you'll see me again in ten days'. Arnould and Price describe this as the commercial offer of a magic developed over the interval of time in a 
seemingly authentic environment (1993, p. 25). Just outside this type of purchasable group activity are private group travel expeditions, for example to climb Mount Everest or access the North Pole, and organised sporting competitions, such as the singlehander's round-the-world yachting race. It is currently not at all clear where these fit in terms of travel, or indeed tourism, as their increasing profile begins to attract a tourism component of spectator involvement, media coverage and schedules. Certainly, Mount Everest is currently the site of a number of buy-a-place climbing opportunities run for commercial profit and answering to a touristic demand for adventure experiences ('Talk to people who have previously climbed with our teams; you get what you pay for and more ... a top quality product for a very reasonable price ... people have always been surprised by how much we deliver.' (Mt Everest 2010 Expedition, Chessel Adventures, accessed 10 September 2009).

\subsection{1 - UNKNOWN - FREE OF RESTRICTION}

The desert, the forest, the mountain - places designated 'wilderness' - have become metaphors of a transitional zone in development of individual understanding or of the source of understanding. In many cultures, the physical journey to dwell in a remote, usually identified as 'natural', environment, such as the forest or desert, is the journey of the hermit or the shaman, who retreat to engage in an exercise in selfconstruction (Baumann, 1996, p. 20). What makes the hermit feel close to God, Baumann contends, is really the feeling of being himself god-like through becoming 'unbound by habit and convention' when an act of isolation freed them from the restrictions of their usual society (ibid). Within current tourism practices there are travellers who happily exhibit changed behaviours through being away from their usual social position, and with a seemingly god-like disregard for the impacts this can cause. These can range from the tour-bus drinking spree to illicit sex tourism. While these cannot be described as retreats, nevertheless this mode of travel throws off restraints for the purpose of self-satisfaction based in indifference to others, both fellow travellers and host populations.

\subsubsection{UNKNOWN AS PILGRIMAGE TO NEW SELF}

Other travellers journey to access change in order to then emerge as a new or different person, as the pilgrim undertakes a pilgrimage. For these travellers, there is a 
'truth' available that will provide the solution to their life's needs but it is always elsewhere, always some distance or time away - wherever they currently are is not where they ought to be. This sense of constant discontent is inwardly-focused, predicated in a search for a (often difficult to name) particular and which is not orientated to an exteriority of alternative possibilities.

Backpacker travel, for example, carries connotations of open-ended journeying that works outside the mainstream tourism industry in alternative venues, locations and transportation, and many backpackers cite alternative travel as the pathway to new selfidentities (Davidson, 2005, p. 50). However, Davidson found that backpacker travellers in India, while their focus on encounter and interaction was often consciously reflective, were still working within an ideology of India as offering an immersion in the exotic and chaotic (ibid). From the immersion, their new selves could emerge, they believed (Davidson, 2005). 'India' was not observed for itself but was accessed as a tool for a process of self-development or possible self-change. India is then reduced to a standard formula of Oriental mysticism, writes Huggan, 'a source of ineffable wisdom, as collective embodiment of an unchanging Hindu mind ... and society and culture are collapsed into a search for inner meaning' (2001, p. 194).

\subsubsection{NARRATIVISATION OF A NEW SELF}

Borrie and Roggenbuck suggest the touristic wilderness experience is constructed specifically as both an exploration of the physical environment and an exploration of the self, leading to a form of self-construction. The 'story', that is the reflection on experience that narrativises the travel into the self, "continues off-site, carrying the experience through time' (2001, p. 203). This suggests that both backpacker and wilderness experiences are emergent, that is, they develop from a sequence of transactions between the individual and the environment and are created in part as personal stories with temporal and spatial qualities (Borrie \& Roggenbuck, 2001, p. 202). The participants in the wilderness tour experiences that Borrie and Roggenbuck studied, continued creating meanings of their experience through an embedding of their emergent stories in the context of their daily lives (2001, p. 203). Similarly, Arnould and Price report that the narrative qualities of the river rafting experience become more pronounced with time and retelling (1998, p. 37). These wilderness adventure travellers were participating in established, guided tours into relatively isolated areas within 
national parks. The backpackers studied by Davidson (2005) were on longer-term travel but participating in an established circuit of destination, accommodation and expectations of social interaction with similar travellers. Both groups of travellers articulate a search for change that they hope their travel will offer - one before the experience, one afterward.

For Clifford, travel can be seen as 'a range of practices for situating the self in a space ... a form both of exploration and discipline' of the self (1997, p. 77). This suggests travel as an opportunity for the possibility of self-construction through changing the inhabited space. The choice of travel without a defined destination involves the space in which the travel experience will occur as it is implicitly situated within the choice, its physicality is embodied in the process of the anticipated travel. For example, to go to sea means having to deal with an unpredictable physical environment, and this is part of the 'unknown' within that choice. Travel consists of acts of movement, transposing the body into spaces whose physical factors are an integral part of the travel experience. The body comes along too, with all its needs and sensory-collecting mechanisms working twenty-four hours a day (and how often are those tales of the toilets, the beds - the beetles - the smells - told?). The physical relationship is inter-subjective in that it originates from awareness of things and people outside the self, and its embodied awareness comes from the physical presentation of difference. In this way, in the choice of travel without a defined destination, the traveller is already prepared to be open to what may present in the situation. The experience is not predicated in a framework of self-development or ultimate solutions but in a receptivity. It is outwardly orientated - it turns to the exteriority of experience. This supports the assertion that choosing the unknown as destination, as suggested in 2.1, can mean any place in the world - urban, remote, populated - because 'unknown' is closely related to the individual's personal level of experience, knowledge and courage. What is the excitingly unknown to one person will be well-known to another, nevertheless both may face their individually unknown destinations with equal anticipation and enthusiasm.

\subsection{NOMADIC TRAVELLERS}

What can be assessed about these travellers who choose to access the 'unknown'? Very little, it appears, due to several factors: this travel sits outside 
destination studies as the destination is not definite; it lies outside tourism discourse of needs, as these are not articulated; it is not easily expressed in established theoretical paradigms in tourism research; and it sits outside the dominant discourse of the touristic gaze. This traveller in not a flaneur, that is, one who does not want to engage with the context but merely to observe and thereby declines responsibility, nor are they a conqueror, seeking to impose meaning. But some conceptualisations, such as that of the post-tourist (Feifer, 1985), have set an intriguing trail of reference.

Feifer's post-tourist is described as less reliant on tourist businesses, less concerned with tourist markers and will rather take up different perspectives or seek out different things with a 'view tending more towards art than order' (Feifer, in Garlick, 2002b, p. 302). The post-tourist's awareness of their condition of outsider, of being a temporary stranger in another's culture (Crick, 1991), allows for a play of meanings within their experience, and in the possible subsequent narration of that experience. MacCannell's suggested postmodern traveller, the neo-nomad, is an imaginative traveller who embraces difference (1992, p. 4). The neo-nomad, MacCannell believes, has a freedom to be creative and interactive through understanding travel as offering chance meetings and dialogues (ibid).

This term 'nomad' is used to describe travellers whose attitude differs from that of the typified group tourist and whose interest lies more in accessing impressions than artefacts (MacCannell, 1992). It contains some interesting resonances: the concept of the nomad has appeared in late twentieth-century philosophy as offering a way of thinking about the world that is more apt than modernist practices (Deleuze \& Guattari, 1987). For Deleuze and Guattari, a nomadic style of thinking is one that synthesises a multiplicity, and that retains the potential for future, different, syntheses through refusing to fix meanings and understandings (1987, p. 23). Braidotti is less discreet: the nomadic state is 'the subversion of set conventions', she writes $(1994$, p. 5). Using the nomad as a figuration for the individual's relation to the world, she suggests that this relation engages in a manner that is neither reproduction nor imitation but rather intensive interconnectedness (1994, p. 5). In an analysis that closes with MacCannell's neo-nomad traveller, Braidotti holds that this nomadic being in the world consists in not taking any kind of identity as permanent and retaining an 'acute awareness of the nonfixity of boundaries' (1994, p. 33 \& 36). Such nomadic strategies 'continually elude their containment' and force transformation (Symons, 2004). 
Thus, when MacCannell applies the term to describe travellers, he is proposing an enjoyment of dis-placed understanding, one that synthesises but does not fix or reduce, as an important contributing behaviour in travel. MacCannell (1992) contends that ways of being out-of-place, that release creativity, are embodied in neo-nomad travellers; these travellers do not essentialise what they meet along the way. If, as Braidotti (1994) suggests, the nomad engages in the subversion of set conventions, then I suggest these travellers are subverting the set conventions of western hegemony in their travel practice. These travellers step outside convention in a non-destructive manner. 'Nomadic shifts designate therefore a creative sort of becoming; a metaphor that allows for otherwise unlikely encounters and unsuspected sources of interaction of experience’ Braidotti concludes (1994, p. 6).

Syed Islam, realising himself to be an out-of-place traveller while lecturing in England, began reading travel narratives to re-place himself within the dominant discourse of his current world. A growing sense of unease while reading western travel books drew Islam to a realisation that some of these travel writers, "with their narcissism and racial paranoia spread across the pages ... had not travelled at all' despite physical global journeying [emphasis in original] (1996, p. vii,). While their bodies had moved, their minds had remained securely seated in/at home. He identifies two distinct travel orientations, which he names 'sedentary' and 'nomadic'. Sedentary travel 'settles for a representational practice that scarcely registers an encounter with the other', it is 'driven by a desire to secure a vantage point from which to carry out a representation of difference ... to establish essential difference' (1996, p. viii). Here, Islam comments wryly on the paradox of such travellers never managing to travel anywhere 'despite traversing continents' (1996, p. 3).

Nomadic travel, on the other hand, is to do with 'encounters with otherness that fracture both a boundary and an apparatus of representation: it is a performative enactment of becoming-other' Islam notes (1996, p. vii). This nomadic travel 'impels one to come face-to-face with the other, without the paranoia of othering that represents the other in relation to oneself' (ibid). Such travel offers a non-essentialist (and a nonsedentary) vision of living. The nomadic traveller allows for an interaction and a learning that marks a way of being in the world, of understanding the self as an individual and relating to the world in which she/he is currently situated, where stasis 
and movement - dwelling and travelling - contribute, reference and meld one to another, neither is privileged over the other.

Certainly this nomadic travel is consistent with MacCannell's neo-nomad. Neonomads leave home not knowing where they will end up, 'never knowing whether their eventual end will connect meaningfully to their origins' (MacCannell, 1992, p. 4). Their most meaningful encounters are with those they meet along the way, MacCannell suggests, for the dominant feature of these travellers is that they travel 'accumulating nothing, collecting nothing but perishables - impressions and stories' (ibid). In this way, they do not travel 'as an invader conquering territory' but as passers-by (MacCannell, 1992 , p. 4); the relation to the other is not an intention to explain and thus reduce through the process of 'other-ing'. Othering does not produce the other, Islam writes; it only produces an othered-other, a creation of something comforting or comfortable by the subject, from within the subject's already-held knowledge, through the production of a reflection, a representational point (1996, p. 80). It is by wrenching the other from their position and turning them into an object of prediction that this othering is accomplished (ibid). Dragging the other into the known realm of the subject is a bordercrossing of duress. For MacCannell's neo-nomad, however, borders are seen as permeable demarcations of understanding rather than limiters, such that crossing boundaries is important to meet the other face to face. The other can be met but never possessed (MacCannell, 2000). Since other-ness, MacCannell says, is precisely that which can never be possessed, the neo-nomad is freed from the grip of desire to possess and is instead animated by a desire to create (ibid, p. 169). This, then, is an imaginative traveller who enjoys a displacement of self-understanding, that is, one who embraces the moments when self is contested or disturbed by difference as moments of creativity.

\subsection{NOMADIC EXPERIENCE}

The neo-nomad or open-ended traveller will have an expectation of their travel and what may occur. However, it includes a willingness for whatever will turn up which differs from an expectation of self-development or self-serving focus on gain of some sort. It is an openness to the outside. It means that everything is an experience. This traveller will not be heard saying 'I am travelling to Colorado and then I will have an experience'. The entirety is the experience, very likely including feelings of panic, determination and doubt present at departure. 
This travel experience differs, for example, from that of a person travelling for business, rest, visiting relatives or other established destination purpose, because the traveller who has chosen the openness of the unknown will expect the experience to be unpredictable. There is acknowledgment in tourism theory that travel experiences are 'highly personal', that they are 'subjectively perceived, intangible, ever fleeting and continuously on-going' (O’Dell, 2005, p. 15). However, as stated previously, research into the nature of experience has tended to focus on concepts of self-development and self-change, concentrating on travel as an inward-looking activity rather than the experience as a potential for the unexpected. Wearing, Stevenson and Young suggest that these narrow conceptualisations are significant factors in limiting the ability of tourism theory to address the complexity of the experience (in press 2009). While there is increasing acknowledgment that the tourist's subjective negotiation of meanings is a determinant of experience (Uriely, 2005), there is a vacillation of understanding between intellectual and intuitive readings of experience (Fenner, 2008). Raymond Williams reminds us that 'experience is a coded word in western and modern culture ... experiences arise from activities and the physical environment, as well as the social meanings embedded in the activities' (1976, p. 126). Johnson expands this definition, holding that experience is more than passively received sense impressions, rather it is a 'complex interaction [of] perceptual, emotional, bodily, historical, social and linguistically-dimensioned elements' that work to make up our understanding of the world (1987, p. xvi). Experience, then, can be defined as an inseparable combination of the physical and conceptual, that is, the sensory input received through the body that is subsequently reflected upon and thoughtfully considered. O'Dell considers that:

Experiences are not always phenomena that we enter by crossing a welldefined threshold. Instead, many experiences seem to take the form of processes that we find ourselves in or realise that we have been in. (2005, p. 132)

As MacCannell has pointed out, the neo-nomad is already aware of the permeability of boundaries and thresholds. However the nature of being open to the outside means that acceptance of change is taken to be the condition of the travel experience.

Here the discussion moves beyond MacCannell's definition of nomadic travel to explore the importance of the other in this experience: not the exotic other offered as an object for consumption - the use-and-discard of tourism promotion of otherness - but 
the other who through their autonomous radical alterity, their fundamental and independent difference, challenges the traveller's knowing of the world and who, in the face-to-face encounter, demands a response from the self.

According to O'Dell, great experiences are very personal phenomena (2005, p. 130); the importance of the other, through the response required in the face-to-face encounter, is enacted at an individual, personal level. By being open to the responsibility which inhabits this encounter, the self of the traveller must accept the unknown of difference. They must also see themselves within that encounter, for the dynamics of the experience may be seen as deriving from 'the way in which the ordinary and extraordinary continuously telescope into one another' (O'Dell, 2005, p. 133). In this manner, the interaction of the traveller, the other and the space in which they meet brings multiple factors into play - the embodied nature of travel, the cultural knowledge (and baggage) of the traveller, the relationship with difference and the perception of possibilities - which offer a moment of changing awareness.

Examining just what that moment means, how it might work, and what the implications of 'multiple possibilities' are, will contribute to understanding the choice of the unknown. But first, the embodiment of experiencing the unknown benefits from the narrative perspective. 


\section{NARRATIVE 3:}

\section{- The SAILING BODY - ‘ALL’ IS IT, THERE’S NO MIDDLE GROUND AT SEA！ •}

The physical environment of the ocean, the hazards of an adjacent coastline and the sheer constancy of motion and change are immersive elements of the sailing experience. You can't get away from them, any of them.

Months into the trip, I note in my diary: This environment is alive. It is not a living thing itself, a yacht, but being immersed in a living environment gives it life too, and personality through its responsiveness to different elements. The water beneath our feet, the air around us, the still bush-clad mountains just over there - all are living things, vibrant. Feel it coming through your skin when you lay your hand against the hull. It imbues us with life too, we are wrapped, woven, into the continuity of a great breathing, energetic constancy of being.

The thing is, there is always movement. At anchor of course but even in a marina berth, for one step onto a yacht and it moves, being buoyant. The boat stirs to changes of tide, the passage of other boats, changes in the wind. This is multiple lives away from concrete paving, glass buildings, muzac, recycled air, plastic trees and silk flowers. Therein lie profound identity differences.

The adaptions we each had made to become part of this environment brought awareness of how change can provide growth, of abilities and confidence. The battles of body - and indeed of mind - figure in the process of becoming something different.

At the start of any trip, the weeks of preparation, the months of planning, the years of dreaming all combine at the single point of departure. Additional tension in this sailing trip lay in not really knowing what would be encountered, nor each personal reaction of four disparate individuals crowded together in physically bounded space Stuart, myself, Elizabeth at ten years old and Alison at eight years old. The sea at the beach edge is not the same as the sea offshore. Wind is lifted and buffered by city buildings and lifestyle; out on the water there is no mediation, just wind on skin, in the face, our invisible unnegotiable driving force. Our reactions to constant movement, constant external physical interference, were unknown. Our first experience of the open ocean would be interesting. 
A long swell, generated somewhere in the southern Indian Ocean, rolls uninterrupted eastward for thousands of miles around the southern coast of Australia and on into the Pacific Ocean. As we set a course south-eastward from Kangaroo Island with our sights on sailing to Melbourne, Oblion gracefully rode the swell, rising to a 'king of the castle' position then fell gently until the next swell rose under her. These long, rounded waves were about 300 metres apart and with a moderate wind from the south-west, it was exhilarating. The light slowly faded from the sky and the wind gradually shifted to southerly and picked up a little. Now blowing across the swell, the wind generated waves which ran, naturally, at ninety degrees to the swell. The motion on Oblion changed from a slow rise and fall to a rise, fall and roll. My snook dinner decided to return to the sea. I had not taken anything for seasickness - I didn't get sick, did I? Oh well, with dinner gone I felt much better. My watch ended and Stuart took over. We could sit along the cockpit seats, legs stretched out and back resting against the cabin, very comfortably. A glance below at the GPS would show speed and position on the softly green-lit screen. With thermals and jackets we were warm enough and Stuart had set the rule that safety harness was always worn and clipped on during night watches. The autopilot gave freedom of movement to plot the position, make a cup of tea, or go to the toilet, so that one person could manage on watch. Every fifteen minutes the horizon was to be slowly scanned all around for lights or noises. Any questions or problems and the off-duty person was to be woken immediately.

The wind increased, the waves increased and Oblion began to roll, pitch, slew and crash on her way. We were about thirty miles off the flat, sandy coastline and no harbour was available before the small town of Robe, some ninety miles away. There was no thought of turning back.

My watch again. It came and went, along with the remaining contents of my stomach. I was being sick every hour. Daylight came. The girls didn't want to get up, but lay cocooned in their dunas, secured in their respective bunks by lee-cloths. Stuart carried on the day's routine as Oblion lurched and crashed against a wind which was now almost dead ahead. There was no point in altering course because there was nowhere the cross direction of wave and swell would give a comfortable motion. My handwriting doesn't appear on the chart for that day, in fact no position was plotted from 2200 hours the night before (my writing) to 1400 hours the following afternoon (Stuart's writing). Neither of us could sit at the navigation desk for long enough to plot. 
I took my watches, heaved over the side every half-hour and looked after the children who had become seasick, even lying down. The chocolate Easter eggs swung and bounced nauseatingly in front of their eyes. The front hatch leaked - everything stowed forward was getting wet, including the end of Alison's bunk. The salami swung relentlessly above the galley and my guts were just as relentless. If they weren't trying to empty up, they were insisting on emptying down. I couldn't possibly use the head [toilet] in the bathroom, so made do with perching on a bucket on the afterdeck, clutching the railings as we rolled and pitched through the disagreeable seas and the bucket skidded to left and right under me. It then had to be emptied and rinsed overboard. Wonderful. Stuart seemed to be in better shape, though he was not much interested in food. In the cabin, things had fallen onto the floor and the vegetables were swinging wildly. During my next watch off, the onion bag broke. I lay in the quarter berth watching the bruised onions roll up and down the cabin sole, adding their pungency to the scramble of books, pencils, charts and shoes sliding up and back with every roll of the boat. No way could I have attempted to clear them up. They stayed. So did the nauseating oniony smell.

Stuart handed over watch again. It was now dark. Stuart's entries on the chart stop at $1720 \mathrm{hrs}$ and resume at $2330 \mathrm{hrs}$. I know I sat my watch out, still being ill and unable to plot the position. Fortunately the GPS showed us to be twenty-five miles off the coast and clear of any charted hazards. I remember being aware that I was not capable of keeping a good lookout and simply had to leave it to chance. I huddled down on the seat next to the companionway and hung on ... my thoughts are becoming macabre, so I repeat a little litany to myself: 'Everything is fine. We are going well. Everything is fine. Stuart is going well. Everything is fine ...' I drift into a dream: I live on a farm high on a hill above the sea ... all the farmyard was dirt, solid, hard earth ... no grass at all ... It felt so very reassuring. I can still bring the image to mind.

At midnight we made a decision and altered course for Robe. Stuart tried to recall what he knew of the harbour from visits by land. The chart showed Black Pig Rocks and Snewin Rock while further scattered reefs and shoals lay off the capes at both ends of the bay. It was now after 0200, dark, and these hazards were not lit. We dropped the sails when the depth indicated we were getting close in and motored carefully towards the vague outline of the shore. Lights appeared, sprinkling the town end of the bay and we plugged in our brand new spotlight. I trailed the cord onto the 
cabin roof and some beacons were caught in the wavering finger of light - the narrow entrance channel. Suddenly we were in, finding ourselves amongst the crayfishing fleet, all very dark and silent inside the little harbour. Another yacht lay alongside the entrance wharf, so we turned to come in behind it.

'Throw a loop over that bollard,' called Stuart from the wheel. The surge through the entrance and the rip of the outgoing tide kept pushing Oblion away from the wall. I had about as much strength as a strand of over-cooked spaghetti. It took numerous tries to throw the line around that damn bollard and I had to fend Oblion off in between attempts as she was sucked along by the tide. Somehow we managed. Then, leaving the onions where they were along with everything else, Stuart and I crawled into bed. It was 0300 hours. We had left Kangaroo Island not quite two days ago ...

A few hours later I was awake: the pattern of watches still working? The girls saw me stir and in a flash were over in my bed for cuddles. They, having been prone for the last thirty-six hours, were feeling fine. Alison told of how she had watched her dressing-gown swinging on its hook and wished she were it instead of herself. Elizabeth had wished she were dead.

'Elizabeth was sick all over my arm, Mum,' said Alison importantly. 'She missed the bucket.'

'A big wave came through the front hatch,' Elizabeth added, 'before you closed it properly. All my books are wet. And Mum, can you put the Easter eggs away? I don't want chocolate any more.' We started to giggle. I described the swinging salami and my dream of the farm which produced more giggles, then left them reading while I pottered vaguely around, tidying. The sun was shining so I opened the front hatch and began pulling things out to dry. Alison's mattress, the sails in their bags, the books and toolboxes. There was a cheerful call from the wharf, now some two metres above deck as the tide was fully out. 'How're you going?'

'John! What are you doing here? Come aboard.' We had met John and his young wife while crewing together for a friend.

'I'm on Expeditus,' John explained, nodding to the silent yacht behind which we had berthed. 'I'm helping deliver her to Sydney with three other guys.'

'When did you get in?' 
'Oh, about four o'clock yesterday. Had an awful time; everyone was sick except me. They kicked me off when I wanted to play my guitar this morning,' he said cheerily. 'Then I recognised Oblion. They're still all asleep.'

'Want a cup of coffee?' I was still a bit light-headed from seasickness but it was great to hear that others had found the conditions unpleasant. If I went carefully enough I reckoned I could manage to light the stove.

'Love one,' said John.

Living on the ocean means relying on certain facets of that environment, for example the drive from the wind and the buoyancy of your vessel in water. When these are threatened, or become threatening, it becomes an immersive situation enveloping all the body and the senses.

It was midnight; we had entered Bass Strait late afternoon and now the stars were obscured by hurrying cloud and wind roared out of the vast darkness. Stuart had reported all was well before turning in at the end of his watch an hour ago. Now the wind was cold and steep waves were beginning to lift our stern high before hissing past in the dark. Oblion was racing along through a night that was getting blustery and darker by the minute.

I called down the companionway, reluctant to wake Stuart but anxious about Oblion's increasing speed. In the dim light of the navigation desk, he struggled out of a warm quarter berth into jacket and boots. The girls slept on, unconcerned: Stuart clambered out to put on his harness.

'We'll reduce the main sail,' he said, looking around. 'Better to be underpowered at night. The genoa seems okay.' The genoa foresail could just be discerned in the darkness, tautly full of wind and pulling strongly. 'Jeez, it's cold out here!'

He clipped on and began moving forward while I went below to switch on the mast-mounted deck lights, providing a bright white pool of light that intensified the darkness. I waited, back at the wheel, to put Oblion head-to-wind. Stuart, clipped to the mast by his harness, would drop the main halyard a little, haul in and secure the reefing line to fold in a bottom section of the mainsail while there was no wind pressure against 
the sail and then re-set the shortened sail. Oblion would then 'bear off', coming back on course as the sails re-filled.

\section{‘Okay,' Stuart called}

Bringing the bow into the wind in the dark was frightening; the lurch and roll as the boat turned, the moment when Oblion lay dangerously broadside to the swell before the bow lifted to the next wave and the wind dropped out of the sails, the frightening racket of madly flogging sails, the loss of forward motion, the wind blasting into face and ears. Stuart had difficulty keeping his footing and jammed himself against the mast. I grabbed the mainsheet to cleat it off tightly: a madly swinging boom would not help. Stuart eased the halyard then secured the reefing line while the heavy corner of the genoa beat wildly about in the darkness next to his head. Oblion wallowed as she lost speed. It would only be minutes before she would be caught by the wind, and blown around.

'Bear away!' Clutching the shrouds with one hand and the winch handle in the other, Stuart scrambled back along the deck. I turned Oblion to settle downwind at her usual steady pace once more as the genoa and the shortened mainsail filled. The autopilot was reset, the decklights switched off. The short illusion of banished night disappeared.

Two more sail changes had been required in the following hour and the gale continued to build in strength. And here I was, with Oblion yet again rushing down the invisible waves and increasing her acceleration with each one.

'Stuart ...' I was scared. How much more was to come? This was beyond my experience and I was starting to talk out loud, a sign, I knew, of rapidly diminishing confidence. I could only see the top of his head in the faint green light from the GPS. The rest was well buried. Now, for the fourth time, he pulled on his boots and gear and clambered into the cockpit. In the last half hour we had changed to the smaller yankee sail on the forestay and, after reefing the main a second time to handkerchief size, had taken it down altogether. Its lumpy bulk, lashed down, shaped the main boom strangely. Now Stuart stood looking into the darkness. 'Let me steer for a while.' I handed over gratefully and huddled down on the seat. I was feeling decidedly underskilled for the situation. 
'We've taken everything off the main. We've reduced the foresail once. We'll take the yankee off altogether and move onto the inner forestay. That means the staysail.' He was thinking out aloud. 'There's still the tiny storm jib and trysail after that. What do you reckon the wind speed is?'

'I don't know. At least it's on the stern quarter. We aren't having to cope with cross seas like off Robe, or a huge amount of heel. But these seas are getting really big, Stuart, and the wind must be gale-force.' I hoped my tension didn't show too much in my voice; I knew my hands were tightly clasped.

'Grab the staysail.'

I climbed down into the cabin, grasping the wooden handholds to steady myself as I squeezed past the girls' bunks to the forepeak. I searched for the staysail in the lurching near-dark - it was the new-looking one, for what help that was. I was feeling sick by the time I carried the sail up the companionway. There was no thought of passing it out through the front hatch. I clipped on and took the wheel from Stuart. The staysail is rigged on the inner forestay so there was no need this time to point up; the relative simplicity of setting the staysail was welcome. Once more Oblion settled down to a controllable pace, easier on the helm. Stuart looked at me. 'You'll be okay? I've got an hour of sleep yet.' It was 0200 , only two hours since my watch started.

'I think so,' though really I had no idea.

Stuart went below but paused to plot quickly before turning in. There were no hazards out here, thank goodness. I had enough to cope with. In the rushing darkness, Oblion's stern would be picked up by a wave, sending her surfing down its front before it rolled past and she was left wallowing in the trough for an instant before the stern rose again. It was important to keep Oblion square to the wave and prevent the bow turning even slightly, because the stern, lifted and pushed faster than the bow, could swing around bringing her sideways on. The next wave might then broach the boat, breaking over her to swamp everything or even roll her over sideways. In the darkness, I could only steer by feel, hoping to maintain a straight course down each invisible precipice.

Only a few hours later and Stuart was finishing his watch: it was pitch dark and I could sense the driven sea's wildness along with the wind's enormous power still out there. It was my turn again after anxiety-tinged, fitful sleep. Dawn was approaching though and gradually the light grew to reveal a horizon only a hundred metres away, a 
seething world filled with tiers of white-streaked waveheads, top on top, to which the small speck of yacht was utterly immaterial. Looking behind was frightening. Coping with the seas by feel alone in the darkness had been better, in some ways, than seeing this. I gripped the wheel, feeling panicky.

'What do I do, Stuart?' He had remained on deck.

\section{'I don't know.'}

'What do you mean, you don't know? You've sailed lots before!'

'Not in a ten-metre boat in a gale!'

I was frightened and consequently angry: we were both tense. Oblion was lifted up and her bow tilted down another white-striped green mountain.

'But what do I do?' I cried, my stomach knotting into a ball at what was relentlessly bearing down on Oblion astern, at what walled us in on both sides and at what we were hurtling down right now.

'Keep her straight. Go with the feel, don't look behind.' A bit late for that! I was scared of these monsters, the complacent, careless power that surged on past Oblion, totally unheeding and utterly menacing. The ocean is not so much unkind or vengeful as awesomely vast and quite oblivious to small things like ships. It has been around a long time and has responded for millions of years to huge masses of pressured air, far distant wind interactions and deep currents. What was one little yacht to this preoccupied giant, chivvied today into an irritable mood by the passage of a cold frontal system? Really, I didn't want to look - behind or front.

Bass Strait was living up to its worst reputation. We stuck the day out together: the girls didn't want to get up and I didn't want to go below. I found a position wedged between the two sheet winches with my back against the windward railings and hung on grimly. We blew past Cape Otway and on toward Apollo Bay. The sea was crashing over Henty Reef, a mile offshore: we gave it a wide berth. Apollo Bay's harbour entrance opens northward, requiring a long passage around the protective Point Bunbury before reaching the relief of calm water.

Friendly locals, surprised that anyone at all had been out there, advised us where to tie up at the long wharf. 'Use plenty of slack. There's a big tide today.' I did my usual struggle with the warps until Oblion was secured. 
Then, prioritising Stuart's need for sleep in well-earned peace, I took the girls for a walk. I felt I was sleep-walking myself. Having been sick only once was quite an improvement but neither Stuart nor I had slept much in twenty-four hours, nor had we managed anything to eat. The wharf seemed to rise and fall under my feet and I wondered, through a mist of tiredness and relief, if this was how sailors get their distinctive rolling gait ...

Months later, our bodies had adjusted. Mentally we had learnt to be cautious and preferred to be prepared well - after all, we had been caught in conditions unpredicted and inescapable a couple of times.

In Sydney, as we prepared to depart from the main pontoon, having stayed a week in the high-class 'accommodation' that was the Cruising Yacht Club's friendly moorings, and busy with lashing the dinghy on deck, stowing everything away and checking that the front hatch was sealed, a young man stopped to watch.

He leaned on the safety lines and smiled. 'From Adelaide? I am too; teaching sailing here now. You'll find it different from now on, you know. They sail here with the front hatch open and bikes on the foredeck. They even tow the dinghy behind.' We gaped in total disbelief, and he grinned. 'You'll see.'

And indeed, we adjusted, adapted, learned the new waters off the east coast of Australia. Today the dinghy bobbed obediently along in our wake. The kettle squealed delightedly as it swung on the stove, which hissed quietly in company. The girls were sharing one earpiece each of Elizabeth's walkman and singing to the tape of Starlight Express, kindly copied for them by a recently acquired sailing friend. 'And I've been u.n.c.o.u.p...' came by on the breeze from the bow '...l.e.d!' as the kettle's wail descended to silence. No-one had been sea-sick for months, I thought, as I carried up two mugs of tea. The automatic brace against movement meant I didn't spill a drop. Life on a lean had become second nature.

Time, as a resource, was different too. It is indicative of yachting life that to stop and then sit for that important half an hour after anchoring, to make sure you are stopped, is no imposition. To a city person - half an hour? Impossible! Unacceptable! Half a minute would be too much. 
I found that selecting the best place, assessing the wind, tide, current, other boats' proximity and swinging circle, then manoeuvring to the right position to drop, reversing to snub properly, paying-out enough chain relative to depth beneath the keel, all added up to a fairly tense time. And when the anchor has gone down, it needs half an hour or so to settle, or at least for the crew to be sure it is holding properly. Settling to wait, selecting a relative-position mark to check to (for instance a headland or prominent beach mark) and then just being still to absorb the feel of the whole place, the water movement, air movement, the relative movement of any other vessels - this was relaxing. And being assured that all was well could mean the difference between a good and a broken night's sleep, for even asleep, any changes in the sound of the water on the hull or the wind in the rigging will be noticed: any change in the actual feel of the movement of the boat will bring a sailor awake instantly.

This time Oblion had settled securely in Queensland's beautiful Pearl Bay and the night had been full of peace. Now, Elizabeth and Alison begged for shore-leave after a morning of lessons. A sailing friend familiar with the bay had assured us that a hole dug in the sand would fill with fresh water, enough to bathe in and as this represented luxury to us, it was an irresistible enticement. The girls had quickly and easily established a friendship, in the manner of sailing kids, with Georgia, from another yacht anchored in the bay with Oblion. Georgia's yacht was on a different scale from Oblion, in size and in conveniences, but her parents Bob and Rachael were keen to come exploring to find these famous soaks of Pearl Bay.

Small birds sang in the swamp trees, the sea whispered placidly on the sand where the three girls gathered shells and splashed in the crystal, sunlit waves, all accompanied by the soft hiss of the reed beds above. My diary notes: I wish I had a video camera to record the quiet shwoosh of the waves, the voices of the girls and to pan along the beach, out to all the islands and islets, across to the high headland and the yachts beneath, snug at anchor.

The steep hills of the Peninsula Range edged the beach of Pearl Bay at its southern end and stretched along northwards until a raised depression, two metres above beach height and containing swampy ground, interrupted their line. The beach was banded by tumbled rock barriers some distance apart. Just past the first one, the first seepage from the swamp trickled its brown water over the sand and we dug enthusiastically but with mediocre results. 
Further on, depressions in the above-tide sands glistened provocatively. A few scoops were rewarded by a quick flow of water and, yes, it was fresh on my tongue. The girls dug, we all dug: five baths of cool, clean water appeared in the sand. The girls and I lavished fresh water on hair and bodies, while Bob and Rachel were content to laugh at our antics. Oh well, Oblion didn't extend such luxuries as a shower, let alone a bath. This bathroom had solar-powered drier and magnificent furnishings, a view to die for and no troublesome smells from dampness and clogged pipes that persistently robbed Bob and Rachel's enjoyment of their on-board two showers and running hot water. When you have neither shower nor bath on board and have become accustomed to what are known as 'pommy washes' (a bowl of hot water, soap and wash-cloth) or seawater rinses, a good wallow in a fresh-water, out-door bath with the sun on your back and the breeze in your hair is, simply, fantastic. Bob and Rachel, really, didn't know what they were missing. Or had I got that mixed up somewhere?

But battling the mind is the hardest of all ...

Under a burden of stars held up by the deepest black of the high coast range, Oblion thumped quietly north along the Queensland coast toward Cairns. The surreptitious lightening of the pre-dawn sky brought a breeze to fill the slack genoa with gentleness. The uncatchable moment when the horizon springs from invisibility into silvery existence and the gradual colouring of 'a thousand dyes' staining far up into the arc of sky to herald the sun's rising - this is given to us, awake or asleep, seen or unseen, every day. Once more it was my privilege to sit humbly beneath the miracle. My handwriting on the chart reads 0425 plotted just past Fitzroy Island where the lighthouse still blinked its white wink to our stern.

The breeze strengthened with the light to a brisk and bumpy passage. The engine was stilled and I stood on the cockpit seat to see the unfolding panorama. It was spectacular. Individual peaks of the Great Dividing Range, here named the Bellender Kerr Range, rose mistily above a smoke-drift that gauzed the foothills. At their feet, Cairns' hotel towers were fine-spun mirages in the dawn-gilded haze which reached out and out across Trinity Inlet. The breeze driving Oblion was no part of that world. She danced past golden tentacles towards a small granite knob on the far side of Trinity Inlet that marked a marina. 
I could not share any of this morning with Stuart, however, for he was not aboard. Following a visit to the doctor the day before, he was on a bus to Cairns instead and should meet us at this marina. His behaviour had gradually been changing over recent weeks to something very different from his leadership at the start of the voyage. Only a week before, when a group of the sailing folk anchored at Magnetic Island had gathered for the usual discussion of passages and experiences, Stuart had struck a discordant note amongst the conversation and laughter. His whole being had been jittery, his conversation disconnected from that around him and not quite making sense. And it had continued as Oblion sailed gently northward, past tropical islands of dense, rich greenery and through tranquil seas of aquamarine and royal blue. He fixated on next year's uncertainties at one stage.

'But Stuart, we have months yet of this year and we haven't even decided what we want to do,' I objected, trying to grasp where his thoughts were going, or coming from.

My words didn't seem to penetrate. Certainly the scenery had meant nothing to him, though when the breeze strengthened, he had shifted focus to sailing and relaxed into a temporary enjoyment of sorts.

His disorientation on Dunk Island, however, had precipitated a decision to seek medical advice. This meant sailing to the nearest town on the mainland, Innisfail, a day's sail away. The next morning was idyllic for sailing - gentle breeze, sparkling water, brilliant sunshine and waves a matter of centimetres high - which ensured relaxed passage with mizzen, main, genoa all hoisted and set, and engine on as well; not a weather worry in sight.

Yet Stuart was unable to be on deck. Something in his mind encased him in fear.

He cowered below in the lowest bunk, battling fright while I sat against the sidelines steering with one foot and stitching a delicate satin wedding dress for Alison's doll. That uncooperative autopilot is hardly a concern on a day like this, still, I must remember to have it looked at soon... Oblion left a ruler-straight wake on the blue water astern. Another yacht's sail danced some way ahead and I sailed on through a tropical dream of islands and sunshine. Stuart refused an offer to steer (so he had control), food (so he had fuel), reassurances (I was being annoying) and slept, or appeared to. 
The young doctor in Innisfail had announced 'Anxiety attacks: probably a postviral complication causing depression and focussing on the boat as it is your major responsibility at the moment. You need to get off the boat and no sailing for at least two weeks.' There was no mooring available in Innisfail so now I brought Oblion in to the marina where Stuart was expected to meet us. Here was the desired residence that would provide a refuge, Stuart's chance to heal. Here, after obtaining a land-side berth, we greeted Stuart. Here, Oblion was enmeshed in a net of mooring lines, fore and aft springers, breast ropes, bowlines, stem lines and land lines. Poor yacht - she was a fly in a web, going nowhere. Stuart lashed the focus of his anxiety into a mesh of immobility and would have nailed the waves to the wall if he could. The doubt that all this was going to help Stuart raised itself silently in my mind. 


\section{EnCountering Difference: The OfFER IN THE MOMEnT}

\section{- Summary •}

There are moments in travel where a shift in awareness occurs (Suvantola, 2002) and a new understanding or perception results. This theory Section looks at what constitutes these moments. Suvantola suggests that there are meeting points in travel $-\mathrm{a}$ convergence of understanding, things known yet unknown, and context - where the relationships between these elements is challenged. I suggest that travel offers the possibility of such moments of sudden insight if the traveller is responsive in the encounter with the difference of the other.

Before this concept of the other is more fully explored, however, there is a body of research into moments of awareness and change that offers understanding of their importance. This is found in the study of creativity. Examining theories of creativity, we gain a conception of how new ideas, that is, insightful perceptions and connections, are developed in the juxtaposition of existing knowledge, new elements and an openness to the possible combinations available (Csikszentmihalyi, 1990).

This is followed into an investigation of the relationship of space and embodied awareness in the travel experience. The self-aware de-centrality of the visitor means that they inhabit a space differently, they are aware of context and connections they may not normally be able to access. Further, it opens the discussion to the role of the other, of difference and the unknown, in this moment of encounter.

Here Levinas' (1969) philosophy of the face-to-face encounter with the other provides a conceptual framework for understanding the responsive relation to difference that Levinas describes as the ethical relation. The face-to-face encounter with the other demands that the self open to the other in response, through the recognition of radical difference.

This moment of encounter in travel has the unpredictable potential of pleasure or dread, things that may confirm and things that may challenge. The traveller is situated for a change of the self. Appreciation of this ambiguity is part of the postmodern traveller's ironic reading of experiences. This ironic awareness of the liminality of the traveller's position - in place but not of it, aware but not 'literate' of the space - is an opening for altered points of awareness and reference. In Losing the Horizon, the 
situational shift of day to night is explored as a critical-creative representation of those moments of shifting recognition, of becoming different ourselves.

This Section concludes that travelling is an activity that provides the opportunity to question the traveller's place in the world and perhaps to reveal possibilities of existence which were previously concealed (Garlick, 2002b). If so, then it is an activity that enables the individual negotiation of identity and subjectivity through a nonreductive relation with the other. This reflexive awareness of change is demonstrated in the fourth Narrative, The Exotic Liminal - those others, being other, becoming other.

\subsection{THE MOMENT}

Every traveller carries their cultural accruements - knowledge, attitudes, expectations, dreams, ways of making meaning in the world, and the meanings of all things they are familiar with from their life and lifestyle - when they travel. We are each the individual product of a stream of experiences, education and beliefs whose influences are as much part of our travel baggage as the suitcase or backpack. These are - willingly or not - brought along into the new place, the new encounter, the unrehearsed situation, of travel. The travel experience is always conditioned by that baggage which the traveller can never leave at home (Garlick, 2002b, p. 297). ${ }^{9}$ Tourists have always been criticised, writes MacCannell, for 'neatly packing Tokyo' into the terms of their own cultural baggage, and for carrying it back, reduced to an affirmation of their own identity, theory or philosophy (2000, p. 175). This comes about because in the new situation encountered, some elements will be known to the visitor; some things can be 'read' that carry a previously-ascribed meaning. This could be a sensation, a sound, an activity, people, artefacts, a building style; these are identified theoretically as 'the object' found in the place by 'the subject', the personal self of the visiting traveller. The object, then, seems to be understood. The subject 'knows' about this.

But the context in which the seemingly familiar object is now encountered is new. In the unexpected view supplied by being within a new context, the traveller is

\footnotetext{
${ }^{9}$ It would be interesting to investigate the relationship of amounts of physical baggage to the nature of the travel encounter. Consider, for example, the physical barrier that baggage can provide as a form of defensiveness, aspects of the enclosure of self-maintenance and self-sustainability, the implicit assumption in the carrying of lots of baggage that the traveller's needs will not be met by the host, and where these situate the traveller's responsiveness.
} 
simultaneously able and unable to read the object. 'Things are there as objects we contemplate but whose meanings in their local context we cannot grasp' (Suvantola, 2002, p. 44). The known meaning does not fit, after all. Something, unknown, is changing or affecting current understanding and interpretation by the visitor. In this context the object has a meaning, an intention and an interpretation that eludes the outsider. The visitor is thus faced with the non-fit of a meaning from one context placed onto a shared object because of its current situation in a new context. We create meaning from our own background (Suvantola, 2002, p. 44) but what happens at this moment of tension, of non-fit?

Here is a moment when subject, shared object, meaning both known and unknown and new context are brought together. This particular combination has never occurred before. For the individual subject, this is a moment where the relationship of each element to the other is challenged. There is a choice - dismiss and ignore, or open up in order to further understand. If the moment is dismissed, it is 'reduced' by only being broken into elements that fit known categories and understanding. This is the reduction to which MacCannell refers, the 'packing into their own cultural baggage' of experience. If the choice is made to reach for a newer interpretation, however, then there is a receptivity to hitherto unconsidered relationships, a thoughtful acceptance and handling or turning over and around, a juxtaposing of elements in an interactive play of potential meanings.

And a shift in awareness becomes available. A point of departure, an opening, occurs (Gablik, 1996) that has not occurred before. This is a moment when new ideas form, or present themselves, it seems. This is a moment of creativity. It is Levinas' faceto-face encounter with the other when the recognition of radical difference, of radical alterity, (Levinas' term for the complete separateness of this other) demands that the self open to the other in response (1969). It is the moment full with promise, uncertainty, potential, from which there is no turning away once embraced and from which will come the new - new ideas, new meanings.

Critically, this moment cannot be anticipated in that it is composed of a random connection of elements, at least in part. It can only occur, so to speak, 'in the moment', in that particular moment of time. To describe it as partially random, although an apparent tautology, is valid because there are some elements that can be actively put together - the traveller has accessed a new place and is receptive to what may be found 
there to start with. Tribe describes such a travel moment as offering 'the possibility to abandon regular cultural baggage and explore new places, self and others' (2008, p. 930). (MacCannell would be content that Tokyo is left intact and a changed tourist returns home instead.) While this moment can produce a range of reactions, from excitement to revelation, pleasure and a heightened awareness, it can also produce a sense of alienation or disorientation. This can be the paradox of aloneness in a busy place, the sense of outsider facing an impenetrability of localised meanings, a selfconsciousness or the disjuncture of tourism brochure hyperbole and the reality of place (Tribe, 2008). De Botton felt a sense of panic when he realised 'I had inadvertently brought myself with me' (2002, p. 20); his thoughts are still located in the anxieties of home and as yet there had been no shift in focus to the present moment and the place at hand. What he had imagined as the tourist experience was not occurring and instead he found himself 'wondering, with mounting anxiety, what I was to do here, what I was to think' (ibid, p. 108).

This moment of encounter in travel, then, teeters precariously for an instant, with pleasure on one side and dread on the other. What is occurring in this moment of encounter with difference is a decentring of the subject in relation to object and context, which acts as a displacement of the self from the central position of certainty. It also contains the destabilising occurrence of an unpredictable conjunction of elements that has not occurred previously, and a disturbance to the domain of the familiar for the self. In this, the creation of new ideas, that is, insightful perceptions and connections can occur that opens to new conceptualisations. Decentring, disturbance, conjunction and conceptualisation: these are co-elements in the one moment and intimately interrelated. They are also elements that appear in discussion of the processes within creativity.

Creativity entails the ability to formulate ideas (Mandler, 1995) through problem-solving and innovation, using imagination (Garoian \& Mathews, 1996) and derives from the verb 'to create' - to bring into existence, make or cause, or originate (Oxford Dictionary, 2005). The traveller's point of recognition of difference, that occurs in the moment of awareness under discussion, can lead to 'possibilities for extending the self' (Wearing \& Wearing, 1996, p. 240), originating new ideas and meanings for the self. The traveller's moment of realisation prompts, then, a similar process to that defined and examined in studies of creativity. Theory of the creative process, therefore, is relevant to understanding the traveller's moment of encounter. 


\subsection{CREATIVITY - MOMENT, SPACE AND PRESENCE}

Creativity theory has been a relatively recent development within psychology and social science studies. Study of creativity has variously approached the creative act, the creative person, the products, the creative process, experiencing creativity, the creative environment and being creative. Defining creativity, therefore, becomes difficult: Koestler in 1964 defined it as the unconscious combination of ideas drawn from different domains (in Bindeman, 1998); Chartrand, in 1990, as that which occurs when an individual steps beyond traditional ways of doing, knowing and making (in Richards \& Wilson, 1990); the Oxford Dictionary says 'showing imagination as routine skill, inventive'. Studies certainly indicate that several stages can be indentified within creativity; initiation, consideration, inspiration and production. Research into the initiating stage - the creative process of seeking for new ideas or the point of recognition of difference - presents similarities to the traveller seeking the unknown.

\subsection{1 - CREATIVE PROCESS}

While creativity is given some definition, the creative process is far more complex to describe. Csikszentmihalyi (1990) holds that the creative process is when new questions are asked or problems are viewed from a new angle. Csikszentmihalyi developed the theory of 'problem-finding' as an essential part of creativity, that is, the process of recognising a dissonance or misfit that intrigues enough to promote examination. I would rather frame this as questioning, for implicit in 'problem' is 'solution' which further implies 'product'. Tying creativity to product limits analysis of the creative process, when often the creative response will result in play and experimentation without a specific outcome anticipated. The expectation of solution or product is predicated in ideologies of universal answers, consistent with the science paradigm of psychology within which Csikszentmihalyi's work has been developed. However, his work did break away from understanding creativity as problem-solving, that is, finding answers to existing or pre-identified problems, and instead raised awareness of the seeking or observational, questing aspect of the creative process which ventures alternative ways of viewing or thinking about the object (in its broadest sense) encountered. Mace summarises this process as perceiving the possibilities inherent in, and deriving from, a given situation and building relations between otherwise diverse concepts (1997, p. 271). 
Across the research of creativity and the creative process, however, there is a consistent identification that the process of creativity is an emplaced interaction of individual and immediate environment ${ }^{10}$. It is both situational and responsive. Interaction is realised between the subject (self), the place, the time, the object (materials, people, concepts) and knowledge. This interaction involves firstly recognising, secondly engaging with, and thirdly allowing a response to, experiences which contain an undefined tension or dissonance, or perhaps a surprising and unsuspected resonance - a difference not met before. Recognition of the particularity of the experience requires interactive openness. Such recognition of difference does not provoke fear but rather an admittance of lack: openness is maintained. Importantly, the attitude of openness is one in which access to a multiplicity of possible elements for creating new understanding is retained; rather than applying a known definition or categorisation which shuts down unassociated elements, openness allows for the play between like and unlike elements. Openness makes engaging with the situation or experience, with the difference encountered, possible.

The subject cognitively, affectively, and physically interacts with materials, concepts, and other people in a discourse between the individual and resources (Gruber, 1989, p. 17). Engaging involves accepting the new elements of the encountered situation, experience or concept, and placing them into a juxtaposition with previously known elements, whereby quite unsuspected relationships may be revealed. Put another way, engaging requires an undisciplined putting together of certain combinations of elements from which process a sudden burst of enlightenment may occur to offer a new understanding of the experience (Bindeman, 1998, p. 71). Tobin observes that a vital aspect of engagement is trust - trusting the process (2004, p. 95). The range of elements available to the subject for consideration within the engagement is also critical to outcomes. While this may seem self-evident, creativity research has identified that not every subject accesses the same number or range of elements. These can include previous experiences, general knowledge, objects, sensory input, people, conversation, sounds, textures - it is impossible to list all that is present at the time. But what is available to the individual, to 'play around with' in a sense, influences the possibility of developing a new understanding; the information, input, knowledge and understandings

\footnotetext{
${ }^{10}$ See Collier 1972, Getzels \& Csikszentmihalyi 1976, Martindale 1989, Bayles \& Orland 1993, Brown, Collins \& Duguid 1989,Mace 1997 for example.
} 
available to the subject as resources serve in making connections between what may otherwise be disparate objects or concepts and involves bringing them together in an innovative way (Mace, 1997, p. 271).

\subsection{2 - CREATIVE RESPONSE}

Confronted with a dissonance or perplexing occurrence, the subject may work very intensively with it but arrive at no 'solution' or revelation of sudden understanding. The work of mixing the individual's personal resources with 'new information from the boundaries of the unknown', which has been presented within the new experience, situation or concept, is the response to the moment (Getzels \& Csikszentmihalyi, 1988, p. 114). Through maintaining a level of interaction between idea and object, there is a continual discovery in the situation, Mace writes; one idea triggers another as the subject feels the way, 'knowing quite clearly what it isn't, yet still unable to see what it is' (1997, p. 277). This is a crucial point in the creative process for it is here that connections are made between like and unlike things, 'meanings from one enrich the meanings of another' and 'unlike things become inseparable' (Bayles and Orland, 1993, p. 111). For artists, Bayles and Orland continue, such shifts are a central mechanism of creativity (ibid). Something emerges from the process that has not been thought before - for an artist this may be the shape of a visual piece, for a scientist it may be the orientation of a molecule - but the final result, Eisner notes, often possesses features that are something of a surprise to the individual subject (1983, p. 25). And here is the so-called 'aha!' experience that catapults Archimedes from his bath.

It is clear from the research discussed above that this creative process is understood as an individual experience. Creativity is, in its very essence, a singular experience. While the process has been theorised, such that contributing elements are identified, predictability remains problematic. The complexity of interactive factors and features of the creative generation of ideas is central to understanding creativity. Similarly to travel and tourism studies, the breaking down of the experience into smaller and smaller facets, which are then studied separately, misses the interlocking multiplicitousness that is the essence of the both the creative process and the individual experience.

One powerful aspect of the creative process which is rarely mentioned in research is the sheer joy, the intense wonder, delight, enchantment even, that 
accompanies the moment of revelation and inspiration. The writers interviewed by Tobin describe the 'enjoyment in moving into the unknown' and the joy in the 'play of mind in finding new combinations' $(2004$, p. 95). The generation of new concepts produces an energy that is exciting and that the artist finds intrinsic to living, in fact could not live without (L Philip-Harbutt 2009, pers. comm.).

This is only indirectly referenced in research coming out of psychology, where a number of claims are made about the 'creative personality'. Research suggests that the creative individual seeks to satisfy curiosity (Getzels \& Csikszentmihalyi 1988, Lubart \& Sternberg 1995, Martindale 1989, Orians 1986) or has an appreciation of, and excitement for, exploration and experimentation (Garoian \& Mathews 1996, Mace 1997, Tobin 2004), but these skirt the statement of pure joyousness consistently identified by artists (J Louey, E Ankor, L Philip-Harbutt 2009, pers. comm.). Lubart and Sternberg (1995) list tolerance of ambiguity; willingness to go beyond one's past knowledge and previously successful uses of resources and to make new ones; willingness to take risks; perseverance; and courage. Tobin's interviews with creative writers identified the importance of the accidental to the creative process; these writers described learning to make use of surprise and to value the unknown. They further identified the importance of receptivity and an alertness to what is going on, describing it as a 'listening attitude' with a 'willingness to hear whatever is said' (ibid). Gablik concurs with this, considering that it is important to cultivate a 'listening self' that is consciously aware of the interdependence of self and difference (1991, p. 10). The creative individual is open to new experiences, Lubart and Sternberg (1995) observe; attitudes toward the unknown in the situation, then, influence the possibility of new thinking.

Both the creative process discussed above and the characteristics of the creative individual correlate closely with MacCannell's neo-nomad traveller who embraces the moments when the self is disturbed by difference as moments of creativity. These travellers accept that they cannot be sure where they may end up, or whether the end will connect meaningfully with the start, but that the encounter contributes towards the creation of meanings and understandings (MacCannell, 1992). Moreover, as noted previously, MacCannell says these encounters are made of dialogue with those met along the way, in a manner of collecting impressions and stories (1992, p. 4), which 
equate to the rich resource base that Mace has identified as an important element in the development of new ideas and creative thinking.

The choice of open-ended travel relates to the characteristics listed earlier, of tolerance of ambiguity, willingness to take risks, perseverance and courage, that are suggested as characteristics of a creative approach to experience.

\subsection{3 - SitUATING CREATIVITY}

Creativity and travel each have a strong relationship to space; both can be seen as accessing a 'social space which allows for learning and growing', which Wearing and Wearing propose as a new way to consider and understand the tourist space (1996, p. 229). Richards and Wilson, examining creativity in tourism practice, cite an example where understanding the relationship between being in a place and allowing space for contemplative interactions has influenced physical layout in the Frankfurt Museum of Applied Art:

[The museum's] policy is now to create space for informal learning and for interaction with others. Instead of ... 'flitting' from one exhibit to another, a profusion of chairs provides the opportunity for more measured contemplation ... and 'affective moments with others'. As such the Frankfurt experiment is as much about sitting on chairs as it is about display. (2006, p. 1218)

The creative process brings diverse elements together in the same spatial location in a way that results in a merging or a fusing of those elements from which new ways of seeing something can emerge, Mace writes (1997, p. 271). The conjunction of subject, place and question signifies the creative space; it is where the material and the symbolic intersect (Richards \& Wilson, 2006, p. 1218). This intersection requires, however, a subject who is receptive to what is being brought into consciousness, brought to mind, brought to attention. For Bayles and Orland, this contact must always 'remain unguarded' in order to experience the 'conceptual jumps that markedly affect the way we engage with the world around us' (1993, p. 68). There is risk in this process; to experience the world through different sensibilities created in the moment of aperçu calls the viewer's own belief system into question, Bayles and Orland note (1993, p. 66). Questioning beliefs can be unsettling, temporarily destabilising and promote a sense of vulnerability for the subject which may be perceived as too uncomfortable or 
even threatening to be able to consider, for it can result in a change of ideas that will impose considerable readjustments across a range of the subject's current practices. The possibility must always remain open that new perceptions will yield unforseen results (Bindeman, 1998, p. 74); this in turn necessitates corrections and revisions in the conceptual constitution of the object or experience as it was previously imagined, and affects the subject likewise.

The response to recognising and engaging with experiences must remain an open response, in order for the creative process of considering like and unlike elements and accepting the ideas generated as a result. 'In making new ideas', say artists Bayles and Orland, 'you court the unknown. This grants access to worlds you may otherwise never fully engage' (1993, p. 68).

\section{3 - SPACE IN THE MOMENT}

Entering into spaces that contain the possibility of the encounter constitute the traveller as actively involved in constructing their own experience and their subjectivity; the self-aware de-centrality of the visitor means that they inhabit a space differently, they are aware of context and connections they may not normally be able to access. Moments of encounter, of course, occur in the physical spaces where the traveller is situated. While accessing a particular place or space can never guarantee such moments or meetings, the space itself is involved in the creative moment, as noted above. Explorations of the relationship of spaces to the social structure and meaning that they also contain indicate that the material form is not an adequate description of place, it also needs to incorporate the meanings that people invest in a place before it can be understood properly (Gieryn, 2000). It is because of this entwining of the physical and ephemeral in the relationship to space/place, that spaces which contain the possibility of the encounter (where the moment of shared object, established meaning and new context may occur together) allow a tourist experience that extends beyond the time and place boundaries of the visit (Wearing \& Wearing, 1996).

And it is as an individual that we experience spaces. Geographer D W Meinig describes asking each member of a small visitors' group at a lookout to talk about the space before them, what it is composed of and something of the 'meaning' of what can be seen. It will soon be apparent, he notes, that 'though we gather together and look in the same direction at the same instant, we will not - we cannot - see the same thing' for 
any space is composed "not only of what lies before our eyes but what lies within our heads' (1979, p. 33). Meinig goes on to describe different viewpoints used in observations of space, such as scientific and geographic interpretations, but also notes that there is a view that accepts everything as being of interest and that in 'transcending the banal tourist search for the exotic every place offers interest' $(1979$, p. 45). This viewpoint, that every space offers something, also requires a decentring of the self and an openness that allows a shift of awareness in response to a moment of encounter. A New York company, Social Fiction, deliberately builds on the 'transcendence' that decentring can offer. Social Fiction generates walks which are undertaken by following a set of mathematically randomised directions - take second turn left, then third turn right, etc - with the intention of taking not only visitors but also residents into their own space 'while removing the restraints of goals and habit', and thereby 'opening space for surprise and discovery of hidden significance' (Pinder, 2005, p. 397).

Users of Social Fiction's walks report a pleasant state of displacement where small details and moments acquire new meaning (Pinder, 2005); indeed Social Fiction describe their walks as designed to 'actively create situations for serendipity to occur: ideas, marvellous views, strange situations, inventions and invitations' (ibid, p. 397). The walker/visitor becomes a creative, interacting user of place. Wearing and Wearing note that response and interaction to spaces can allow the traveller to gain an experience which 'impacts on the self in some way' (1996, p. 229). While they do not go further than this in exploring the impact, Suvantola's work suggests that such an experience opens a new dimension by 'challenging our senses to open up to things we do not usually pay attention to' $(2002$, p. 47). The traveller responds to the difference of the space if they are able to engage with what is presented through simultaneously 'seeing' it and bringing what they already know to bear. In a distinctly Australian tone, Horne describes this as going out and having a look for ourselves; we may even gain new ideas, he says, adding '.. if new ideas are what we want; otherwise, of course, this merely confirms old prejudices' (1992, p. 368). Ooi reports that 'tourists notice what they expect, what they already know ... it is a challenge to get them to pay attention to things they have imagined wrongly ... [they] seek out what they expect [emphasis in original] $(2005 \text {, p. } 63)^{11}$. In this regard, the physical aspects of place are inseparable

${ }^{11}$ For example, the search for the photograph that was presented in the brochure and a subsequent re-photographing of it, with the tourist within it. It should be noted, however, that imaging self into the pre-imagined scene uses the other as object for the experience and precludes engagement with both space and the other. 
from the space's social aspects of interpretation, representation, and identification (Bourdieu, in Gieryn, 2000).

The role of the space in both the travel experience of encountering the other and in creative theory invites further analysis which can only be referenced here. Space can be considered as working at perceived, conceived and lived levels (Lefebvre, 1991) and as politically structured through planning the built environment (O’Dell, 2005). This means that space can be structured by dominant groups for particular purposes, including specific tourism purposes, and this affects people who come into contact with it. Dominant interpretations can be both experienced and resisted by users of the place and the layers of meaning which reside within (particularly, public) spaces can be understood as a constantly changing array of noticed, considered and bodily experienced meanings. The possible encounters with the space are almost infinitely variable, providing a 'set of moments' as Soja describes them (1996, p. 260). The relationship of the meeting space to the moment of encounter and the generation of new ideas is best understood if spaces are seen as 'meeting grounds ... vibrant with people and potential' (MacCannell, 1992, p. 2).

\subsection{THE OTHER IN THE MOMENT}

MacCannell's description explicitly includes the presence of people as part of the dynamism of the meeting ground, the space of encounter. Two aspects of this can be considered: first, that the presence of the other is critical to the creative encounter and, secondly, that the attitude of the self, the traveller, is also critical if any potential for developing new ideas is to be realised. The other is the domain in which we can find the 'presence-at-hand' - the responsive moment of engagement - that we seek, writes Suvantola (2002, p. 46). The immediacy of the face-to-face encounter brings the traveller into awareness of the presence of the other and into the 'now', the present time, not the past or a future prediction, so not an abstract conceptualisation of meeting difference nor a reminiscence. This focus on the present moment can have an intensity that is not always achievable when a person is subsumed in everyday busy-ness. Suvantola considers that physical distance between 'home' and 'away' positions is the only way to constitute enough tension to generate the intensity required for a moment of encounter. I would suggest that the attitude, the openness, of the traveller is more critical than physical distance from home in seeking the possibility of encounters that 
generate new ideas. Rosalyn Diprose also believes that the creation and transformation of ideas can only take place within the 'field of the other'; and by field Diprose is encompassing not only the physical space and place where the other is met but also the spheres of difference, perspective, self and radical alterity that are present (2002, p. 126). New ideas and new connections are made in the 'numinous, magical moment' of a shift of awareness that creates a point of departure (Gablik, 1991, p. 43). In such moments, in Gablik's (1991) description, we are co-creators of the patterns that interweave a continuum of life and meaning.

Both Diprose and Gablik are describing an interaction that is highly responsive in the moment. There is a sense almost of relishing difference. This aligns with Levinas' (1969) description of the encounter with the other as beginning in a position of responsiveness ${ }^{12}$, even if it can be quickly overtaken by culturally learnt responses of distrust or caution or defensiveness. Suvantola (2002) writes that 'shallow' experiences, ones in which there is no sought change, engage by 'attributing characteristics' to the other. He is describing a process whereby what is already known is applied to the new situation. While we all use the knowledge we have in any new situation, Suvantola is discussing a blinkered engagement that is not open to what is being offered by the situation or any alternative manner in which the situation could be experienced. This refusal, to be open to the other, places the traveller as dismissive of radical difference through reducing the other to fit into what the traveller already knows, their personal knowledge, and this will limit the experience. For, writes Levinas, the other 'teaches me alterity', and this teaching 'breaks ... the imperialism and violence of self-knowledge that would limit the other [and the self] through the imposition of familiar ideas' (in Diprose, 2002, p. 136). Instead of remaining within self-knowledge, the encounter can 'open me to think beyond myself and therefore beyond what I already know' (Diprose, 2002, p. 126).

De Botton (2002) notes that, in travel, having the right question to ask 'predicates a connection'. It generates excitement; although 'most things do not come affixed with these questions', the right question 'allows an evolution of curiosity' (De Botton, 2002, p. 123). Levinas describes this as a conversation with the other wherein

\footnotetext{
${ }^{12}$ Levinas names this the 'ethical 'response. He holds this stance which recognises the separate autonomy of the other as a first, or original, ethics which exists before all else. It places the subject as responsible to the other. Refer 4.4 for further discussion.
} 
the presence of the other 'overflows the idea a thought would carry' (1969, p. 174). The ideas that are possible within this moment are greater than can be imagined by the self. The response to the other opens the opportunity for thinking beyond what is already thought, where the alterity of the other itself is what provokes and prompts thinking. Levinas describes this as 'living from' ideas (1969, p. 113). This living from ideas does not come from dispassionate contemplation but from enjoyment (Diprose, 2002, p. 132); enjoyment is, significantly, also cited as interwoven with the creative process.

\subsection{THE EMBODIED RELATIONSHIP}

In considering the creative moment as a point where the embodied meeting leads us beyond what is already known, the traveller who engages in an ethical response can be considered a participant in an experience of creativeness. Bodily materiality and sensation impact on our intersubjective sense of the world, on how we understand ourselves and others, (Brandt, 2006). This occurs as a pre-linguistic signification that is 'felt'. Brandt considers that shared meaning is possible in the absence of spoken verbal language and that 'I feel' is a source of information that should have equal value with material data that can be presented evidentially (2006, p. 145). Because sense is prereflexive and purely embodied, it is a difficult concept to explain linguistically but that does not reduce the use made of it nor the influence it has on understanding experiences. Gurevitch (1999), in examining the relationship of body and spoken language, observes that embodiment of knowledge and understanding emerges in the performance situation where the body interrupts the intention and flow of the spoken word. Watch a comedian at work - the discrepancy between word and body is used to highlight human behavioural and ideological inconsistencies for us to laugh at. The body acts out a threedimensional interpretation of the mind's ideas; in the flows and hesitations of the body are clues to the nature of human processes (Gurevitch, 1999, p. 538).

The body is integral to the subject's reactions and interpretations of place; an awareness of embodiment allows us to challenge our established readings of difference, to start to undo the colonial privileging associated with the gaze (Pezzullo, 2007, p. 175) by involving the individual through a range of senses and removing the safety of distance implicit in the separation of the viewing position. In the third Narrative, the physical demand of bodily and sensory engagement with travel was illustrated. A theoretical appreciation of the role of the body in travel will 'help to remind us ... that 
when we look, sit, listen, we do so in an embodied subjectivity' Pezzullo notes (2007, p. 175). Embodied theory contributes to an understanding of the moment of encounter but should not limit that understanding through an exclusive focus on performance. If it is taken that the body has meaning only through its actions, this neglects the role of the other in conceptualising the self (Diprose, 2002). The self is certainly constituted in a body, but an account of the understanding of the relationship between body, self and the other is part of the self. That relationship is conceptualised into an identity of self: however, because it is constituted through a relationship with the other, it is also open to change. Diprose believes that body-identity is thus fundamentally intersubjective and is forever 'ambiguously caught between objectivity and subjectivity' (2002, p. 69). The embodied nature of travel makes appreciation of this ambiguity part of the postmodern traveller's ironic reading of experiences. This ironic awareness of the liminality of the traveller's position - in place but not of it, aware but not 'literate' of the space - is an opening for shifting points of awareness and reference. From a conscious expression of these shifting contexts of meaning and representation of becoming other, tourism studies can expand the possibilities of presenting more of the richness of potential that the moment of encounter holds for the traveller.

The familiar diurnal pattern, the shift between day and night and back, is used prolifically as a metaphor for a changing self. The sequence of loss of certainty, reconceptualisation, and a final re-awakening, winds through the metaphorical passage of the night in literature and film, and are more familiar to the traveller than is often reported.

\section{- LOSING THE HoRIzON: THE LIGHT OF Night -}

Metaphors are a technique for representing complex relationships. A 'burning ambition' adroitly refers to the all-consuming, single-focus concentration that ambition can generate; it refers to the damage that can be sustained by things adjacent to that ambition, even if unconnected with the ambition itself; it refers to the intensity of focus that ambition can exhibit; it refers to the time ambition can last usually implying short but also applicable to a long-held ambition as coals or embers which smoulder for a long time. All this conveyed in one neat metaphor - for ambition cannot really 'burn', it is a concept 
not a physical object - and whose success in ambivalence has ensured its continual use. Writers continue to use metaphors for liminality, for the creative response and for the relationship with difference - all complex experiences that struggle for expression. Each of these is an experience of a 'non-fit' where what is known becomes a slippery tool, inexpert and only semi-effectual.

Pratt (1992) notes the use of the night in travel writing as a method for positioning the subject for reflective consideration of otherness. In the darkness, hidden as it were from the harsh light of day, the position of being different, of being gazed upon as visitor, as being obviously and visibly other, is simultaneously embraced and put aside. The subject is empowered or re-empowered, from a situation of disempowerment. Invisibility enables reflection on vulnerability and uncertainty to be reconsidered. Night then is structured as a metaphor for the alternative ways of being. We contemplate but cannot interpret; what is required are fluid boundaries of perception to provide the means for imagining. As in travel, 'things are there as objects we contemplate but whose meanings we cannot grasp' (Suvantola, 2002, p. 44). There is a slightly strange and foreign aspect of things seen in the night, which make me feel I am not quite in the place, Droit worries (2005, p. 55).

The complex and multiple plays with reactions and idealisations of night ooze their way into literature, architecture, songwords and urban myths. In urban myth, the blinding lights of the following semitrailer threaten the young female driver, only to be revealed as a saviour. The accruements of night - moon and stars - similarly carry ambivalent and contrasting symbolism: moon of romance, moon of wolves; stars of Australian songlines, stars of Broadway; stars as impersonal, follow your star - starlight and star-struck. And then again, moonlighting, mooning around, mooning someone, moonstruck. Shades of rebellion in 'moonlighting', linking the opposite, shades of mesmerised in 'moonstruck'. What was known and certain wears new clothes and merges and flickers into the deeper shades that fill the night. What seems straightforward shifts under our touch. Magic dwells in the night; 
streetlamps conjure up the sound of muffled horses hooves and carriage wheels though a hundred years have passed, evoke mist and framed warm window-light though the cars are parked nose-to-tail, ready for the morning. Hot nights of tension and sweat when voices explode from doorways propped open. Cold nights of icy hurrying when sound is frozen to silence.

Night the protector - the safety of darkness for a myriad of active, busy creatures. The safety of dark's coolness for desert life, when the lack of sunlight is release from hiding. Night the protector - lack of light conceals from the sighted, obscurity sidles the unsanctified act into being. Anonymity, enemy of western factuality, endorses behaviour, release, voice. Mythology of change is deeply rooted in the sensory requirements of the dark. Night creatures' eyes loom huge to collect what light is available. Humans must reassign authority to hearing, feel, odour. Thus what is known must be re-learned, re-interpreted, reabsorbed. The palette of day colours is replaced. The spectrum of day sounds closes. Lights in the office tower flick to black, solitary space burns on - lonely night worker? the cleaner? rush, or lazy, forgetfulness? Half-drawn curtains and drying clothes on racks are thrown into view in the apartment tower opposite, the snap of light coincides with what's for tea and what do I wear tonight. We take on an-otherness to match revealed iridescences hidden during the day. We reconfigure the known with the newly perceived; this street is not the street I walk in the day - distances are unfamiliar, outlines unrecognisable, sounds resonate differently.

Vision uses perspective and an horizon, it binds a relation. Escher's drawings take vision for a walk, leading it inside itself to another realm of impossible seeing. Dali and Picasso separate the pieces of vision's accepted arrangement and reshuffle them for multiple vantage points. Vision is forced to become a participant rather than the dictating spectator. Viewers read such complex and contradictory forms and begin to negotiate some form of new paradigms within which to construct meaning. In the darkness, vision's perspective is lost, earth 
and sky are seamless; our feet inform on gravity's pull, our ears take sound seriously. Complexity of form looms; our reading is contradictory and our night vision impaired through over-reliance on day-supported visibility. Moonlight offers a seemingly familiar visibility, but the light is less and the dark, darker. Crisp demarcation of moonlight and shadow shortens perspective through the loss of scattered light.

Lights, though, reform and disarm the night. They flash and pulse; the shabby preens into sensuousness, the ordinary into exotic. Even burgers seem romantic by candle-light. Hooded doorway's single light enjoins a whispered invitation with hints of within. The laundromat becomes a warm place of belonging; the cafe, a joining of family. Theatre lights promise pleasure, the pub's light-filtering shutters promise conviviality. Without vision, we ourselves are not viewed, are not seen, observed, gazed upon, critiqued - and this is the freedom of the night. It is also the terror of the night. It is the shift in perception and perceptive ability that allows difference to be assumed. Day life fades with the daylight; responsibilities of the working day are left behind, closed off. The responsible cloak discarded, different personalities are on display. Masquerade, carnival - loss of inhibitions to a sensory response; a donned mask emboldens. Being someone other than our day-self. In the night, an empowered subject is called forth, for whom uncertainty, vulnerability and the invisible bring joy, plenitude and an expansion of self, Wright explains (in Pratt, 1992, p. 223). We are multiple selves, becoming other in manifestations of our faceted lives. We meet alterity and dance with wolves - or is it that we meet the night selves of others in the night whose day selves are unrecognisably alien to us? The night forces awareness of what we don't know - as does the presence of the other. How will one react? A choice to 'go with the flow' places trust in intuition. Intuition overflows rationality, draws on knowledge, emotion, reason and experience, together to inform the current, the now. Vision, Levinas (1969) says, conditions the relation between data, imposing a pre-existing expectation; but lack of vision, lack of light, does not 
indicate nothing is there - the void is a form of enjoyment and separation.

Night is also the predator; night is too real for the homeless. What rites of passage are accorded to the night that are becoming other - death, love, birth? And gendering of the night - man of the night, woman of the night. Shades of meaning, shadows, the Shades themselves. Why is it that road movies are always of traversing distance by daylight? In Australia we know of the long night drive, the travel to relatives, the journey to the city if you are a country child, gazing into the black bush edging the countless miles. No glimpse of homestead window here. Travel by night felt as undertaking risk or a passage of trust; long-haul resets the body into a misaligned rhythm. Lone Australian truck drivers on long-haul report the disorientating bright lights, seen above the road ahead, that defy categorisation. Yet the experience of disorientation, incomprehension, self-dissolution, can give rise to a serene receptivity (Wright, in Pratt, 1992, p. 223).

Night disorientates day; are the worlds of day and night reconcilable? Does one become an article of faith while we are in the other, Droit wonders (2005). Night provides a metaphor for imagination and vulnerability that are disallowed in practices of western competency. And the moon in the night has been a metaphor for change, for shapechange and mental change. Learnt, anticipated, effect of gravity, effect of light's pull? A crazy day in the dementia ward invariably prompts the check - what is the phase of the moon tonight? Full moon and madness have links that nurses are not taught in theory but learn quickly in practice; likewise on nights of the full moon leaders of youth group find their charges show a sudden, unbridled manifestation of energy unsettling craziness. Light can certainly reshape - flowers fold, others open, in response to the darkness. For a diver, the blue-silver, moving sea-ceiling is intoxicating in its covering beauty but light is bent and deflected by the water and dispersed by a mere handful of metres to a darkening medium of alternative life. Night-dive and perception shifts the water is more silky, the eyes more sensitive, sound is unchanged but 
touch is magnified. And lack of light allows seeing - glowing lifeforms, sparkles of phosphorescence.

White light's multi-coloured unity sources life, growth, energy and, of course, vision. Its importance is revealed in metaphoric usage: to 'shed light on' something is to enlarge someone's understanding; a face 'lights up' in recognition; 'enlighten me' invites a communication, a sharing of knowledge. 'Seen in this light' locates an interpretation into a different context. To see the light - well, seeing the light 'is seeing the invisible in the visible' (Zajonc, 1993, p. 342). Indeed, Zajonc notes, we can wake each morning for sixty years yet never see the light (ibid).

For within the deep shades there is a shift, imperceptible, of a new medium. Sound drops away, a different timbre of darkness is felt, although as dark as ever. The new day presses against the indiscernible eastern edges of the world, its unseen presence exerting an inevitability of change. In the morning light things reconstitute themselves slowly; the cock crows. Night gives way to its other.

\subsection{THE REFLECTIVE SUBJECT - NARRATIVISATION AS CREATIVE SUBJECTIVITY?}

I have suggested that what is occurring in the moment of encounter with difference is a displacement of the self from the central position of certainty through an unpredictable conjunction of elements which provokes a disturbance to the self and which may lead to the creation of insightful perceptions and connections that open new conceptualisations. This involves a certain dwelling on and exploration of the various elements presented in the situation - a reflection.

The reflection on experience, that develops concepts which will influence both knowledge and the use of knowledge, can be in the form of narrativisation. Richards and Wilson, researching creativity in tourism practice, consider that narrative provides the means to link disparate experiences together 'into a distinct, individualised whole' (2006, p. 1214). While there are a number of particular meanings of the term 'narrative' in theory, I am using it here as the individual imaginative self-reflection on perceptual and embodied experiences through which ideas and concepts are formed. Johnson contends that the connections between experiencing the world and the systems of 
abstract symbols that are constituted into an understanding of that world, are developed by the imaginative handling of the information received through experience (1987, p. 19). Experience itself does not confer meaning; the process of imaginative narration allows meaning to emerge from the moment of shift of perception.

Richards and Wilson hold that 'it is increasingly necessary for individuals to piece the discrete fragments of experience together' (2006, p. 1214). They contend that there is a need for an individual coherent story 'that says something' about who the person is (ibid). In Narrative 3, the difficulty when this does not happen started to appear. Richards and Wilson suggest that everyone has their own individual narratives, which are 'arguably becoming a more important underpinning for our identity'; this, they add, is 'an important part of the reason why people travel, or why they travel as they do' (ibid). The travellers at the start of this thesis who were interested in the unknown as destination were noticeable in their lack of articulating any intended outcome. Only one sailing individual self-identified as contracted prior to travelling to write his experiences for a magazine. The traveller's encounter with the other that allows difference is not always easy to express in language, however, the casual individual narrative was a powerful element within the experience of the unknown. Discussions - of events, scenarios, experiences, conversations - were constant, important interactions around the driftwood fire or gathered together in a host's cockpit.

Gilmore (2005) has suggested that for a change of understanding to occur in the response to the event, the experiencing of such an event is not sufficient - it must be accompanied by a reflective acknowledgement of that experience. For Levinas, this suggests that:

[t]he primordial essence of language is ... in the presentation of meaning; language comes to me from the Other [because] the essence of language is the relation with the Other. The welcoming of the face ... commands inward discourse. (1969, pp. 206-207)

To ask something's meaning, writes Nozick, is to ask how it is connected:

For a life to have meaning, it must connect with other things or values beyond itself. Meaning ... seems to lie in such connections. (1981, p. 594) The problem of meaning is created by limits, Nozick continues; 'We cope with this by, in little ways or big, transcending these limits' (1981, p. 599). Making connections 
between disparate or diverse elements in an imaginative way is the process of creative development of new ideas and conceptions which can take the individual beyond her/his current limits of knowledge and understanding. Richards and Wilson's suggestion of narrativisation is one form this process can take. Levinas identifies the active involvement of reception and contemplation when he writes that the face-to-face encounter demands 'the very distinction between representational and affective content' (1969, p. 187). This process 'generates enjoyment' and 'is endowed with a dynamism other than that of perception' (Levinas, 1969, p. 187); it goes beyond simply the received information to a reflection on the experience that is imbued with joy.

Travelling can be seen as an activity that provides opportunity to question the traveller's place in the world and perhaps to reveal possibilities of existence which were previously concealed (Garlick, 2002b). If so, then it is an activity that enables the individual negotiation of identity and subjectivity through a non-reductive relation with the other. Foucault (1988) identified that some individuals resist beliefs dictated by institutionalised knowledge-power structures; rather, there is a way in which the individual constitutes her/himself in an active fashion through the practices of the self. The individual encounter that opens to the alterity of the other occurs in an unexpected moment and allows for possible new combinations of elements that can change understanding. This can be imagined as a point where resistance to institutionalised knowledge-power structures is enacted. Perhaps it was a growing realisation of the occurrence of these unpredictable moments that led Foucault later to suggest that: 'Since ... the self is not given to us, I think there is only one practical consequence: we have to create ourselves as a work of art' (1997, p. 262). Travel offers the potential for us to do exactly this through a situated encounter with difference. Here, the Narrative once more offers insights. 


\section{NARRATIVE 4:}

\section{- EXOTIC LIMINAL - THOSE OTHERS, BEING OTHER, BECOMING OTHER •}

Itinerant people walk in the dappled space of the liminal borders, between woodland and grassland, between ocean and dunes, between light and shade - between 'normal' and 'different'. One becomes conscious of being held to be different when travelling. It can raise an awareness of being out-of-place from all viewpoints. Where does one belong? For us it began to show in its varying presentations early in the trip.

- Those others

Yes, the elegant, recently renovated Robe Hotel did indeed have showers available for, er, yachtspersons. 'No, there's no charge. Top of the stairs. And - ', glancing at our salty hair and shoes, ' - enter at the back. The green door.'

That evening we felt like burglars, skulking round the back of the hotel hunting for the green door. It was there, as promised, along with the showers at the top of the stairs - all cream tiles, large mirrors, fluffy towels and lots of hot, running water. With clean hair and clean clothes, we sauntered down the front stairs like normal people to take a table for dinner. The backpacks of shampoos and dirty clothes disappeared under the long white tablecloth quite satisfactorily.

There is also the liminality of the newcomer - the judgement of potential, experience, a grading of possible acceptance. Fishermen who harvest the sea view other users against that medium of ocean as livelihood; whether oil tanker, container vessel or family yacht - vast, cumbersome, or apparently frivolous - these seem to be held as poorly credentialed to be on the ocean at all.

We took Oblion in to refuel at the Robe wharf. We tied up, as directed, on the outer side of a grubby trawler which was berthed in front of the fuel pump. I had to scramble over their untidy deck to take the cumbersome hosepipe. I staggered back, negotiating their tackle and doghouse and hauling the heavily awkward, smelly hose in great tugs behind me. I passed the huge nozzle to Stuart who disappeared below. The twin diesel tanks were under the stern quarter berths: mattresses and bedding had to be folded back and the wooden bases removed to access the filler caps. I heaved more hose over the pushpit. The trawlermen leaned on the fuelwharf bollards above, observing, impassive. I suppose they had seen many yachts come and go and certainly refuelling was an everyday activity for them. For us, though, this was our First Port of Call, our 
first refuelling of The Trip and we had just done our first Ocean Sailing on Oblion. Only capital letters could mark the significance, for everything was new to us. Stuart passed the nozzle and some money up; I stumbled my awkward way back across the trawler's working tackle with the fuel hose and handed over $\$ 60$ for the $\$ 55.60$ of diesel. The fuelman proffered no change. I hovered for an instant then slunk away, from him, from the wharf, from the horizon-focussed silent watch of the 'real' sailors. I wondered when and if the line to acceptance would ever be crossed.

- Being other

For some, though, an association with what they perceive as exotic offers an interim position close enough to almost touch something they can only dream about being, lacking perhaps courage or the chance to achieve it on their own. Sitting out bad weather for a couple of days in Victoria's isolated Waratah Bay, the sheltered waters were relatively calm enough to invite going ashore to explore and, hopefully, get some proper bread - the baking had not been successful. With our shoes in a backpack, we surfed onto the beach, dragging the dinghy well up above high water mark until we returned. Curious brick ruins lay beyond the beach but before we could reach them, a hat swooped past on the wind. It belonged, we realised as Alison rescued it, to an elderly gentleman walking along the adjacent road. He was grateful and answered my questions about bread with a shake of his head. 'The little shop along the road is shut. Gone into Melbourne for a funeral but I'm sure we have some spare milk and bread. If you explore the rocks under the cliffs,' he addressed the girls, 'you will find some rockpools and caves. There is a small path up the cliff. Follow this to the road then knock at the second house. I'll be back by then.' With that, he left us.

We looked at each other. 'Do as he says, I guess,' said Stuart.

Little starfish hid shyly at the bottom of the rockpools scoured into the limestone. Crabs and sea anemones waved at us while turban snails pretended to be empty shells. Bigger pools had forests of sea lettuce and funny bubble seaweed, Neptune's beads. Elizabeth and Alison delighted in miniature ravines and interlinking runnels until they found the caves and a stream which, stained a clear tannin brown from the bush, came trickling down the rock. Tearing them away from these delights to climb the pathway up Bell Point took us past the Waratah Bay light, lonely in the 
middle of the daytime bush. A light in the dark is an old and well-used simile, but lighthouses, quite apart from their protective role, assume life and personality in the darkness. The reassuring pulse of light, as important as a heartbeat, lets the sailor know he is not alone. (At least it used to - there are very few, if any, lighthouse keepers left in Australia for all the lights have been automated.) Nevertheless, the feeling of a link with other people remains and is comforting in the vastness of the ocean at night. We paused to pat Waratah Light and thank it for guiding us into the bay, then climbed on up to the road.

An old dog wheezed brief defiance as we approached. The gentleman and his wife invited us inside their home: they would take no payment for the bread and milk they had waiting for us. Instead, they made cups of tea and showed photos of Walkerville, as the small settlement further along the bay is called, in the days when the Waratah limestone was quarried and converted to lime for building. A busy place with four lime kilns and a long jetty, it lost out eventually to a limestone deposit discovered closer to the city and transport. The brick ruins are all that remain of the kilns while the jetty was destroyed in a wild storm some sixty years ago. Now the bay is left in peace. With many thanks for their gifts, we said goodbye and followed the bush-fringed road as it curved steeply down to the beach and the dinghy, and our movable 'exotic' life. We got soaked trying to get the dinghy over the surf, Alison couldn't work her oar and was yelled at by her father and I pulled a muscle trying to keep the gifts of bread and milk from being saturated; such fun, this exotic lifestyle ...

Our liminality also produced - well, sympathy.

Moored securely to the wharf at Ulladulla on the New South Wales coast, we were waiting out an extended period of rain. It had already kept us cooped up for three days and now it was Sunday, and still raining. Stuart's Salvation Army upbringing had him decide it was time to have a 'proper' Sunday, so we set out in all our wet-weather gear of gumboots, waterproof pants, beanies and well-used jackets to visit the local Salvation Army Corps, as listed on the town map. However, it was unquestionably absent on the ground when we had trudged across town to the address indicated. Not even a sign to indicate where it might be now. Never mind, there was a Catholic church back a way that would be fine, Stuart said. We were early for their service and huddled damply under the dripping eaves for a good half an hour while waiting for the church to be opened. When a kindly-faced member of the congregation arrived, we were pleased 
that soon we would be able to be inside and warm; everyone was feeling a bit soggy and cold by now. We politely made conversation by asking her, as a local person, where, actually, was the Salvation Army hall?

One glance had apparently been enough. 'Dear, I don't know, but the Saint Vincent de Paul Shelter down the road will be open shortly.'

I had thought we looked quite smart, for yachties ...

Finally the rain cleared and the seductive beckoning call of the unknown brought restlessness: time to move on. Stuart was coiling the springer on the foredeck and everyone had had breakfast and seasickness pills - except Alison, who had refused to take one since Western Port and who was proving to have the best sea-stomach of us all.

'Hello there.' An elderly face peered down at us from Ulladulla's wharf made high by a very low tide.

'Hello,' responded Stuart cheerfully. 'Lovely morning.'

'Yes. I've been down to see you several times but you haven't been here.' The man seemed disposed to chat. 'I always come down to see if there's anything I can do for sailing people like you. I always wanted to do what you're doing but the wife - '

'Gets seasick?’ smiled Stuart.

'No, died,' the man said sadly.

'Oh.'

'And now I've retired here and I try to help visiting yachts. I've got a car, you see, and that's useful. Is there anything I can do for you?'

'Not really, we're just about to leave.'

'I've only got the garbage to get rid of,' I joked, 'because everything else is done.'

'I'll take it.' The old man was eager. I felt embarrassed, taken aback for my flippancy. He truly wanted to be helpful so I passed up the small bag of rubbish.

'I'll be back in a minute,' he told us and disappeared.

'Give me the genoa,' said Stuart. 'Girls, take the cover off the main.' 
We were planning a short sail, about twenty-five miles, today. The stern mooring warp was onboard and only the forward warp remained to be freed off when our elderly friend returned, hurrying along the wharf.

'This is for you,' he called and handed down a plastic supermarket bag. 'Have a good trip.'

At this display of open generosity my heart squeezed into a ball of reproach to earlier insensitivity. Nodding away our thanks, he freed off the forward warp and Oblion swung out into the harbour. The solitary figure on the wharf raised a hand in farewell.

'Look, fruitcake and apples,' said Stuart, checking the contents of the bag. 'And a packet of barley sugar. He must have nipped up to the shop.' We looked back at the now empty wharf. It is a strange responsibility, sailing others' dreams.

There remain, however, two sides that abut a liminal zone, although the point of actual change is so blurred as to be indiscernible. When can one say where one is, or why? There are subtle pressures that eat at the choice of the liminal or different.

Friendship comes quickly when there is a shortage of other children. Sailing kids are receptive, tolerant, responsive, observant and self-possessed. They have to be. Playing and sharing with someone you didn't know yesterday becomes second nature and an open-mindedness develops which reaps its own rewards. It is rare to meet a selfish sailing kid. This time we were enjoying the experience of Oblion being moored slap-bang in the middle of a thriving, striving, busy cit. She was moored fore and aft, alongside a bunch of other yachts, to the wooden pylons in the Brisbane River - highrise on one side, busy Castle Bridge downriver and the little passenger-ferries bustling workers across-river day and night. The girls had quickly made friends with Dylan and Brooke on the neighbouring yacht and we had met their mother, Liz, whose conversation was full of interest, insight and anecdotes, all fuelled by an eager, vibrant fascination with life.

Today, Stuart had gone ashore into the city. The river had flowed quietly past all morning and the wind had eased so that Brooke and Dylan rowed over to share fresh cake and play. The burners on the stove were not working very well but the oven was still cleanly efficient and I baked slices, the girls' favourite chocolate chip biscuits and 
currant cake. Much of which was being demolished in between games of cards and a general happy silliness. Now Stuart had returned but with a long face.

'It's all those people going to work. They've got to me. How can I be here, having a wonderful time while they are slaving in offices? Doesn't seem right, somehow.'

'You're not feeling guilty, are you?' I exclaimed.

He looked shame-faced. 'It's that protestant work-ethic I was brought up on. It's getting to me.'

We rowed next door to discuss this dilemma with Liz, who laughed. 'Though it's not really funny,' she added. 'That guilt feeling is real, so real it has forced sailing folk off their boats - I've seen it happen. You have made a choice that the people you saw today can't or won't take. With the dangers and risks of sailing come the benefits: one of those is flexibility of time. Just don't let the guilt get to you. Remember, you're doing what you chose: so are they.'

- Becoming other

Then the unknown of the mind crept in to change our world, a very private liminality of mind. Mental illness does not sit well with the ocean.

Oblion was securely moored in Cairns and to all appearances things were normal; we cooked, hung out washing, rested, read and met our neighbouring yachties. My diary holds the other story: Stuart would disappear, I had no idea where, to return hours later. 'Just walking', he would say in answer to my worried queries. He went on and on about what to do with Oblion and had an obsessive need to have me sit and talk with him, which really meant listen. I tried to grasp the slippery non-reality of his mind. He seemed more coherent with a full stomach and I put huge helpings of eggs and bacon before him in the hope of ballasting his thoughts to coherence.

But nothing could settle Stuart's mind. He announced: 'Now, we'll transport Oblion back to sell her in Mooloolaba.' I stared at him, speechless. 'We'll load Oblion on a semi-trailer,' he continued. 'I've done the costs, rung around and stuff.'

'Oh, Stuart, it's not a good idea.' I tried to keep my voice level and reasonable. 'It's not necessary!' 
I stared at this man who had skippered Oblion through thousands of miles of difficult ocean. He did not register my words, seemed to hear only what was inside his head. Sympathetic strangers in the marina spoke to me of their experiences of various illnesses, of Chronic Fatigue Syndrome and the Ross River virus. I was recommended a doctor and Stuart made an appointment but insisted that he go by himself.

'She thought I was mad,' was all he told me on his return.

By next morning I knew I had to make a decision.

Through the sailing clubroom's open windows, adjacent to the marina, light and chatter spilled into the night. Only a few metres away inside the deeply shadowed telephone box, I watched a little pad-toed gecko as it worked its way up the phone box's panels to the top, translucent between me and the clubhouse light, until it froze into stillness. Other people's lives flowed on over the beer glasses and nut bowls in framed squares of yellow warmth but I leant against the glass, grateful to be part of shadowed solitude for the few more moments. I had only to reach a few centimetres for the telephone, but not just yet, not quite yet.

'Hi Dad.' Did my voice give me away? 'I'm going to sail Oblion back to Mooloolaba with the girls. She will go up for sale there where there is a much better market. Stuart will take the bus and join us in port. I'll get extra crew as I go.' I stopped. 'I think this is the best way.'

The pause at the other end was less than a breath. 'You have my full confidence,' said my father, five words of understanding, agreement, faith, support: I turned and walked back to my family and my yacht. I gave no thought at all to my femaleness in relation to taking charge - there was simply a decision to be made and actions that had to be taken. It was my responsibility and my role. But our culture genders the sea, that great body of impersonal, beautiful, encircling, restless water. At least it genders sea-activity.

Tim and Kylie came aboard as crew, the girls moved to the stern quarter berths, Stuart had his bus ticket and Oblion was cast off for the start of a voyage south.

Some days later, we approached Townsville harbour. The glow of Townsville's lights outlined Cape Ballarenda ahead and Magnetic Island was a greater black mass against a black sky, indicated only by the presence of a red oscillating aero beacon on the central peak to port. West Channel separated island from cape and our position put 
Middle Reef well to port. The unlit cape was now the dark bulk abeam, barely visible against the larger mass of Castle Hill beyond. It was close to midnight now as Oblion turned to enter Townsville marina. Tim and Kylie stood ready, warps in hand. The sails were stowed and I swung Oblion neatly in toward the visitor's berth on the fuel wharf.

'You're right, mate,' called the bloke from the marina who had materialised out of the night. I barely noticed, settling Oblion perfectly against the pontoon. 'Yep, mate, bring 'er up here, you can stay for the night at the top end.' Tim and Kylie, however, barely suppressed their laughter at the look on the bloke's face when he saw this 'mate' step up from the wheel... Were competent women skippers really that rare?

We moved to a berth on the inside finger early next morning to wait for Stuart. My diary: Stuart came down in the morning: wouldn't get on the boat, wouldn't stay put, kept moving away and moving away. Couldn't connect through to him. It's like there's an invisible, impervious, sound-resistant plate-glass divider. Called to the girls to stay onboard with $T \& K$ and hurried after Stuart's retreating form. He couldn't bear to be on the marina. Wanted to go into town to do some shopping but useless. It's like he's off his head: any choice was beyond him. Couldn't speak to the kids at all. So unlike him. Came back to Oblion but he shot off again.

I sat on the deck in despair. This could not go on. He had to go back to Adelaide and get treatment. I ran after him and suggested we go to the nearby swimming pool with the girls. That was okay and the girls happily came with their dad. At least I could sit on the lawn with him in one place, briefly.

'I'm booking you onto a flight home. Today. The family will take care of you until you are better and you'll get good care there.' I took a deep breath. 'And the girls and I will sail Oblion to Mooloolaba.'

I left him in the company of Elizabeth and Alison while I found the phone booth. 'Dad, I'm sending Stuart back. He can't manage any more. I've booked a oneway ticket so that there is complete break, no suggestion of return. He'll be leaving tomorrow morning.' I crossed my fingers that Stuart could manage the hotel tonight and a taxi in the morning. 'We'll keep going south as arranged. It's a very early tide tomorrow but I'll use it to get through to Airlie Beach at least, while this north-easterly lasts.' How my father felt, or Stuart's family would feel when they met him, I had no idea. Here and now was enough for me to manage. The girls took the news calmly and 
when I rang Stuart's brother later, all was in order at that end. The look of relief and hope on Stuart's face at the decision was eloquent; no further words were required.

We didn't even re-victual but were sailing with the tide by 0530 hours. Once in Airlie Beach, however, I searched for new crew for Tim and Kylie had to get back to Cairns. On the marina noticeboard was a small white card advertising 'experienced skipper for delivery and charter work'. I was conscious of just how vulnerable we could be at sea, one female and two girls in a confined space, but the tall, grey-haired man in impeccably-pressed white trousers and shirt who arrived in response to my phonecall was very pleasant. He had Master Mariner 4 qualifications, was beautifully spoken and courteous. We could be away in twenty-four hours, he said. I thanked him and said I'd let him know, then checked at the sailing charter office to see if they had used this man. The office staff spoke firmly in my visitor's favour: yes, he had worked for them and was reliable and experienced. He would be very good. I left, feeling optimistic. Outside, one of the charter skippers grabbed my arm.

'Look, you ought to know,' he said, some hesitation in his voice. 'This bloke has just split from his missus. He drinks and he pushed her round a bit, if you know what I mean. Just thought I should say something before you make a decision.'

I looked up into his concerned, suntanned face. 'Thanks.'

After the girls were asleep, I sat thinking. How could there be two such opposing views of the same person? Should I stick by my own, favourable, first impression? But - the merest beginnings of imagining possible scenarios, given the isolation of our position at sea, was frightening. Even the smallest risk was too much. I rang and told the gentleman he was not required.

'Try Mana. She'd be good,' one of the marina-based scuba-diving instructors advised next day.

A female? No-one had mentioned qualified women before. I hadn't even thought of it. Mana swung aboard at the appointed interview time, tall and tanned, and with her long, thick, blond plait swinging confidently. She handed me a card: 'Mana Castensen. Blue Pearl Yacht Charters and Sail training. Owner operator.' Within minutes, Alison and Elizabeth were sitting one each side of the visitor, conversation punctuated by a huge laugh which appeared to be a Mana feature. I hardly had to say a thing, except to negotiate rate of pay and departure date. 
And so an all-female yacht, if anyone was watching, could have been seen many days later, sailing toward the tricky passage of the Narrows beyond which lay Gladstone's safe harbour. The harbour was our goal but today's immediate problem was to balance tide and ship's draft to take Oblion over the drying banks at the centre of the mile long Narrows. The passage lies between the mainland and Curtis Island and floods and ebbs from each end, meeting in an area called the Cattle Crossing. Barely a boat's width across, the Crossing is marked by century-old cattle ramps where farmers made use of the daily parting of the waters when mustering cattle. Indeed, the biblical analogy can be carried further for if your timing is wrong, your vessel will find itself doing a small-scale re-enactment of Noah's Ark on a two-metre hillock: this crossing is marked 20 on the chart, that is, at low tide the seabed is two metres above water-level. So tide height was critical to getting through and we needed to arrive at the start of the passage at 1645 hours.

Eight miles of a Strait led to the bend just above the Narrows; it was 1530, the engine was stilled and Oblion ghosted slowly and silently along with the turning tide which would carry us, we hoped, safely through. Alison and Elizabeth organised themselves into depth-watching shifts. Mana set out two wine glasses for there was always a group of boats, anchored and waiting, also intending to pass through the Narrows. Now they came into view, anchored just above the bend. At 1635 we assumed positions. At 1640 Oblion sailed gracefully without pause or hesitation past the anchored boats, receiving very satisfactory stares of disbelief at the sight of an allfemale crew reclining, glass of red in hand, in the cockpit. We toasted them distantly as Oblion cruised round the bend, oozing control and confidence. Once out of sight, our act dissolved into shouts of laughter and instant action. The genoa collapsed on deck, the engine was started, the wine was gone in a gulp: it was 1645 precisely. Through the channels, over the Cattle Crossing, accounting for the markers one by one - all with enough water under the keel being counted calmly out by the girls. When I finally looked up from charts and depth-gauge, the light was fading and Gladstone Harbour's beacons winked in the distance. We had done it.

And at the back of my thoughts, behind the concern over Stuart, the responsibility for the girls and Oblion, and the challenges each day presented anew, there was an awareness that, actually, I rather enjoyed being 'other'. 


\section{Other And Event: Philosophy of Possibilities}

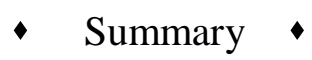

The relationship of the self and the other that is critical in the travel experience of encounter, is a contested one in philosophy. In this Section, this relationship is explored.

The historical position in western thinking is predicated in the other and the unknown as a problem, one to be investigated and resolved. The other has also been viewed as simply a mirrored self, a reversed figure only presented as a reflection and made available for the use of the self. However, Levinas (1969) holds that the other is not the simple reversal of identity and is not formed out of resistance but is prior to every initiative.

Levinas' work is explored to further understand the moment of encounter because he offers a conceptualisation of the relationship with the other that is not reductive of the other, but allows a space for accepting what the other may offer. This suggests that the creative moment can only occur in the presence of the other, and that the key to this encounter is the response of the self to the difference of the other.

An understanding of how the moment itself can offer multiple possibilities is gained through an examination of Badiou's (2003) philosophical account of the multiple events present as possibility within a situation such as the moment of encounter. Badiou's work on multiplicities provides an analysis of how the creative moment of encounter contains the potential for new ideas.

The movement of the traveller into the unknown is an act that positions the self in a situation which holds the elements of a potential event, one that may change the self through the development of new ideas and conceptualisations. It is suggested, then, that the self is constituted through the relation to the unknown engendered in the moment of encounter. There is an active positioning of the self for change.

It is realised here that Badiou's approach makes use of an ontological philosophy while at the same time recognising the element of what he terms 'poetry' that is also required for a full understanding of the experience of the moment of encounter. Levinas' account of the relationship that is non-reductive is based in a phenomenological philosophy. Here are two contrasting, indeed opposing, philosophical 
approaches that each contribute a critical element of understanding the traveller's moment of encounter. They are both relevant to the construction of individual subjectivity that is evidenced in the sought encounter with the unknown. The next theory Section considers how this contributes to contemporary theories of the subject. Before that, though, the mirror as a powerful metaphor for the relationship with difference is explored in Regarding reflection: La réflexion regardée and the responsive encounter with difference that allows wonder is recorded in the Narrative.

\subsection{UNIVERSAL TrUTHS}

The 'other' is the most profound of what our human, ethical and imaginative faculties must confront and are confronted by (Shapiro, 1996, p. 42). It is the relationship between the subject (the self) and the person who faces me (the other about whom I know nothing and can know nothing), that is contested, and that is implicated in how we see ourselves and how we see those who are outside our self, and establishes our relationship with the world around us. Energetic debates continue over whether internal knowledge is pre-existent and how much is learned from outside, whether one is present before the other, how much of either is present in order to recognise the alternative. The Enlightenment period from the seventeenth century sought to break away from the limitations imposed by religion and feudal tradition and began to place the subject as central. This developed into modern discourses and philosophies of individualism, personal rights, ownership and contract that have profoundly affected the western world through the development of modern political, legal and scientific ideologies. Early phenomenologist Edmund Husserl held that the subject can only understand itself by transferral from the experience of meeting separate animated bodies, that is, that the realisation that other separate bodies exist (Simms, 1997, p. 8). There are different orientations to analyses of the relationship of subject and other; one is taking the other as serving the selfhood of the subject which subtly subjugates the other into a satellite/centre relationship of other/self, while more recent phenomenological understanding of the other as a separate and autonomous identity to which the self can respond has been the attention of twentieth-century philosophical discussion. 
A growing belief in humankind's ability to critique, observe and order their world is what characterises the Enlightenment period. While this search has developed a method of examining the physical world, it has struggled with universal features of ways of being - of beliefs and thinking. A universal human understanding of the world, Johnson notes, presupposes that all humans have access to a 'value-neutral, a-historical framework for correctly describing reality' (1987, p. xxiii). The need to believe in the possibility of a value-neutral framework was part of breaking away from explanations of the world provided by religion; this consequently demanded a language for describing reality as observed in the physical world. The tools applied to develop these new ideas and descriptions were drawn from Greek philosophy - the tools of logic and reason. At the same time as applying these tools, the Greek dialectic of the separation of mind and emotion was adapted into these newly developing sciences of observation, though this separation may also be seen as vestigial influences of religion's prioritisation of the soul over the body.

The application of these tools to the detailed dissection of the natural world, through inspection and observation, grew into the new and exciting concept of a 'rigorous' scientific method. In the social realm, the rights of the individual were being championed. What grew from discussion into discourse was an ontological framework of a belief that, by assembling all the 'rights' and 'truths' of any object, subject or situation, the single, final explanation would be known: its fundamental, universal truth would be revealed. The whole story would be known and could be verified, told and recorded - the great narrative story of the universe was accessible, long as it may take to get all the facts revealed and ordered.

Grand narratives still have a remarkable hold on contemporary life (Dean, 2005, p. 55); their expectation of reaching a final answer, an identifiable and complete resolution, continues to permeate western politics, law, economics and medicine and is continually re-iterated in western literature, movies and television shows. The dominant western discourse is framed in an expectation of being able to finish off and move on from situations, as though the nasty comment from the primary school teacher does not cling to and influence the rest of your life - as we know it does. (Even then, we may enter counselling later to resolve, solve and attempt to finally shelve that comment and its continuing effects ...) The dominant discourse of the Enlightenment, metaphysics, can be characterised as 'a striving for the realisation of an ordered and rational totality' 
which 'sought control over the natural world through complete knowledge of it' (Garlick, 2002b, p. 294).

The underlying principle of the universal grand narrative is that there is a single 'truth' which can be found and which will situate and complete the object or concept. It is metaphysic's big-picture approach with the focus on the 'classical problematic' of being, truth and subject (Badiou, 2004, p. xv). It identifies difference, the other and the unknown as a problem to be investigated and known (read this as 'solved'). These beliefs in accessing and identifying 'fact', 'truth' and 'right' establish, by default, the existence of opposites,: 'fiction', untruth' and 'wrong'. Positioning understanding and knowledge as a choice for the identifiable, correct answer limits situations of learning because once taken, the choice is immutable - for the 'fact' is unassailable. All decisions pertaining to and associated with that fact can be taken to be reliably solid and un-requiring of further debate or attention. Diprose observes the assumptions this fixity requires:

That I can be held accountable for my acts is the rock upon which morality and the law are built. The idea that the thinking self is given before, and remains unchanged through, the act, and indeed through sequential actions, is the rock upon which the social contract is built. (2002, p. 61)

\subsection{UNIVERSALITY'S LIMITATIONS}

A discourse which is based in metaphysics will always select one (concept, situation, object, subject) as the preferred, and privilege that one over whatever is taken as its opposite - take the male/female, white/black, West/East, civilised/uncivilised oppositions of western ideologies as examples. (The currency of such divisions was reflected in Narrative 4, in the observed reactions to being a female skipper.) The Industrial Revolution imposed a social separation of work and home, and the assigning of value to paid work over unpaid (read, non-productive) endeavours further underscored a hierarchical division of activities, attitudes and cultural values. This oppositional dualism permeates western thinking, including establishing the self as opposing the other in an adversarial discourse of dichotomous relations. To reduce, absorb, or appropriate what is taken to be 'other' into being something the 'same' is enacted through an assumption that there is a preferential way of knowing the world and 
that difference can be dissected and re-arranged according to this accepted known. This denies difference its entity and autonomy as well as its pre-existence and its originality. Reduction, absorption and appropriation therefore mean to subdue or bring back into line. This acts as a removal and denial of difference. The violence that such acts of denial perpetrate is enacted on the other, for example, through language and institutions of knowledge - if there is no name for you, you are not recorded, written down, listed or data-based and, in western-based systems of knowledge, you consequently do not exist. This occurs in spite of sensory information to the contrary, that you are standing before me and asking for identification. You thus have no rights, and certainly no redress. Institutionalised knowledge - who has access and how, the teaching of the skills required to access it, what is shared and how - establishes parameters of understanding. The violence implicit in rendering the other invisible and silent through the manner of (non)inclusion - processes of reduction - is deeply embedded in western institutions and ideologies.

Levinas' experience of the twentieth century wars in Europe where people could cause harm to others through a categorisation of race, religion and ethnicity at the same time as holding a belief in progress and freedom led him to examine the human experience and challenge metaphysics as a way of understanding being in the world. In metaphysics, the relation of the self to the other is subordinate to the relation to Being, where the question of Being appears as a reflexive conversation with the self and is thus closed to alterity (Woods, 1997). Phenomenology, as a system of understanding our way of being in the world, addresses the problem of self-identity through suggesting a move from an introspective to extrospective, or contextualised, understanding (Simms, 1997, p. 3). Husserl and Heidegger were influential on Levinas' thought through their use of phenomenology to approach the nature of human relationships. For Husserl, the subject can only perform the apprehension of her/himself through a transferral that proceeds from an empathy with the other. However, Husserl believed this was achieved through the subject placing her/himself in the standpoint of the other, an egocentric rendering of the other as appropriable. Levinas considers that the egocentric view does not do justice to our original experience of the other person. This is enacted, according to Levinas, in the face-to-face encounter, through acknowledging the absolute difference, the radical alterity, of the other. 'The basic condition for all understanding requires one to test and risk one's convictions and prejudgements in and through an 
encounter with what is radically "other" and alien ... only by seeking to learn from the other, only by fully grasping its claims upon one, can it be critically encountered' (Bernstein, 1991, p. 4).

\section{3 - SELF AND OTHER}

There are a number of approaches that twentieth century theory has taken toward metaphysics' problem with alterity and the principle of self and identity (Spanos, 2000, p. 173). These include Heidegger's 'nothing', Derrida's 'trace' or 'différence', the 'surplus always exterior to the totality' of Levinas, Deleuze and Guattari's 'nomad', Bhabha's 'hybrid' and, most resonantly, Said's 'émigré' (ibid). These theorists demonstrate a deconstruction of the totalizing single answer privileged by a metaphysical representation of being as (self-reflexive) Being, in which the relationship of self and other begins to be approached differently.

Following on from Husserl, Sartre and Lacan considered that the self was constituted through the negation of the other. Both refer to the other as the mirrored self, a reversed figure generated by the self. The other is only useful as a reflection of the self, as a distorted or unrecognisable self through a reversal and therefore unfamiliarisation of the self. Thus the other does not impact or affect the self, it is recognised but only has a relation to the self through the existence of the self in reflection. The self is distanced from the other by figuring the other as mere reflection; there is no responsibility to that other.

The mirror is a powerful metaphor of separation; it is repeatedly used in art, film, photography and literature as metaphor for the ambiguous relation with the reflected, de-familiarised self/other. Constituted within Narcissus' compulsion with the mirrored self is the act of ignoring the other. Taking the other as mirrored self is a damaging, reductive negation of alterity and a misleading pathway to the self.

\section{- REGARDING REFLECTION: LA RÉFLEXION REGARDÉE ।}

Narcissus gazed, fixated, and deaf to the calls of Echo, his love. Blind to beauty other-than his own; deaf to feelings, enraptured by a surface.

But surfaces are treacherous - one breath and all is distorted, the I shattered, the eye profounded, the self profaned. Without the mirror 
surface, before the shiny metal smelted and beaten to warriors' weaponry, polished for death, worked for decoration, wreathed in protecting symbols - before metal, did humans only ever see the other? How - where - was the self? Expression of face, shape of body - were these unrealised, simply embodied as an entity? Did one paint the others - met, embraced, fought or sought - on the rock wall, or was it a self placed up there? How to compose 'self' if never seen? The handprint is perhaps a self mark, though in Australian Aboriginal culture it is an indication of responsibility, of enacted burden of respectful care, accepted gradually through birth, progressive initiation, stepped learning. Stepped as walked, too, feet to landscape.

Yet in metalled communities, the shiny stuff of hunting, cooking and violence simultaneously, showed self to self; the individual sees self in the held piece - 'Here am I!', I am revealed to me, assuredly there is an I every time my hand brings the surface before my eye, my gaze, my wondering, amazed stare. No ripples disturb my other self here. No illusions here. 'See...' showing to a neighbour, '...that's me!' The other holds the surface to their face - 'So it is!' 'No,' reaching to twist it back, 'this me!'

Self interest blossoms, mirror-fed.

But the reflection returns nothing, not voice, not subject or object, it is passive and silent, untouchable, lacking both dimension and time. How, then, is this 'me', who occupies physical space and leaves traces for return? See the dog who sniffs the mirrored surface and dismisses it, the child who looks behind the standing mirror for the person framed there so clearly, the caged songbird who choruses frantically for a love presented in illusion. Poor bird.

And the mirror of the clothes shop presents a new you, an image sought, an affirmation of fresh possibilities of self. The mirror of the theatre dressing-room presents a starkly illuminated canvas on which to paint the audience's anticipated illusion for their consumption. The mirrored motel foyer expands narrow confines to complex layered depth of 
illusory sumptuousness. And the tri-mirrored lift's endless echo of image charging in tandem up to the thirty-fourth floor with the self of myself - impossible to escape - which one is the real reflection, or the real me?

The mirror delivers desire, for the self reads only that supplied by her/his imagination. The anorexic sees the undesirable confirmed, in defiance of laws of reflection and light: thus luminous transparency reflects darkly, opaquely. Mirrors in fairy stories are more overt, commanding, provoking, directing and misleading through voiced interventions of the reading of self. The soft, warm reflection of silverbacked Renaissance mirrors line European castle ballrooms, even yet, with that seductive pinkness which makes the human skin soft, delicious, sexy, pure, ignoring age and gender. No wonder resistance is recorded to the clarity of gaslights when city reformation swept darkness from view: why work to display imperfection? Preferable is the layered work of concealing imperfection that these beautiful mirrors give in their fairyland generosity.

Harness, then, the mirror; make use of its gathering, its tricksy bending of revelation. For all light received is gifted back, nothing held or retained; generous-hearted mirror, open-handed one could say. See the rebounding mathematics of angle and return that allows the gathering of sunlight in great mirrored bowls, coercing bright light into a captured energy conversion to fire fridges, stoves, engines $-\mathrm{ah}$, and lightbulbs.

The straight mirror of discipline for perfection of embodiment in the dance rehearsal studio; the paradoxical surfaces that reveal something otherwise concealed - rear-vision mirror, convex street mirrors for seeing around corners, dentists' little mirrors on sticks, angled to peer ... And so we live with, and work by, indeed discipline the self through, a surface. Yet we are dealt further paradoxes - the Protestant souldamnation of self-gaze strains against the social damnation of incorrect presentation (think the interview, the shop assistant, the perfection demanded of uniformed Horse Guards on London duty). The surface serves and condemns, entices and beguiles, yet it is merely a tool, a 
prop. A disconcerting revealer such as those mirrors that catch us unawares - 'Do I really look like that? That is not me - it must be distorted - it is a shonky surface.' Be wary, for reflection does distort even at the first face of it, it is not a reversal of self? A disconcerting sense of estrangement haunts this partly-recognised self.

And there it is - stranger-ness. This other, if I look, is not me. I inspect this other, not passively, but to imagine myself differently, to see the other that others see, to see the other here. Another face keeps surfacing in the familiar; I am called to look beyond what it is I have come to see. The intrusion of the strange(r) disturbs the self who wants to see nothing other-than itself, so that it can find itself reassured as the only subject in the world. Living on the water, perfect stillness is eeriness, it means no wind, no movement, stasis, the concern of becalmed, the a-normality of a moving, living environment. Narcissus could only be enraptured because of the mythological creation of absolute stillness. For a sailor, the flicker of the surface signals the wind's thought, disturbance of the air, unseen but present, that heralds an opening. So the flicker of the stranger in mirrored reflection signals the permeability of the surface and - the mirror becomes portal, threshold, an enticement to an-other universe.

To enter, however, requires the shattering, the scattering, of the self, the breaking up (or down) of the static reflection. Diving into the still swimming pool holds a joy - sensual air-to-water immersion, joyful disturbance into sparkling, whispering movement. A bringing-to-life of that reflected self, now immersed in a water world. Weightless body, the blue below instead of above. To breathe here is to die - a strange inverted topsy-turvy world, on the other side of the surface here. Stepping through the portal has mythologically carried all these - the inverted, perverted, reversed, sinister - that shapes our approach to the other, evidenced in interpretations of Australia's antipodean peculiarities. These to be 'set right', wrested from otherness, either by removal or abjurement. Stepping through to the other side is metaphorically bravery or madness - or indeed death. Such ambivalence 
follows us into travel. The portal is simultaneously an inside and an outside, each one alternated with the viewpoint. It is a mysterious entity paradoxically capable of allowing entry and barring entry, permitting and blocking, a continuously paired opposite and a continuity, a supple boundary.

What might the traveller find of the other, if the step through the portal is taken? What of their self? What might be lost? Open the door, extend the stride. Take a deep breath for on the other side everything will be other; I will have to reorder my body, and my words, along new lines. I will enter into reflection.

\subsection{WELCOMING THE OTHER}

The work of Bhabha (1994) and Said (1978) opened up understanding of the reducing and destructive tendencies within western practices that operate toward the other. This has resulted in an examination of power relations between Indigenous peoples silenced by western practices and the structures, ideologies and political influences, that position them this way, bringing awareness of the violent distortion that imperialistic colonisation and exoticism bring to the sheer complexity of traditions that sit outside the western dominant representation of the other (Bernstein, 1991, p. 68). A welcoming or gracious face turned toward uninvited western visitors in the past was more likely to be interpreted within a frame of suspicion and fear, exhibited in behaviour of assertion and control which enacted violence toward the other. While the tendency of the self is to exaggerate the other's difference, arising out of anxiety and uncertainty in regard to the self's own identity, what is disconcerting is the perceived ambiguity of the other, in the appearance of both similarity and difference simultaneously (Shapiro, 1996). It is a short step to being caught up in the implication that difference, this undefinable other, is threat. Similar examination of the disempowerment of the other has also been applied to gender-aligned power differences, while studies of colonisation, referred to above, expose the silent, the oppressed and those condemned to oblivion because they don't fit the western discourse of knowledge (Leith, 2001). The other, in these studies, does not exist except in relation to a discourse dictated by a dominant western culture. Into this debate, however, the issues of hybridity and fluidity of identity and the construction of the subject challenge 
the validity of a dichotomous stance of the self/other relationship. Butler (1990), writing from a feminist perspective, also challenges the opposition of self and other. The self, she writes, is not constituted in a binary relationship of rational essential 'I' as subject against an object, but instead as many subjectivities, politically constructed, a process of 'becoming' through acts (Butler, 1990). Through this, she allows for the possibility of the growth and change of the self. Certainly established practices of exclusion that push the other toward an outside, where it is reduced to a simple non-self, contrast with the postmodern celebration of difference (Symons, 2006).

As fluid relationships become part of people's everyday ways-of-being in the current world, can there be a relationship that is mutually respectful, openly responsive? Constructions of the other as object and as the negative of the self render the other as without autonomy, without voice, and fail to do justice to the other's existence (Wild, in Levinas, 1969). If it is only through other bodies that the self gains knowledge of itself, as object to another's subjectivity, then the introduction of the other is necessary 'in order for intuition to proceed from the purely internal to an exteriority' as Simms notes (1997, p. 7). The acceptance of the external world, presented through experiences, as a relocation of understanding the self from purely what is carried within, requires an intuition, an immediacy of apprehension (ibid). We learn from the other only by grasping the other's claims upon us (Bernstein, 1991, p. 4). Moving the self away from a centred position reveals the contextual nature of subjectivity.

Levinas' philosophical understanding of what happens in the encounter with the other resonates with travellers who seek the unknown and with postmodern orientations toward difference. Indeed, Kingsley wrote of her travels as a lone European woman in Africa in the nineteenth century [lone in that she was the only European with a supporting party of Africans who cooked, carried, guided, paddled and made her journey possible generally]. She mused that uncertainty and vulnerability are made fearful only through the need for certainty and control (in Pratt, 1992). The grip of desire, as MacCannell terms this need for certainty, is a behaviour of controlling for a surety of outcome. Remove the compulsion for predicted outcomes and all sorts of possibilities are sudden potentials in the situation; allow uncertainty, and the unexpected - which can be exciting, wonderful or frightening - is available. This requires accepting personal vulnerability but as Kingsley also noted, such vulnerability is not something to fear in itself. The encounter with the other demands an ethical response that does not 
masterfully erase that which is different and unsettling, Levinas contends; while it can certainly be said that it is in the response of openness that vulnerability lies, herein also lies the potential for gaining new ideas and understandings.

\section{5 - LEVINAS' PHILOSOPHY OF THE ENCOUNTER}

'The other is not the simple reversal of identity and is not formed out of resistance but is prior to every initiative' writes Levinas (1969, p. 38). There is something 'strangely compelling, indeed strangely convincing', about Levinas' thought of the singular and irreducible alterity of the other as 'face' (Davies, 1993, p. 252).

While all the body expresses feelings, the face is the most expressive and it is in the face that we display thoughts, emotions and responses, both openly and inadvertently. 'The imperative of responsibility is articulated in the locus of the other who faces, the face of the other', Levinas considers (Lingis, in Levinas, 1998, p. xix). Facing is both appealing and contesting, it is the move by which alterity breaks into the sphere of phenomena (ibid). For Levinas, the response to the act of facing is responsibility, where responsibility is a relationship with the other and their alterity. The encounter is an experience of immediacy, the other is recognised as not self and the question is - How do I then relate to the other? The face-to-face meeting demands a meaningful response the self is responsible to offer something, Levinas contends; the response that is ethical in its respect for the integrity of that other, is one that begins in generosity (Wild, in Levinas, 1969, p. 13). Ethics in this relation, Bernstein explains, is to assume the responsibility 'to listen carefully, to use our linguistic, emotional and cognitive imagination to grasp what is being expressed - and we must do this in a way where we resist the dual temptations of either facilely assimilating ... or simply dismissing' (1991, p. 65). This respect for the separate alterity of the other occurs before any cognisant categorisation or limiting explanation is put onto the difference of the other. It is -

[t]he respect for the other as what it is; other. Without this acknowledgment, which is not a knowledge, ... without this 'letting be' of an existent other as something existing outside me in the essence of what is (first in its alterity), no ethics would be possible. (Bernstein 1991, p. 184)

The word radical implies at the base or most fundamental level while alterity can best be understood as difference, not being the 'same'. Radical alterity, then, is a 
descriptor for the absolute singularity or the complete separateness of the other, the one who is unknowable in the utter difference that faces me.

Human interaction, Levinas believes, begins with an ethical position, a response in relation to the other. The face disrupts by coming 'as a meaning which signifies by itself' [emphasis in original] (Davies, 1993, p. 263). There is no referent, nothing known to refer to, so that the disruption is to the self's consciousness: any internal understanding I may have had about myself is brought sharply into a relativity against someone else's knowledge of their own self which I am unable to access. This is profoundly unsettling but also reveals myself to my self in that I am being looked at by another. It is only as a result of the relationship with another that a sense of self other than as an interiority can emerge: my sense of self derives from another, rather than being separate from and prior to any consciousness-of-other (Woods, 1997, p. 53). Levinas turns the Cartesian dialectic on its head, explains Simms - it is not through knowing myself that I know the other, but rather that I am indebted to the other for knowledge of myself (1997, p. 11). To manage the disruption caused by the face of the other, what is needed is to maintain a sensibility to the 'sameness of the other with ourselves', a recognition of the other as a human individual, while at the same time sensible of the radical alterity of the other that 'defies and resists reduction' (Bernstein, 1991, p. 74).

Our ethical responsibility is to acknowledge the other as existing in their separateness. We have an ethical obligation to try to understand the other not simply in our own terms, but to recognise the singularity, the separateness, of the other (Shapiro, 1996). For Levinas, the face-to-face relation is where one can escape the western binary of suspicion to an ethical relationship "which subtends discourse and is not a species of consciousness whose ray emanates from the I, [but] puts the I in question ... [and] this putting in question emanates from the other.' $(1969$, p. 195) The response to the act of facing is a responsibility which is a relationship with the other and his alterity, and this relationship is constitutive of our subjectivity (Lingis, in Levinas, 1969, p. xix).

Levinas' philosophy opens a way to a postmodern subjectivity; because the ethical response to the face of the other precedes knowledge and allows the self the opportunity of recognising itself as other, it also allows a playing with multiple meanings and identities without damage to self or other. The ethical response pre-empts sensibility (beliefs and ideas); that is, the risk inherent in responding to the face of the other is 
understood second to the first response of acknowledging that responsibility. Levinas writes:

If the transcendent cuts across sensibility, if it is openness pre-eminently, [then] it cuts across the vision of forms and can be stated neither in terms of contemplation nor in terms of practice. It is the face; its revelation is speech. The relation with the Other alone introduces a dimension of transcendence, and leads us to a relation totally different from ... relativist and egoist experience. (1969, p. 193)

Thus the demand in the face-to-face encounter for unconditional response belongs to the self alone; it is not a general demand but an individual, personal and direct one. Neither does it sit in a systematic articulation of prior identity such that limits can be imposed. It is the relation with the other that specifically introduces a dimension of ethicality and opens the way to a response that does not condemn the other through assumptions of recognition.

\subsection{RESPONSIBILITY - THE FACE OF THE OTHER}

Because the imperative of responsibility is articulated in the face of the other, this is the move into the embodied world of phenomena that diverges from and challenges ontological frames of reference. Levinas reads western philosophy as having been shaped by the Greek problematic and functioning within 'the Same and the Other' (Bernstein, 1991, p. 68). The primary thrust of this tradition in philosophy has always been to control the 'other' by reducing difference to something that is already known and familiar - and therefore able to be put into a category that implicitly names it as lesser value, through the diminishing of its potential voice. In simple terms, by identifying elements of the other's way of being as fitting into our own existing categorisations of meaning, we are in effect saying 'the other is just like me'. The process of making the 'same' ignores and discards anything that cannot be fitted into existing understanding. It therefore prevents possibilities of learning new ways of thinking about our relationship to the world, about our being-in-the-world and it is disrespectful of alternative ways of being; it is underscored by the presumption that our existing knowledge is enough and more correct than other possibilities.

Levinas holds that ontologies establish a right/wrong dichotomy, and thereby gives power to those setting the rules and to those who find themselves on the 'right' or 
'in' side. Any setting of rules involves categorisation, yet everyday experience shows that inevitably there are elements that cannot be fitted neatly into either/or categorisations. Levinas states:

The relation to being that is enacted as ontology consists in neutralising the existent in order to comprehend or grasp it. It is hence not a relation with the other ... but the reduction of the other to the same.' $(1969$, p. 45)

Husserl's and Heidegger's work on the empathetic relationship to the other that exists external to the self was the beginning of an ethical dimension in phenomenology. The intersubjectivity of an empathetic relation is what moves ontological knowledge of existence into a phenomenological knowledge of the nature of that existence (Simms, 1997, p. 8). Subjectivity can then be understood as relational rather than self-generated.

This is pivotal to Levinas' critique of dialectical philosophy; the reduction of the other, the fitting of the other into some pre-known frame of reference. When this happens, difference is only accounted for as a variation of something already known. It excludes the possibility that there could be things that are not known to the self, that are outside the fixed ontological boundaries. It also blocks the questioning of those boundaries and the assumptions they enclose. What happens, then, when the self realises that the other cannot be fitted into the established schematics? How does the individual deal with the situation where one is unable to get a grasp of the situation? How often does this precipitate violence, in a literal sense? Lack of allowance for difference does not make difference go away; lack of allowance makes the situation too small to hold the too-many meanings present. Because lack of allowance has nowhere to move to, no option or alternative, it has to reject difference. This can be done figuratively, such as nuances in language and reporting that subtly denigrate, or literally, in intent to destroy, remove or force. Marking the other as a 'relative difference' within the structure of a totality is 'a discursive manoeuvre that puts into effect the concreteness of egoism' (Islam, 1996, p. 81).

Levinas' argument holds that ontology, as a model of consciousness, is preoccupied with essences, that it is underpinned with 'the notion of struggle' (Woods, 1997, p. 54). The other is viewed as hostile, whose autonomous being is inherently a threat to the self's interests (Woods, 1997). This way of thinking of the world allows no space for learning, only for surmising; it allows no space for thought outside a 'gain or loss' frame. The possibility for change of the self in response to the presence of the 
other, the possibility of something other than a defensive/aggressive stance, is minimised, as any change will increase vulnerability. For Levinas, there can be 'no hierarchy nor logic' because of the absolute alterity of the other (1969, p. 195); use of either implies a knowledge of the other which, in the other's alterity and separateness, is not possible. The ethical relation therefore 'consists not in comprehending but in relating and thus language or discourse is needed' [emphasis in original] (Simms, 1997, p. 9). Vision and discourse are both necessary parts of the face-to-face relationship (ibid); vision tells us of the other's alterity while, Levinas contends, discourse 'opens divergence ... and contests the meaning I ascribe' (1969, p. 195).

\subsection{GENEROSITY AND OPENNESS}

Levinas names the openness to give, the handing away or handing over that foregoes individual ownership, 'generosity'. It is unpredictable, for who knows when generosity or giving may emerge to be enacted? Moreover, generosity engendered in the encounter will always offer more than the self can know and results in an overflow. Levinas locates radical generosity as outside ontological discourse, suggesting that generosity does not sit within a framework of making meaning through establishing rules. Rather, generosity precedes or bypasses rules, crosses the boundaries set by rules or seems to be ignorant of rules. Levinas proposes that the encounter with the face of the other is the point where generosity is enacted; the self opens to the other in response to the need for the other's alterity to be recognised and respected for the immutable dignity of its difference. We can never escape the real possibility that we will fail to do justice to the alterity of the other (Shapiro, 1996), even in a response of generosity. The justice that is required is that of allowing the other to remain separate and not be reduced to the 'same' through assumption. The effort to offer justice is sometimes expressed in the phrase 'remaining open-minded'. The justice required may fail due to our own self-absorption. It may fail due to fear, or lack of courage - the first fed by hegemonic beliefs and accounts, the second fed by an awareness of risk in the possibility of change to the self. But none of this changes the radical alterity of the other. The other exists separately from me and nothing actually changes this.

The self must accept that this other exists in complete separateness and thus absolute difference, and the only way to connect to the other is to reach out, though this must also be without any expectation of response. Even-handedness is not neatly and 
reciprocally assured, unlike the deeply ingrained tendency in western discourse that highlights and valorises symmetry in relationships (Bernstein, 1991, p. 70). It is quite the opposite. This is a crucial aspect of the response to the face of the other - by establishing the relation to the other as radically asymmetrical, Levinas demonstrates its irreducibility to reciprocal equality of sameness. While even an asymmetrical relation is nevertheless a relation (Bernstein, 1991), and the response is clearly not a double event of symmetrical relationship, it is in the uneven and non-reciprocal opening of the self to chance learning in the encounter with difference that allows the other to engage or not. It means I may be ignored or refused. There is a register of vulnerability, of susceptibility to being affected, in the asymmetricality of Levinas' responsive relation. The exposure to alterity - an openness opened by the outside - is the way by which the subject opens itself (Lingis, in Levinas, 1998, p. xxiv); and the appeal and contestation of alterity then affect me without any mediation; it is the very experience of immediacy (ibid, p. xxv).

Levinas uses the openness of the face and the reach of the hand as metaphors for the invitation to engage. Responsible communication that allows difference depends on an initial act of generosity; by speaking to the other, I come into a relation with the individual while my autonomy remains intact, as does theirs (Levinas, 1969, p. 14). In doing this, the heart and the face are opened and, through generosity, allow the possibility of connection, of learning. The hand may reach out to touch the other's hand. Voice may employ language to articulate response. In the look or the touch that does not demand, expect or dismiss, lies the opening to communication wherein ethical responsibility becomes the basis for interaction. In this response, we realise and enact our responsibility. The generosity in the ethical response, Levinas writes, offers 'powers of welcome, of gift, of full hands, of hospitality' (1969, p. 205). This generosity, which Levinas names 'enjoyment', is a sensibility and a condition of subjectivity (1998, p. 51).

\subsection{THE PROCESS OF SUBJECTIVITY}

Subjectivity, for Levinas, is construed both as a process - of moving out to meet an object-other, and as a product - of negotiation with that object-other. Levinas conceives of the subject as a desire which remains unfulfilled or unsatisfied (Woods, 1997, p. 60). It is here that Levinas' philosophy of the face-to-face encounter and MacCannell's understanding of the neo-nomad traveller, lacking any desire to possess 
and looking to create, can be seen to be contiguous. The imaginative traveller, who accepts the responsibility inherent in the face of the other, will take the displacement of self-understanding that occurs in the moment when the self is contested or disturbed by difference (process) as a moment that holds the creativity they are seeking (product) in the development of their own subjectivity.

Levinas has given us a way to understand the important relationship between the self and the other whereby the self is decentred and how this opens the self to learning and developing new ideas. He has described the encounter with difference where this occurs. 'I love things that seem impossible' goes the Cat Empire's song, but how to describe this complexity of the situated but incalculable, therefore chance, moment of encounter? It is necessary then to look at the philosophical understanding of complexity and multiplicities present in situations of encounter. The historical roots of western philosophy as the search for universal answers makes grasping multiplicities very difficult; in the twenty-first century, Badiou looks at the way situations provide the potential for the creative moment of encounter to happen.

\subsection{BADIOU'S PHILOSOPHY OF THE MULTIPLE}

To understand our relationship to the world in which we travel, reside and function, it must be considered as existing within and because of multiplicities, Badiou writes (2004, p.xiv). In philosophical terms, in order for 'being' to be thought about, to be 'thinkable' as Badiou describes it, our being has to be considered on the basis of multiplicities (ibid). That is, being needs to be understood within of the context in which we find ourselves, the situations in the world we find ourselves in. Each situation, described at any one instant, contains many possibilities. Badiou (2003) explains that a situation is a presented multiplicity of elements, which are non-particularised and undefined; these elements are the basic units of the structure of the situation and the combination of elements produces the occurrence of an event as a 'site' within a situation. In order for the subject to be constituted, what must be argued effectively in the situation of this subject is 'a multiplicity that is anonymous and egalitarian', which is to say that the multiple contributions of the situation are not chosen or delineated by the subject in any way (Badiou, 2004, p.xiv). Response will be chosen, of course, but the constitution of the situation itself is not. In this way, Badiou contends, being is 
expressed through events, where events are sites of occurrences within any situation (2003, p. 10).

When events without assignable causes happen that disrupt the order of established situations and when decisions are taken by subjects to work out the consequences of such events, then new situations emerge as a result, which contain a new subject, that is to say, the subject is changed by the happening of the events within the situation (Badiou, 2003, p. 8). Physicists, attempting to describe the expanding possibilities of a universe in constant change, also struggle with the calculation and prediction, not only of chance occurrence, but also the consequences of chance occurrences in non-predictable processes. Non-predictable processes are those that cannot easily fit into a framework of predictability, probability and thus determination (Lechte, 1995, p. 101). Badiou draws on this mathematical work to examine how philosophy may also view complexity and multiplicities. 'Open System' theory describes a system whose normal state is disequilibrium, transformation and change and contains a fundamental element of indeterminacy (Lechte, 1995, p. 101). In such systems, throw-of-the-dice effects become important, that is, the effects of disorder, chance and random distributions are taken seriously (ibid). If a subject is in a situation that contains disorder, chance and random distributions, then this contains the potential for disequilibrium, transformation and change of the subject. When the radical alterity of the other is acknowledged, then the face of the other is itself an event within a situation that can change the subject. The face brings the unknown and unknowable into the situation. The response to the face pre-exists knowledge of any reply from the other. Action therefore pre-empts prediction. In this way, 'problem' comes after 'possibility'; by making the response first, all of the other could be present in the moment, every possibility is potentially there. The other's potential cannot be problematised. Indeed, Badiou describes the need for finding an expression of 'the possible and its realisation' rather than the familiar paradigm of 'problem and solution' (2004, p. 77). This is reminiscent of Foucault's 'fold', of one constantly referencing back into the other, between the visible and the sayable (Badiou, 2004, p. 77). The boundaries cannot be maintained as being clearly identifiable.

The mathematical theory of the behaviour of complex systems known as Chaos Theory describes the overall behaviour of groups of large numbers of elements, and, similarly to Open System theory, this is a system description which has demonstrated 
instability of prediction when applied to the chance effect of a singular event on an individual. A theory of the multiplicities present in a single situation, Badiou considers, 'requires both a reference to poetry and a basis in mathematics' (2004, p. xv). In order to describe the collection of concepts that are represented in the situation - those of multiplicity, pluralities, being, the event and the subject - and simultaneously describe the unpredictable nature of unlike elements coming into contact with each other, philosophy must retain both the mathematical condition and the poetic condition (ibid). What seems to be suggested is that the ontological description of the multiplicities present in a situation needs to be combined with a phenomenological description of the potential responses of the individual subject, in order to adequately understand the encounter that changes a person. Indeed, Badiou suggests a 'postmodern conceptual assemblage' of the multiple, the event and the 'generic' (by which term he is referring to new forms of knowledge generated) that should be used to transcribe the classical assemblage of being, truth and subject into an effective understanding of complexity (2004, p. xv).

\subsection{Potential AND THE EVENT}

Philosophy has always striven to provide a description of the experience of being. Badiou argues that a description of the experience of being is more a general theory of the event (2004, p. 98). The event, as discussed earlier (4.9), is a 'site' within a situation. The single event can be taken as a 'fragment of being' as it is where any combination of all the elements of the situation is possible; an event is thus marked by the underlying multiplicity of the site (2004, p. 99). In this way, the event is a point of rupture with respect to being (2004, p. 99). Crucially, Badiou explains, the inherent instability within situations harbours unknowable sites, that is, the potential for many events exists. However, the occurrence of an event is completely unpredictable, it is a chance occurrence (2003, p. 27). Within this, the moment of encounter and the moment of creativity can be seen as being sites of a chance event that are located within a particular situation. The movement of the traveller into the unknown is an act of placing oneself in a situation which holds the elements of a potential event. Embodied action in a certain sense creates the event. The embodied nature of being interacts with the mathematically proscribed possibilities; as Badiou says, the relation between 
elementary belonging and partitive inclusion is the key to thinking of the multiple (2004, p. 76).

The subject, then, cannot postulate 'being' as self-generated; rather than initiating being by action, being emerges through a chain of actions within a changing situation (Badiou, 2003). A new subject emerges from the chance encounter of individual and event. 'Chance subverts habits and allows for new combinations and interpretations', Janesick notes (2003, p. 72). The self, then, is constituted through the relation to the unknown engendered in an unstable moment of rupture or disturbance. Further to this, the subject is not limited to the recognition of the occurrence of the event, but extends into a prolonged investigation of the consequences of such an event (Badiou, 2003, p. 6). 'This investigation is not a passive, scholarly affair; it entails not only the active transformation of the situation in which the event occurs but also the active transformation of the human being' (ibid). The event, Badiou concludes, irrevocably changes our relation to the world.

\subsection{DYNAMIC SINGULARITY}

While the event changes the subject's relation to the world, such events are nothing other than chance encounters (Badiou, 2003). For Badiou, the multiplicities evident in a situation cannot be given a unity; 'there is no unified totality that encompasses these multiple multiplicities ... no basic or primordial unity to these multiplicities', and thus a break with the classical unity of being, the essential oneness of everything which allows categorisation or totality is possible (2003, p. 10). Levinas places this break at the moment of the face-to-face encounter with difference: 'The other teaches me alterity ... and this breaks the closed circle of totality ... the imperialism and violence of self-knowledge that would limit the other [and the self] through the imposition of familiar ideas' (Levinas, 1969, p. 171). The moment of Levinas' encounter is synonymous with Badiou's point of rupture with respect to being.

The situation that can be seen to be a highly dynamic, inconsistent multiplicity, contains the unlimited possible combinations that give the potential to the event where the being of the self, the subject, is addressed in the moment of the face-to-face creative encounter. Therefore, writes Badiou, 'We need a philosophy open to the irreducible singularity of what happens ... that can be fed and nourished by the surprise of the unexpected' (2003, p. 55). Such a contribution will allow us to propose a new 'singular, 
not universal' understanding of the subject, 'because it will always be an event that constitutes the subject', Badiou (ibid). The travel choice that places the individual self for potential change can contribute to this. The moment of ethical response to difference can open the self to new worlds of meaning, hitherto unknown and unsuspected. In this resides a potential for wonderment and joy. 


\section{- NARRATive 5: CASUal WONDER •}

Month by month, wonder, joy and delight were casually present. It may have been a widening awareness - an awakening awareness? - but it was an odd counterpoint to the sense of earned therefore deserved reward, or bartered exchange, of the onshore working world. But so often enchantment is diminished by the inadequacies of language, and because of the slow movement of season and time at sea, we were never really sure which month it was, anyway; so these gifts were simply celebrated in the moments they presented.

- It might have been March ...

Sunset glowed across the sea, burnishing the curling, crashing breakers and the distant sandy beach on the mainland. As dusk fell, Griffith Island Light beamed out. The resistant granite base of sandy Griffith Island shelters Port Fairy's entrance from the prevailing blustery southerly weather. The entrance required concentration; pass the island then a swing north in a long arc around shoals and double back to the breakwater arms. Port Fairy now lay before us. Enchanted, we gazed at the silhouettes of tall Norfolk Island pines against the last of the orange sunset sky. Tiny welcoming lights glimmered by the water's edge as we glided into the river. A long, white-painted, wooden wharf lined one side of the river, where evening strollers and a fisherman shared the quiet dusk. Children's voices drifted across the water from a playground, and warm-lighted windows showed friendly in houses fronting the now-shadowed river. Port Fairy's gossamer magic caught and held us.

Secured and a swift tidy done, we abandoned Oblion for the enchanted shore. Right now the girls were aiming for that playground while Stuart felt in desperate need of icecream. I was happy to go anywhere. For me, a bend in the road, a rocky headland around which you can't quite see, a track disappearing up a hill or an intriguing glimpse down a valley are irresistibly enticing. We meandered along the wharf, into the playground and back through the town until, everyone satisfied, we returned to Oblion to fold and stow five sails while the girls settled at the table with a more familiar magic of coloured pencils and paper. 
- $\quad$ Later on ...

'Ian told us about Cape Bridgewater didn't he?' I asked Stuart. We were sailing briskly and would clear the Cape by three miles. 'He said something about a big cave and seals.'

'Yes,' replied Stuart. 'But it means turning across the swell to go in and come out. And we want to get to port today.' There was a pause ... The purpose of embarking on this adventure was to experience the world, not tick off a list of destinations as fast as possible, wasn't it?

'Prepare to gybe,' said Stuart. Half an hour later we were in the lee of the towering headland and the swell dropped right away. The chart indicated deep water close under the cliffs but, all the same, we approached the eastern point of the Cape gingerly under engine power. Three capes - Bridgewater, Nelson and Grant - jut like fingers from the end of a promontory which divides long Discovery Bay to the west from Portland Bay to the east. Ancient volcanic activity had lain a huge basaltic plain over much of this area and a massive black basalt platform is prominent at the base of the Cape's 120-metre limestone cliffs. Following the cliffs and curving away eastward is a vast and beautiful bay backed by rounded sand dunes that curve, then fade, then rise to Cape Nelson.

The sea surged around the basalt platform and the boulders strewn along it. The cave was there - big enough to take Oblion, though maybe not all of the twelve metre main mast. A deserted power boat was anchored close by the mouth. We puttered slowly closer. Suddenly four sea lions slipped off the platform where they had been lying unobserved. They came swiftly through the water and swam once around Oblion before arrowing back to the rocks, their light brown bodies easy to see in the clear water. The girls, up on the long bowsprit, clung to the railing and called in delight. 'Did you see? Did you see?'

The reconnoitring party must have returned a favourable report for there was an eruption of sea lions from the rocks and platform, sliding and flopping into the water and heading for Oblion. Stuart dropped the engine to neutral and put Oblion into a tight circle, her stern turning to the cliff just as the sea lions arrived. Elizabeth scrambled to the afterdeck. 
'Mummy, look!' Sea lions tumbled around Oblion, rolling and diving. They leapt out of the water like dolphins and swam under the boat as we turned to circle back, swapping direction effortlessly to catch us.

'Mummy, take a photo,' begged Alison.

'It won't work with our little camera and them in the water.' Our small automatic camera was capable only of quick snapshots.

'Please, Mum!' I gave in to the eager faces.

Two round, black heads appeared near the rocks. Masks distinguished them from the sea lions.

'Divers,' Stuart pointed. 'That explains the power boat.' The Cape is a popular diving spot though not easily accessible. We waved enthusiastically and a black wetsuited arm waved back before the two heads disappeared underwater.

We could now see large groups of sea lions along the rocky platform, basking in the morning sunlight. Up to three hundred sea lions can be found in the colony, one of several along this coast. Our attendants escorted us as we turned to move out across the bay bound for Portland once more. The girls hung over the stern until they left us, leaping and cavorting still, heading back to their sheltered colony. Elizabeth and Alison were so excited they ate a whole packet of BBQ Shapes biscuits between them: Oblion took up the resumed course and we settled to another day at sea.

- A few weeks later ...

My diary: we are not moving today. Friday and the 13th - I am not superstitious but boats is different! Under sea-lore, leaving port on a Friday is to be avoided as it brings bad luck. Instead we invited the older sailing couple moored nearby, to afternoon tea. Following an impressive afternoon tea experience on a German couple's yacht earlier in the month, we had bought a white dinner set, an unbreakable white dinner set, should I add? Oblion had good quality plastic plates, deep bowls, and plastic drinking glasses but having been set a precedence, I now served cake on white plates with paper doilies and tea in cups with saucers. This couple were in their eighties and still sailing the coast - they made us feel like babies. They enjoyed their tea though. 
Afterward, Stuart went up the mast to add a second halyard. Steps reached to the top of each mast but it was difficult to work from them while holding on with one hand. For this reason, Stuart had packed his old trapeze harness from dinghy racing days and now he had rigged a safety line for himself before getting me to hoist him up on the main halyard. He was working on the masthead block when school finished for the day and the local kids rode their bikes down to the jetty to catch up with the world. The kids stared down at Oblion with unabashed interest. Being low tide, Stuart, at the top of the mast, was on eye-level with the jetty.

He asked the bunch of kids if they knew how to get oysters off the rocks that he had noticed earlier. They were amazed. Surely everybody knew that? When he shook his head, eager explanations tumbled down from the jetty and fierce arguments broke out among them as to the best way.

'You'd better show me,' said Stuart, the greedy oyster-lover. Abandoning the halyard work, Stuart was down the mast and up on the jetty in a second. The kids deserted their bikes to follow him along the beach - a Pied Piper affair of chattering, hopping kids and one scruffy sailor. They disappeared round the long curve of shoreline, arms waving and voices piping into the distance. Some time later, a cheerful Stuart returned with three oysters and a blunt knife. 'They eat them straight off the rocks at the far end of the beach,' he said, 'and I learnt how to prise them off. But I'm not sure I'm game to try them. I've seen what goes into the water from the trawler moorings opposite!' He looked rather dubiously at his collection and we broke into laughter.

- And then ...

The day was made for sailing. Genoa, main and mizzen all soared, full and white, above the deck. We sailed a gentleman-sailor's broad reach in glorious sunshine, blue sky above and the sea sparkling in our wake. I sat dreamily on the afterdeck while Oblion rose and dipped over the waves. There would be no need to dry out the forepeak or wash salt off the foredeck today. Stuart pottered around contentedly. The strange railing by the mainmast had become known as the walking-frame and was very valuable for bracing against when working the winches or to tidy away spare lines as he was doing now. The girls sat together on the leeward deck, feet dangling over the side, bodies and faces pressed against the safety netting. As Oblion dipped, their feet were 
submerged, producing squeals as they kicked the water. This became a popular position for good days at sea, along with wrapping up in a blanket and lying along the sunniest sidedeck, reading.

'Mum!' Elizabeth climbed quickly into the cockpit; Alison and Dad had gone below to make lunch. 'Mum! There's a budgie on the mainsail.'

'What?'

'There's a budgie on the mainsail.'

'There can't be: we're five miles off shore.'

\section{'Look!'}

I clambered forward to peer around the mizzen which blocked my view. Sure enough, clinging to the leech of the mainsail was a little jewel, glowing blue and green, the budgerigar. 'Hey Stuart, come and look!'

The budgie fluttered to the mizzen sheet and looked at us. Elizabeth anxiously crumbled a piece of bread and scattered it on the cabin roof. Budgie didn't move. 'He must be hungry, Mum, he's flown a long way.'

'He's probably seasick,' I said drily.

'Where did he come from?' Stuart wanted to know. 'What's he doing five miles out at sea? There's not even another boat in sight, either.' The budgie hunched his little shoulders as he swayed with the motion of the boat.

'We could keep him, Mum. We could keep a bird on board.' Months earlier, suggestions of guinea pigs and goldfish as suitable onboard pets had been quashed, firmly. Now Elizabeth was desperate to catch the budgie, producing her crab net to help. But where could we have kept it? We had to dissuade her.

The budgie stayed for half an hour or so, then flew off across the waves. Elizabeth watched until she lost sight of it but we were none the wiser as to how or why it ever came to be resting on Oblion.

- A better place for birds ...

A number of yachts were moored to the bank of the river while waiting for bad weather to clear, before setting back out to sea. I was tugged from dreamless sleep by 
liquid notes. The soft light of dawn washed the cabin and the river sang a faint, murmurous song past the hull but that was not what had drawn slumber aside. I lay quite still, in the half-and-half state between awake and asleep, wondering if in fact I had heard anything. Then the smooth, luscious notes fell again, so beautiful I lay in open-mouthed wonder. They were repeated, the cadence exact, the sound warm, belltoned; what bird produced it I didn't know. I listened as the light swelled, unable to stir Stuart awake for fear of losing the song and the singer, absorbed by the radiant sound. Long after it finished, I lay, still enthralled, memorising the notes. When I woke again, it was to the sound of the kettle whistling and Alison asking for the Vegemite. No-one had heard anything unusual - and could their new sailing friends Amy and Jack come over, after lessons were done?

Amy was free after lunch: the four kids climbed the gnarled trees lining the top of the bank. We could hear their voices but they were hidden from view except when trying the vantage point of a neighbouring tree. Parents, returning from a shopping trip into the local town, were successfully ambushed before the gang raced off to swim. I happened to mention the early morning birdsong.

'I heard it!' Mark, Jack's father, turned to me. 'It's the Pied Butcher bird and it's really something, isn't it? Beautiful.'

I stared in amazement. Mark threw his charming, disarming grin at me. 'I've got a book you can look it up in, if you want.'

'So have we: now that I've got a name.' What Bird Is That, the classic guide to Australian birds, told me: Distribution - throughout most of Australia except the south, which explained why I had never heard it before, and Voice - Superb: its notes are among the most melodious utterances of all Australian birds. Indeed.

- And dolphins, always ...

Oblion flew blissfully along under mainsail and jib. Suddenly, dolphins arrived, two adults and a baby, to joy-ride the pressure wave of the bow. We hung over the bowsprit railing, laughing as they dipped into the wave, rolled away, re-appeared, swapped, and seemed to laugh back at us. Their grey, streamlined bodies kept pace with Oblion seemingly without effort, the water glistening around their dorsal fins until, with a cheeky flip of the tail, they dived and disappeared. 
Alison disappeared below a few moments later, returning with the song book. 'Let's sing. They might come back!'

The girls chose The Gypsy Rover, with its strong rhythms and story of requited and defiant love. The trolling line whirred its news that dinner was on the hook and off to port the hinterland was gaining height as the Dividing Range drew back toward the coast, having retreated 150 kilometres inland to incorporate the Blue Mountains. The coast showed a series of interesting headlands backed by forested inland hills and isolated peaks. Ahead lay 'a breakwater harbour of diminutive size' tucked in the lee of Crowdy Head, itself a distinctive wedge of rock promontory up ahead. With that irresistible description, how could we sail past? The sunny day and brisk wind put everyone in a good mood and the ah-de-dos of The Gypsy Rover chorus trailed out over the water in Oblion's wake.

- $\quad$ Island gifts ...

The soft dirt track led away from the tiny beach into Fraser Island's aromatic forest. Tall Kauri pine stretched above, blackbutt and bloodwood trunks rose out of a scramble of fern and brush. Satinay trees also grew on the island but their timber was soon known to be resistant to marine borers and had been well harvested during the years when timber felling was allowed. Skink trails showed in the fine dust of the path, tiny footprints astride the tail-line. The forest gave way to bushland of sheoak and paperbark where sunshine fell strongly on our shoulders after the leaf-patterned shade. Here banksias in bloom attracted the attentions of honey-eaters and a tiny robin hopped briefly in and out of view. Pigeons whirred away to safety and the hum of bees was strong. Where the bushes thinned out to be replaced by grasses, pink wax flowers and the tiny purple flowers of bladderwort peeped out. A log bridge across the creek led on to where the bush resumed with the forest canopy crowding beyond. We turned to follow a snaking trail to the creek bank.

The sedges grew thickly. A kingfisher flashed past, bright green plumage brilliant against the grasses. The creek, its water strained glass-clear by its seeped passage through deep layers of sand, poured past endlessly, swiftly, chuckling and joyous here, silent and smooth there, down through grassland and forest to the sea. Yabbies lurked in full view on the bottom, Alison begged her daddy to play Pooh Sticks at the bridge, Elizabeth bemoaned not bringing a bucket. The warm, still air pressed 
everything into afternoon somnolence - except the mad humans. Feet dangled into sweet water for once while sandwiches were alternately fed to mouths and yabbies.

- Ocean gifts ...

With their intriguing names, Finger and Thumb Rocks called like a Siren song. They made a line to the infinitesimal gap of further horizon between Goldsmith and Linné Islands ahead. Either side of these islands the horizon lay broad and clear, but that small space held all the allure of goldfields. I was under the compulsive influence of 'what's around the corner?' again.

We were preparing to depart Brampton Island's anchorage, then, as the yankee caught the breeze and the bow swung away from the shore, Stuart grasped my shoulder. We both saw it, the humped, black back of the Brampton dugong - just the back, twice, as it browsed along the shore. It was a fine farewell gift.

The line provided by Finger and Thumb rocks held us to clear water and Oblion, with dinghy Bea in tow behind, sailed up the in-drawn embrace of the converging shores. The narrow passage of deep water squeezed to a Victorian era waistline between the two lovely islands. They both modestly decline the urge to dramatic scenery, instead having softly rising hillsides with eucalypt-green shawls and the merest ruffle of petticoat white showing at the shoreline. On the other side we laughed in amazed delight at the vista of islands: the rest of the Sir James Smith Group close to hand, Lindeman Island further ahead and the Whitsunday group beyond. It was like being a child, suddenly placed in the middle of the pile of Christmas presents and told to start opening. Which to choose? That one has beautiful paper, that one looks good, oh that one has the biggest bow. We were picking up one island and putting it down to reach for the next.

- Response to the moment ...

Receptivity also brought moments of inexplicable certainty, intuition if you will. Hearing and listening to the insistent voice - was this more possible at sea? Was there less of the aberrant and useless 'noise' that distracts attention from subtle awareness? Whatever it was, superstition and the sea go hand in hand. Sailors listen to that voice: it is talking the specificity of this moment and you, right now, here. By the time I found 
myself skippering Oblion southward, with an imposed timeline from my contracted crew, I at last knew to listen.

The coast was out of sight, thirty-five miles westward. As the day drew in, I cooked up a sausage hotpot and deliberated on our own course for the night. The fair conditions encouraged continuing but, though much moderated, the wind was still endlessly from the south-east, just where we needed to go. The choice was a course thirty miles eastward to take us outside High Peak Island, adding at least seven hours before we could resume a clear course in the direction we wanted, or to run south down the inside passage with High Peak Island and its sectored light to port and the unlit Duke Islands to starboard. This rock- and islet-scattered twenty-mile passage was considerably shorter. I chose the latter.

At 2000 hours the girls and Mana were asleep, Mana preparatory to coming on watch at 2300 hours. Bending over the navigation desk, the position I plotted at 2045 put Oblion well clear of Hannah Rock and progressing nicely. I returned to the quiet night and the darkened cockpit, to find the autopilot had disconnected again. It had been temperamental during the last hour or so: wiggling the plug produced temporary compliance but only for a few seconds. That felt like a wire was loose in the plug. Oblion continued serenely through the night while I disconnected the autopilot and took the wheel to consider how best to manage this. I could lash the wheel when I next had to go below to plot, that would work. Or I could wake Manna and we could do a joint watch overnight. Or I could just continue for the moment. Even as I thought, a growing unease made itself felt. I did a slow, 360 degree scan of the darkness around Oblion. Nothing seemed untoward, no sight or sound of fishing trawlers. Ships did not use this passage yet the unease was becoming insistent. Check your position, said a voice in my heart. The course was set to keep Oblion well clear of known hazards, but the voice was demanding now.

I listened. The wheel went over, Oblion was suddenly running off the wind westward, where I knew there was immediate clear water. Mana shot out, hair tousled, roused instantly by the changed feel of the boat.

'Steer due west,' I ordered and dived below to the navigation desk: explanations would wait. The plot placed Oblion close - too close - to Low Rock yet I had seen and heard nothing to indicate the presence of anything in the water. Our present course was taking us away from the immediate danger and I rechecked my readings and plots 
before going up for another visual check. Mana said nothing as I searched for audial or visual indicators. I could find none. Down to plot the current position, which looked much more reassuring, and up to set the new course and then I was able to tell Mana what happened. During the forty-five minutes between autopilot failure and my sudden action, Oblion had been set one and a half miles west. A tide annotation indicates a west-south-west set of one and a half to two knots at the flood in the immediate area. Hand steering to a compass bearing does not show up such a set, only when the course is plotted on chart or GPS can it be seen. This time I had rightly trusted that little voice, wherever it came from. Mana and I shared the rest of the night hours together, though the next 'rocks' were Cheviot Island and Steep Island, and at eighty-eight and a hundred and forty-nine metres respectively they were not likely to remain unseen. The autopilot would wait for daylight.

- $\quad$ Shared joy ...

When Pete and Jenny's yacht and Oblion were both well-settled to anchor in the northern bay of Curlew Island (close to the Great Barrier Reef), it was all ashore in acceptance of Pete's offer of a Curlew Island Walking Tour, departing whenever all have gathered and at a cost of bring your own lunch. Ours consisted of boiled eggs, cheese sandwiches and bottles of water.

Dappled light flickered filigree under the trees; it was as if we were taking a walk underwater. Pieces of blue sky had fallen through the leaves and taken wing to flit about the shadows attached to butterfly bodies. A multi-textured flaking bark textured the paperbark-tree uprights holding the sea-like roof above. The ground rose, we broke out from under the trees upon a shore of hillside, cast up on to deep grasses rippling fawn and green and studded with wattle clumps. Pete's dark head bobbed strongly forward borne upward on long-strided impetus. A straggle of hats bobbed in his wake, eddying, diverging, but drawn willy-nilly along. Over a ridge and down into a bowl of deep cream grasses, hissing quietly in the breeze. The partridge shot out from the grass by my foot - the shriek shot out of my mouth almost simultaneously - and the panicked, clattering beat of the bird's wings matched perfectly that of my heart, both fading away gradually into the bright sunlight. Enough that I could hear the loud laughter of my family as they rolled about on the hillside, arms wrapped round aching sides. Humph. 
The partridge and I sought to settle our respective ruffled feathers at opposite ends of the island ...

On the far side of the sun-filled bowl, the back of Curlew's peak rose up: on the sea side it rears 159 metres almost directly up from the sea to form the south-eastern corner of the island. Here I could see it lifted steeply to a plug of rock. Steep slope meant hard breathing, so the laughter eventually quieted to panting breath and conserved conversation. The grass ran up to break upon rock and scatter handfuls of tussocks as a wave scatters foam over a rocky shore. Those tussocks of tough spinifex grass were useful to those of us trailing in Pete's wake. Looking over my shoulder I could see the sun-drenched bowl below, the grass slope beyond and the darker bush covering which reached out over the rest of the land. The peach-slice beach and bright aquamarine water of our anchorage peeped over the ridge we had climbed earlier: I turned my attention back to the girls and keeping my footing. Time to look properly soon enough. The final rock summit loomed in cool shadow against my left shoulder. Pete had disappeared up ahead followed by Jenny and Stuart. I could hear the girls voices ahead also. The step around onto a brilliantly sunlit ledge was unexpected.

'Mummy! Look!' The girls were perched about a metre above my head on the top of summit rock. The others were shedding rucksacks in preparation for lunch. The two-metre-wide ledge ran around to merge into the seaward edge of the ridge but I caught my breath at the view directly down which showed steep slope plunging to cliffs and the sea. I stopped breathing altogether momentarily when I lifted my gaze to the view outward. Sapphire sea to the horizon, serene under azure sky, islands sharp nearby and hazed to deep blue smudge far away, clear air to give eagle-view of unblemished beach, dainty, silent, lace-trimmed. I traced with mind's eye our earlier passage from the south, and gazed and gazed, turning slowly to take in the almost 360 degree view. The Percys there, the Bedwells far away over there: Oblion was not visible, half the bay being out of sight behind the ridge.

'Mummy, can we have our sandwiches up here?'

Dragged back to practicalities, I passed around food but paused with the camera in my hand. Thoughtfully, I turned over the idea: it would work, I was sure. The subsequent series of over-lapping photos make a sixty-centimetre panorama of that beautiful view. 
After lunch we followed Pete down the coastal spur. Deep springy grass smothered the island side of the spur, providing a bouncing mattress for the girls to leap into, arms outspread and faces alive with laughter. From the ridge we could see down to our respective yachts at anchor, then it was back through the butterfly-filled bushland and over the rocks to the far end of the beach, where we surprised the little black periwinkles into snapping shut with tiny 'clicks' in alarm at the vibrations of our approach and falling off their rock perches in consequence. Laughter gave energy to tired feet, unused to all-day shoes. Those same feet were grateful for the cool sand and skipped in and out of the waves, in no hurry go anywhere than here. This was living beauty ... 


\section{Travel For Change: SubJEctivity AND WONDER}

\section{- Summary}

The conjunction of alterity, the event and the responsive self in the moment of encounter allows fresh combinations of elements of the experience to form new conceptualisations and ideas. The subject then has a changed relationship to the world through the development of new meanings for their being in the world. In this theory Section, I suggest that the other (alterity) and the event (multiple in the situation) are formative of the subject and that this is, therefore, a contribution to Badiou's (2003) call for a new understanding of the postmodern subject - one that reflects the role of alterity and multiplicities.

Differing critical approaches to the subject are discussed and the disciplinary approaches of cultural studies, sociology, literary studies and philosophy (contributors to examining the travelling subject in this thesis) are examined for their contribution and their limitations to current theories of the subject.

In the previous theory Section, Levinas $(1969,1998)$ provided a phenomenological understanding of why the moment in travel can offer a relationship with the other while Badiou $(2003,2004)$ provided an ontological understanding of how the moment contains the potential that makes each encounter with the other unique. I suggest that, because both the other and the multiple are required in concepts of the subject and understandings of subjectivity, both phenomenological and ontological understanding of the subject are required to contribute to a theory of the subject that is contemporary. The juxtaposition in philosophy, of addressing both generalities and the significance of powerful individual moments in making our subjectivity, is explored in critical-creative writing in Talking of Great Matters, before new ideas of the subject are discussed.

Finally, I propose a new model of the subject that is commensurate with the travelling subject we have been following throughout this thesis. This model supports the travel theories discussed earlier in this thesis. MacCannell writes of the 'spiritual reach of the touristic consciousness' through which the tourist does not try to contain everything in himself, but instead incessantly transgresses the boundaries of his own existence (2000, p. 175). Clifford understands travel as a condition of living, one that is inseparable from dwelling, and as a search for 'difference, wisdom, power, adventure 
and an altered perspective' that lets uncontrollable, unexpected things occur; as such, travel is a crucial site where being human is constituted by displacement (Clifford, 1997, pp. $31 \& 90$ ). Both place the study of travel as offering access to recognising the subject as situated in, woven through, and developing from joyfully embraced multiplicities.

\subsection{ALTERITY AND MULTIPLICITIES - BEING IN THE WORLD}

The unknown as destination, from the preceding discussions, is chosen for the increased opportunity for changing the traveller's individual perception of the world, that is, their subjectivity. This occurs because the nexus of alterity, the event and the responsive self allows fresh combinations of elements of the experience to form new conceptualisations and ideas. The traveller subject then has a changed relationship to the world through the development of new meanings for their being in the world. Hence I suggest that the other (alterity) and the event (multiple in the situation) are more than formative of the subject, they are integral to the subject. It is our being in the world, as an integrated material and cognitive entity, that is informative of our being in the world. The subject can actively access embodied experience for developing the understanding of their being. This then becomes a contribution to theories of the subject and Badiou's call for a new understanding of the postmodern subject (2003, p. 55).

If the subject is an ongoing development through moments of a conjunction of self, the other and the event, the occurrence of these moments is unpredictable - the situation and the outcomes are unpredictable occurrences. The moment exists as potential; does this mean the self also exists as a potential alongside its current being? Badiou deals with the potential of the event through an ontology of mathematics. Levinas deals with the potential of the encounter through a phenomenology of responsiveness. We need a philosophy of the self that includes both of these. Change and potential are interrelated; accepting change means accepting the potentialities inherent, even when undefined and non-limitable. Constant change is often declared as the everyday condition of postmodern living; certainly, the acceptance constant change can be recognised as advantageous toward living fully within a world which exhibits continual evolution - physical and social. To live with no change would be to remain in 
a fixed relationship where all elements of a situation are constant in their correlation with each other. Here the subject would be as fixed as all other elements, with no possibility of change or growth. Since this seems impossible when we consider the constant dynamism of the world in which we live, the potential within change must therefore be able to be incorporated into, or reflected in, understanding the subject. The subject, we need to acknowledge, is also a dynamic, constantly changing entity

In terms of actions within situations (such as the traveller's choice), an acceptance of multiple 'solutions' in our way of dealing with the world is inherent in a situation of constant change. It is problematic to demand a definitive right or wrong way of seeing our place in the world; rather, acknowledging alternative pathways and choosing under varying criteria (for choice still has to be made, we cannot embrace and enact all options simultaneously) allow tailoring solutions to the individual situation. Thus choice becomes an identification and assessment of desired outcomes that will be paired to a pathway that fits for this particular moment. Next time the situation will be different and another consideration of the possibilities presented will identify a new conceptualisation or pathway. There is an infinite 'try this'. It means that 'particularity and the singular have significance' (Bernstein, 1991, p. 58), that the individual action and the specific situation must be taken into consideration and not treated as exceptions. It means metaphysic's practice of privileging one solution or answer over all others becomes meaningless, since the oppositional structure is incommensurate with multiplicities. Instead, we work in and with 'preferred', 'chosen', a 'moving toward' which do not fix needs and situate outcome for continual re-assessment. It allows for the dwelling in moments of wonder of Narrative 5.

\subsection{THINKING THE UNKNOWN}

Making connections between disparate or diverse elements in an imaginative way is the process of creative development of new ideas and conceptions, as noted in 3.5. While this comes under a variety of names, including reflection, intuition and narrativisation, traditional concepts of employing a process of reasoning to make those connections are predicated on using current knowledge in a consideration of what is being presented. This does not allow for the reception of what is being presented and a subsequent thinking that employs this new knowledge in the process of that thinking. Without accepting the new that is presented and using it to become part of our thinking, 
there is no possibility of enabling a new figuration that then lets what we know expand. 'The object of reasoning is to find out, from the consideration of what we already know, something else that we do not know' writes Johnson [emphasis added] (1987, p. 19) What Johnson is expressing is, however, a form of metaphysic's reduction of the other. His understanding limits the new to fit into the individual's established parameters. For Levinas, generalising what is presented in the situation:

... does not only mean, in all innocence, their comprehension, but also their being taken in hand, their domestication, their possession. To possess is, to be sure, to maintain the reality of the other one possessed, but to do so while suspending its independence. Reason, which thus reduces the other, is appropriation and power. (1987, p. 50)

Applying current knowledge through a process of logic to understand new experience as it occurs is the classical process of reasoning. I suggest that, while the application of current knowledge using logic and reasoning can be valuable in the construction of meaning, it is not applicable for understanding the kind of experience travellers seek to access through the unknown. Rather, the experience, the meeting with the unknown other, provides multiple views, angles or ways of referencing - and these are employed in the consideration that immediately follows.

In the process suggested above, understanding and meaning are not generated through interpreting what we are given in encounter with difference, but $u$ sing what we are given in the encounter. Thinking is not done only with what the individual already knows but uses the new. The product of that thinking cannot therefore be anything other than new. That particular combination of understandings has never before existed. Employing what the other has offered is the pathway to new ideas and knowledge - this is the process of creativity. It suggests a contribution to Badiou's (2003) call for a contemporary subject because within this process, the other's difference is incorporated into the individual's thinking but the other's alterity remains.

At the start of this thesis, attention was drawn to a number of references made in tourism literature to 'something that happens in the spaces of travel' that 'impact on the self in some way'. These observations of development of the self 'in some way' can now be understood as changes in the individual's subjectivity through an active process of engaging in travel. It is an illustration of the contemporary subject as a dynamic entity within complexity. In philosophy, structuralist, deconstructuralist and post- 
structuralist positions produce different readings of the subject and these are important to this discussion of a contemporary subject.

\section{3 - CRITICAL APPROACHES TO THE SUBJECT}

The structuralist approach holds individual subjectivity as an internally located but culturally responsive self-consciousness. For Levinas, however, the subject is emergent from il y $a$, from presence. Levinas holds that, through empathy with the other - that is, through intersubjectivity - the model of subjectivity is 'modified from knowledge of existence into a knowledge of the nature of that existence' (in Simms, 1997, p. 8).This breaks from the structuralist understanding of the subject as being created by the social and cultural systems in which the individual is placed. For Levinas, this structuralist viewpoint has its focus on underlying (Universal) principles and causes which shape the subject and which, while it decentres the humanistic position of self-forming, centralised individualism, takes attention away from individual human consciousness and choice. Through the relationship with the other, individual human consciousness and choice have an active role. The self is the locus where alterity makes contact, not as a metaphysical locus engendered by the inner being 'for its own exhibition' but as created by this contact, Levinas argues (1998, p. xxii). The exposure to alterity as such - an openness opened by the outside - is at the basis of the manner by which the subject opens itself, Levinas says; importantly it is not, he is careful to make clear, that the outside is a metaphysical inside, for this would reduce the other to serving the organising self $(1969$, p. 13).

Deconstructionist approaches contest the relationship of subject and system. If the system forms the subject, it could be said that the subject is a passive participant in the process through allowing her/himself to be formed (Gubrium \& Holstein, 2003). The subject is required to 'be' before the system can be enacted upon them. However, phenomenological philosophy highlights the contingency of all human arrangements and concepts in the relationship with difference (Leith, 2001, p. 22), challenging notions of the subject as passive. Foucault considers practices of self-formation of the subject 'an exercise of self upon self by which one tries to work out, to transform one's self and to attain a certain mode of being' (in Starkey \& Hatchuel, 2002, p. 644). Deleuze and Guattari (1987) argue that the subject is marked by 'becomings' - defined as processes 
of constant renewal and change that constitute an irreducible openness toward the new (Symonds, 2006) - such that the self is intersubjective with context and difference.

The more recent developments of post-structuralist critique have moved the focus onto subjectivity as process rather than product (refer to 4.7). In this, poststructuralist approaches understand subject positions and places to be constituted within and through discourse. For Butler (1990), the self is not the essential rational 'I 'or binary opposite of objective/subjective concepts of self, but many subjectivities which are politically constructed (refer to 4.4). The individual is 'always-already' a subject constituted by discursive practices and by language, Butler argues (1997); subjectivity, then, is a process of 'becoming' through repeated acts and this process opens up possibilities for the self to grow and enlarge (Wearing, 1998, p. 55). The subject is better understood as 'un-centred, un-certain, not entirely present, not fully representable ... this is not a self that can be revealed by a process of self-reflection' alone (Rose, 1997, p. 314). For feminist post-structuralist analysis, the subject is seen as 'split between the social through which we emerge and the corporeal life we lead' (Dean, 2005, p. 60); these aspects of subjectivity are in continual flux, 'conditioning our emergence [and] our ability to recognise and be recognised' (ibid).

\section{4 - DISCIPLINARY CRITIQUES OF THE SUBJECT}

Further to critical approaches, different disciplines bring varying foci of interest to understanding the subject. Cultural studies, sociology, literary studies and philosophy, already contributors in examining the travelling subject, have particular relevance in this discussion.

Cultural theory, as demonstrated in feminist post-structuralism above, holds that the subject cannot produce her/his own self but that the subject is formed from discourse and the surrounding cultural values and norms. Subjectivity is dictated by the social politics of knowledge, in the Foucauldian sense of knowledge in its relationship to power and institutional management. Practices of subjectivity are not something that the individual invents, Foucault asserts, they are patterns that are proposed, suggested and imposed on him by his culture, his society and his social group (1988, p. 11). For cultural studies analyses, subjectivity involves three things - the unconscious, social forces, and the multiple subject positions that each individual occupies (Leith, 2001, p. 28). 
In contemporary cognitive theories used in the social sciences, subject formation is viewed as convergent with experience. The focus in sociology and anthropology, for example, is on lived experience and holds that the subject is identified through language which directly reflects subjective and lived experience; the literal translation of talk thus equals embodied experience and its representation (Denzin, 1997, p. 5). The cognitive subject exists independently and is capable of self-representation,

While language is central to the subject in social science's discourses, literary theory places language and the subject in a different relationship. Literary analysis moves between three aspects of the subject: the formal grammatical subject, subject as subject-matter, and authoring of the subject. These each establish particular relations which retain a narrow analytical focus. The formal textual subject is always opposing or situated opposite an object; the subject as central matter of literary production questions the origins of self-knowledge; and because the subject is always formed in and by language, the author's presence is 'ghosted' into any representation of the subject.

Philosophical consideration of the subject addresses issues of consciousness, self-awareness, identity, agency and self-determination. These are approached through either ontological or phenomenological frameworks in western critical analyses. While phenomenology looks at the subject as realised through consciousness and experience, the ontological subject is held to be formed in and of the mind, separating mind and body of the self. The core debate is whether the subject exists by itself, having an identity of its own, or as an entity 'necessarily existing in relation to the world' and whose identity is constituted by these relations (Fløistad, 1986, p. 2). In the vernacular, this is the 'nature versus nurture' debate.

How is a subject, who consciously places the self to affect subjectivity (as it seems the traveller who chooses the unknown does), then reflected in theory?

\section{5 - LIMITATIONS IN THEORIES}

The examination of how the subject is, indeed, formed in part by unpredictable, multiplicitous events adjunct to the moment of encounter with the other, challenges these theories and discourses of the subject. Something else is required of the various constructions of the subject as outlined above; limitations become apparent. 
Cultural theory, in emphasising social and cultural forces, has little place for the subject's processes of choice and responsibility which are enacted within those forces. It has already been noted in 3.5 that Foucault found it necessary, in his later writing, to address his earlier observation that some individuals resist such forces and constitute their own subjectivity in some manner. Cognitive theories deploy the independence of the subject through the emphasis on the subject's individual self-expression and drawing on this to represent the cultural whole. The significance for the subject of the interaction with the other is not clearly considered. Literary theory works in the realm of language construction of the subject such that the role of embodied experiences in the formation of the subject is excluded. And all three remain trapped in binaries - a Cartesian residue in postmodern thinking; subject and society, subject and observer, subject and object.

The oppositional philosophies of ontological and phenomenological views of the subject polarise the question of whether the subject exists by itself, or in relation to the world. Ontological discourses that exclude relational and embodied aspects of the subject create difficulties; there is no opening for self-identifying relationships (for example, familial) or embodied expression to be included even when it is a core subjectivity for the individual. Levinas holds that such ontological separation is a philosophy of power (Islam, 1996, p. 88) as it establishes certain relationships with the world as being not just of little but of no consequence in the figuration of the subject. Phenomenology directs attention to the social construction of intersubjective reality through interaction of subject and world.

The question needs to be asked - why must these views be mutually exclusive, in the mathematical sense of having no shared areas? At the very least, there is a shared interest in understanding the subject. There is a need, as Badiou expresses it, for reconciling 'doctrines of the subject' (2003, p. 3).

\subsection{REQUIRING A NEW APPROACH}

'In the contemporary world, the subject can no longer be theorised as the selfidentical substance that underlies change, nor as the correlate of an object', writes Badiou, for 'we now live in the multiple' (2003, p. 3). Multiplicity and the other must be recognised as integral to the notion of self (Garlick, 2002b, p. 301). Understanding the subject then requires weaving the experiential aspects of corporeal existence closely 
with processes of the mind. I suggest that because both phenomenological and ontological approaches contribute to understanding the traveller's choice of the unknown, both are required to work together to fully theorise the subject. Both ways of knowing the subject are required to contribute, to work collaboratively, in order to provide a more fully dimensioned picture of the subject. Without this, the risk is of repeating metaphysic's reduction, of offering 'a new form of one best way' (Starkey \& Hatchuel, 2002, p. 654).

The phenomenological and ontological understanding of the creative moment of encounter with difference that alters subjectivity - as per the moment in travel that encompasses more than desire and object - will enable a subject as interactive in selfknowledge and their experience of the world through a process of constant change. As in the use of those beams of light on a sculpture, where greater dimension is revealed while the object is not reduced or changed, both phenomenological and ontological understanding of the subject contribute insight such that theory can demonstrate a greater acumen. Through accepting that subjectivity requires phenomenological and ontological coexistence in theory, we may be able, as Badiou desires, to 'install philosophical thought at the periphery of art and propose a mixture of the conceptual method of philosophy and the sense-orientated enterprise of art' (2003, p. 44).

And there is space to express the experience of wonder and intuition in engagement with the world.

\section{- TALKING OF GREAT MATTERS -}

A final talk of great matters, of profound matters, in this research journey. Yet a phrase repeatedly whispers: 'a leaf falls ...' Small things and big things; the authoritative generalisations and the powerful individual moment of significance. In this is a relationship of difficulty, for philosophy recognises both and seeks to address each, while battling an entrenched polarisation. Ideas are implicated in materiality which is implicated in ideas. This thesis slides between polarisations: the experiential voice of material travel; the thinking voice of ideas; the questioning voice of exploration. Ideas form in the body of the mind will that perhaps encapsulate the new? How difficult it is to talk with authority about a personal, insubstantial, culturally bounded entity, the 
'self', that is subject to multiple readings. Individuality, agency, identity, self, subject - a confusion of interpretations, in part because we are human beings unpacking the human. 'We' are not an abstract concept. 'We' live, and feel our thoughts, feel our ideas with body and emotion. The moments in travel that every traveller is familiar with the ones that thought returns to, the ones that are recorded in nonerasable sensory brilliance - these are incorporated into the self and, inscribed there, influence this individual's response to the world. Can it have a name? I like 'Presented Wonder'. The choice to develop new ideas, to see things differently at a personal level, within the framework of individual receptivity, has other names, too, such as 'the butterfly effect'. Such moments are like the oyster's unsuspected pearl - it lies in the hand for a brief interval of focussed, entranced, immersion. The moment envelopes the self, context, other; the world stops. The soul lights up, the heart is enthralled. Such moments live forever in reminiscence, brightly coloured in emotional and sensual memory. They teach an openness, if the lesson is realised.

Yes, a leaf falls - see, against a wall of brilliant autumn-orange foliage. The veins are revealed now, the process of growth clear in a tracery of delicate lines, its story of sustaining sap and summer abundancy etched distinctly in brilliant decline. Feel the tracings of life, work them into representation of self from the disclosure of the moment.

A leaf falls - see, through the dimmed light of damp, green humidity. It touches and settles, layering its offering of riches to the accumulated humus, the life-wealth of the community. Smell, now, the living diversity, of the spring of forest floor underfoot. An ant comes, appropriating purpose to home-building. Moments shift awareness.

A leaf falls - and is swept into denial, removed, extinguished in the dark confines of The Bin. See, this time, that meaning is fixed - leaves are on branches. Leaves exist passively, where directed to grow. Allow the falling leaf, and the perfection is revealed as mirage. Fixity of purpose is control of meaning, an assurance of stasis. 
For texture and scent, sensory information, exert an attention that cannot be ignored; the outside forces itself upon the inside, awakens trains of thought, raises associations that tremble on the edge of possibility. Bravery lies in daring to grasp the instantaneous, commanding resonance; the embodied passion wraps revelation around the beating heart. The offer is boundless. Receptivity consents to possibility, and the outside presents multiplicities. Keep the mind free and aware, for context changes the perceived and received, and the delight of ideas shakes wonder into joyful wakefulness. And we know the world differently.

Narratives give textual translations of moments. The self is changed but imperceptibly, so gently, that the shift is only recognised through retrospect. These things change and are not spoken: trust and be open; listen for what is offered; ask and admit lack; know some things will remain unknown; accept the presented; hold the moment of awareness of multiplicity; greet possibilities; heed intuition (the amalgamated voice of body, experience and knowledge); and embrace the embodied response that establishes cognition.

For look, the apple falls - Ow! - and Newton is granted access to worlds he may otherwise have never fully engaged. Consider, here, the contributions of subjectivity!

\subsection{APPROACHING THE SUBJECT}

Moving the concept of the self away from a centralised position uncovers the contextual nature of identity; recognising context allows concepts to be introduced into the discourse of the subject, including embodiment, culture, relationships and the role of the other. Acknowledging the integration of individual and context in theorising the subject provides for 'that condition of undecidability' that allows for the very possibility of thought, decision and creativity (Garlick, 2002a, p. 573). It is from the allowance of the possibility of active response, thought and creativeness in the making of meaning which constitutes the very basis of our being human - that a new subject can be conceptualised. 
This proposal of an integrated approach is not without precedence. Deleuze and Guattari suggest a replacement for ontology and phenomenology, that of 'nomadology', that works from a non-sedentary position for writing history (1987, p. 23). Nomad thought, they say, synthesises a multiplicity without hindering the potential for future arrangement of ideas thus expressing 'becoming' rather than 'being' as the central philosophical tenant. This would give a provision for theory to reflect processes of constant renewal and change that are immanent in the multiple. Islam offers the notion of 'positive ontology', where being is in permanent flux and allows a joyous becoming (1996, p. 102). Olkowski (1999), drawing on Deleuze, suggests an 'intuitive ontology' in order to describe the actualising of the virtual multiplicity which is the formation of subjectivity.

Levinas' exposition of the response to the face of the other crucially allows a space for forming the subject through a process of displacing the self as central and situating the self to form new ideas. It allows for encountering the other to be the opening to changing the self through a responsive and ethical act of openness. 'Rather than attempting to fit the other into my scheme of things', writes Levinas, 'I am put into question, effecting the transformation of what I enjoy and suffer from into concepts' (1969, p. 174).

Implicit in the descriptions of Levinas' ethical face-to-face encounter in which the other is not reduced - an interaction that allows the other to 'be' and the self to learn, through a sense of wonder dependent on the open response, from what the other offers in her/his integrity - is the very existence of a sense of 'wonderment'. 'Wonder figures as a specifically embodied ethical relation which has the potential to move us out of ourselves, towards the otherness of the world' writes Fullagar (2001, p. 291), explaining that 'the moment of wonder...is born of an attraction to difference that respects the irreducibility of that otherness' (ibid). Fullagar further adds that 'in the opening of the self through wonder, there is an embodied living of time and space in the present' which contains 'a recognition and respect for the boundaries of otherness' (ibid, p. 302). And wonder, in the end, acts reflexively onto the subject's awareness of new possibilities of self.

Subjectivity - that is, affecting one's own sense of self through choice to access difference - does not equate to self-development or constructing self-identity. It is placing oneself in a relation to the other in the intuitive understanding that 'the other's 
teaching and its ethical dimension, initiate meaning' (Diprose 2002, p. 141). Making meaning, then, is the product of differential relationships but not at the cost of erasing difference.

\subsection{A NEW SUBJECT POSITION}

Here, then, is the proposal. The subject is immanent in the external immanent in the subject. Or, subjectivity is inherent in the physical and perceptual aspects of the self and the world that are inherent in subjectivity. The complexity of the human as being, is that the material world (physical self and experienced environment) is processed into the ideas and conceptualisations that make the world of that being. The individual self opens the world that is external through a thinking about that world that has been developed from experiencing that world. This integration can only be expressed in a cyclical manner: the cognitive informs the physical and the physical informs the developed/changed cognitive which establishes the physical which informs the developed other, ad infinitum.

The implications of an understanding of the subject in this way are several. It is established that the subject is an on-going process, a spiralling loop with no end or closure which is commensurate with the growth and development of the individual. Subjectivity is seen as an active process both physical and cognitive, allowing for individual enactment in the processes of subjectivity. The individual role of both active choice and personal response is accorded a place in this model. The role of randomness, the effect of multiplicities, is included in that the loop is an ongoing process. Similarly, the role for all the 'new' and different that is encountered, the role of the other, is integral in this model. It also allows for the refusal to change, encounter, engage that is also presented across the range of human interaction with the world. Finally, it models the interrelatedness of complexity through the conceptualisation of the ongoing loop of subject development.

From its beginning in an examination of a choice in travelling, there are implications of travel in this understanding of the subject. Travel itself models this concept of the subject, that the physical and cognitive are indispensible aspects of each other. A second implication of travel is that travelling is a choice to 'be' through risking the physical self in new material environments, in order - through engagement - to change understanding of both self and world, to 'be' differently. Furthermore, travel can 
be repeated without becoming repetitive in relation to this model of the subject; it can be undertaken more than once and still offer a new opportunity for different understandings of the world and the self. Based on this model, it can easily be comprehended that travel has been undertaken in many societies, not just western, over more millennia than is currently acknowledged in travel and tourism research. And finally, there is an associated possibility for understanding the dominance of westerners in the profile of current travellers: the entrenched western expectation for single solutions is incompatible with the recognised complexity of the world. This produces a tension that I suggest underlies much of postmodern western society, and travel - for the personal exposition of individual subjectivity - may be the seeking of a resolution to that tension.

Finally, implications for tourism studies, where this thesis originated and remains contextualised, can also be discerned. This model of the subject provides a framework for a different understanding of the traveller. It also provides a new framework for examining motivation to travel. And through this theory of the subject, the on-going effects of travel in, and on, living can be recognised. This opens exciting possibilities for future research.

In relation to Badiou's (2003) expressed need for a new understanding of the postmodern subject, the attributes associated with postmodern being mentioned in 1.5 interest, fascination, play, inventiveness and creativity - can be recognised as incorporated in this model of the subject. These attributes are descriptors of the choice to engage with the world and conceptualise the results, in a dynamic interaction with the multiple presented elements of the encounter. In relation to Levinas' exposition of the ethical encounter, this model acknowledges the response to the other as the position where the openness to the outside acts as a recognition of 'all that is not known' as possibility. And this model supports the travel theories discussed earlier in this thesis. MacCannell writes of the 'spiritual reach of the touristic consciousness' through which the tourist does not try to contain everything in himself, but instead incessantly transgresses the boundaries of his own existence (2000, p. 175). Clifford understands travel as a condition of living, one that is inseparable from dwelling, and as a search for 'difference, wisdom, power, adventure and an altered perspective' that lets uncontrollable, unexpected things occur; as such, travel is a crucial site where being human is constituted by displacement (Clifford, 1997, pp. $31 \& 90$ ). Both place the 
study of travel as offering access to recognising the subject as situated in, woven through, and developing from joyfully embraced multiplicities. 


\section{CONCLUSION: VieWING THE JOURNEY}

This thesis began in an awareness that the dominant paradigm in tourism research is that of objectivity. Through a process of intervention in the spaces of critical knowledge production, this tradition in research of a clear proposition with a definitive, argued outcome was challenged through the use of critical-creative and narrative explorations of a complex phenomenon that is tourism and travel. The result is therefore not a proposition and argument that can be summarised to a single conclusion. In fact, throughout the thesis there has been a consistent criticism of both the possibility and validity of conclusive final statements. Rather, there has been strong emphasis on modelling complexity.

This Conclusion, therefore, is taken as the opportunity to revisit the thesis' originating intrigue and the journey that has ensued in exploring this. The metaphors of travel are deliberate; this is, after all, a project to further understand the nature of travelling and why humans persist in moving around.

\section{Points OF Departure}

The observation that initiated this research was that of a group of travellers, setting out into the unknown, willingly accepting whatever may occur and seeking to meet face-to-face with the people and places that may arise. Their 'unknown' as destination was chosen precisely because they did not know what they would find, what it would be like or what might happen.

The question, then, was; What did it mean to choose the 'unknown' as a destination when, unlike more established tourism practices, it does not provide a framework or specified purpose and has an undefined ending?

Initial searches seemed to indicate such travel is not reflected in tourism studies. However, it also held an indication that something could be learned from examining travel that is specifically open to the singularity of what may happen, to the surprise of the unexpected and where choosing a destination and mode of travel is to deliberately open to the potential of the unpredictable.

This collection of terms - singularity, surprise and the unexpected, openness, potential and unpredictability - were identified as also used in reference to the postmodern subject. Examining the choice of the 'unknown', therefore, holds the 
possibility of extending current understanding of postmodern subjectivity through understanding the traveller subject.

Before moving on to explore this traveller subject and the experience of travel in the choice of the unknown, an examination of the tourism literature indicated a currently expressed need for more flexible and interpretive approaches in tourism research. Qualitative methodologies which use intuitive and creative capacities were suggested as applicable perceptual diagnostic tools because these can reflect the shaded meanings, affiliations and identities that tourists experience in travel (K Hollinshead, 2007, pers. comm.).

In response to this need, a multi-vocal presentation was chosen for the thesis. This multi-vocal presentation is also considered a contribution to tourism studies; through introducing narrative, theoretical and critical-creative writing into tourism studies, it was hoped to expand the exploration of the nature of experience and the relationship of the individual and the other. Through this dismantling of an established approach, concepts of the unknown and the other in travel could be re-examined in a manner to produce unexpected insights. Now we can ask - has this been achieved?

\section{FOLLOWING THROUGH}

In Section 1 Tourism and Travel: Paradoxes in Theory, the position of the tourism researcher was revealed as often awkwardly positioned between multiple disciplines and methodologies. The researcher's personal involvement in the practice of research was acknowledged and the opacity of experiential data also realised.

Definitions of key terms and a summary of the major theories in tourism studies helped establish the parameters of research. The contribution of several disciplines were identified as being specifically applicable in examining the question raised - those of tourism studies, cultural studies, creativity studies and philosophy.

In Section 2 Choosing the Unknown: Paradoxical Nomads an important aspect of this particular research into the experience of travel emerged, that of how the use of tropes, metaphors, discourse and contextualisation, in discussing travel and tourism, can change and challenge the meanings of both the written and spoken word. Discourses develop within particular times and places which determine what it is possible to speak, write, or otherwise communicate (Foucault, 1992) and the discourses of tourism are no exception. It is easier, as Islam noted, to express and discuss travel choices in the 
context of extremes, to map the 'exorbitant differences ignited by nothing less than the spectacular' (1996, p. 157) than to express an intention of being open to the surprise of the unexpected experience. Because the dynamics of the experience may be seen as deriving from 'the way in which the ordinary and extraordinary continuously telescope into one another' (O’Dell, 2005, p. 133), the language of research can sometimes be found to be frustratingly inadequate.

This was demonstrated in attempting to define the term 'unknown' as used in describing a travel destination. It can refer to both the social unknown of cultural difference and the physical unknown of geographical space. It was then suggested that the 'unknown' destination can mean any place in the world - urban, remote, populated - where the unexpected is allowed to unfold. It was acknowledged that unknown can also have implications of freedom from restriction or pilgrimage to a new self, but that these are predicated in a poverty of relation with the place and people of the destination, rather they focus on the internal self. The contribution was put forward that the choice of the unknown as destination is a choice to access diversity and change, such as is found in liminal zones, but that such liminality is identified by the traveller individually.

Section 3 Encountering Difference: The Offer in the Moment led to an account of the experience in travel of the moment of encounter with difference. What was shown was that we consciously change as the situation around us changes. This can occur as a response to a situation we have chosen to inhabit for this moment, as travel can offer, but what is particularly significant is the willingness to see things in a different way. We change through a choice to shift points of view. Across tourism research there are many references to travel, journeying and being a tourist as passages to new ways of life, as spaces where identities evolve, as impacting on the self in some way (for example, White \& White 2004, Wearing \& Wearing 1996, Suvantola 2002); this relationship of change and situation would appear to be the critical element.

It was recognised that there are 'moments of encounter' in travel which are experienced by the individual in very personal ways. The interaction of the traveller, the other and the space in the moment brings multiple factors into play - the embodied nature of travel, individual cultural knowledge, a relationship with difference and the perception of possibilities. These combine to offer a moment of changing awareness. This comes about because in the new situation encountered, some elements are known to the visitor, but that at the same time, 'things are there as objects we contemplate but 
whose meanings in their local context we cannot grasp' (Suvantola, 2002, p. 44). This was the moment when subject, shared object, meaning both known and unknown and new context were brought together, and for the individual subject, this was where the relationship of each element to the other was challenged.

The change to the self that occurred was in the development of new understandings, or conceptualisation. This moment of realisation was similar to the creative moment examined in studies of creativity. Across the research of creativity there is a consistent identification that the process of creativity is an emplaced interaction of individual and immediate environment. It is both situational and responsive. Interaction is realised between the subject (self), the place, the time, the object (materials, people, concepts) and knowledge. Travel consists of acts of movement, transposing the body into spaces whose physical factors are an integral part of the travel experience. The physical relationship is inter-subjective in that it originates from awareness of things and people outside the self, and its embodied awareness comes from the physical presentation of difference. In this way, the creative moment and the moment of encounter in travel could be seen as similar, in placing the individual for the development of new ideas. What was shown to be significant in both creative theory and the traveller, however, was the attitude of openness to whatever was presented in the moment.

The term 'nomad' is recent in tourism studies as a descriptor of travellers whose attitude differs from that of the generalised tourist (Feifer 1985, MacCannell 1992). In particular, MacCannell's (1992) suggestion of a new kind of traveller, the neo-nomad, who wants to create experiences and seeks encounters that embrace difference, was identified as pertinent. MacCannell suggests that the postmodern neo-nomad traveller is an imaginative traveller who enjoys a displacement of self-understanding, that is, embraces the moments when self is contested or disturbed by difference, and who seeks chance meetings and dialogues (ibid, p. 4). This concurred with Syed Islam's identification of two distinct travel orientations, 'sedentary' and 'nomadic'. Nomadic travel is to do with encounters with otherness that fracture both a boundary and an apparatus of representation, and that requires meeting face-to-face with the other, 'without the paranoia of othering that represents the other in relation to oneself' (Islam, 1996, p. vii). 
This moment of encounter in travel, then, could be considered to be precarious, with pleasure on one side and dread on the other. What is occurring in this moment of encounter with difference is a displacement of the self from the central position of certainty through an unpredictable conjunction of elements which provokes a disturbance to the self and which may lead to the creation of insightful perceptions and connections that open new conceptualisations. Travelling can be seen as an activity that provides the opportunity for such moments, which reveal possibilities of existence which were previously concealed (Garlick, 2002b). Travel, then, could be described at a conceptual level as an activity that enables the individual negotiation of identity and subjectivity through a non-reductive relation with the other. This relation with the other is significant to the potential for change in the situation of the moment.

In 4 Other and Event: Philosophy of Possibilities, it was demonstrated that viewing the other simply as a reflection limits, and misleads, the self. The relationship with the other, with difference, needs to be freed of the tendencies of western practices of seeing difference as a problem to be resolved. Levinas' philosophy of the ethical, non-reducing response to difference in the face-to-face encounter with the other provided a philosophical framework for understanding the importance of this relation. The metaphor of the mirror, as reflecting the other for the purposes of the self, was turned another way, to be viewed as portal or threshold, thus becoming the opening to a new space. 'The other is not the simple reversal of identity and is not formed out of resistance but is prior to every initiative' writes Levinas (1969, p. 38); it is not through knowing myself that I know the other, but rather that I am indebted to the other for knowledge of myself (Levinas, in Simms, 1997, p. 11).

Levinas' philosophical understanding of what happens in the encounter with the other resonated with travellers who seek the unknown and with postmodern orientations toward difference. One of the reasons travel research could contribute to philosophical questions of meaning and subjectivity is that tourism is not a one-way action of the tourist upon the host culture but the subjective experience of a two-way interaction between tourist and host (Wearing \& Wearing, 1996). 'Two-way interaction' implies not only the presence of two separate parties and some reaction between them but the importance of that other party. Philosophy seeks to reflect, and reflect upon, the relationship between individuals, individuals and their society, and the personal 
understanding of ourselves in the world, that is, our subjectivity; the presence of the other, I suggest, is integral to the travel and tourism experience.

To understand our relationship to the world, it must be considered as existing within multiplicities (Badiou, 2004, p.xiv). That is, being needs to be understood within of the context of the situations in which we find ourselves. Each situation, described at any one instant, contains many possibilities. Accessing Badiou's (2003) philosophy of the multiple explains that a situation is a presented multiplicity of elements, which are non-particularised and undefined; these elements are the basic units of the structure of the situation. The single event is where any combination of all the elements of the situation is possible; an event is thus marked by the underlying multiplicity of the situation's elements (Badiou, 2004, p. 4). The moment of encounter, then, is demonstrated as a chance event located within a particular situation. The imaginative traveller, who accepts the responsibility inherent in the face of the other, will take the displacement of self-understanding that occurs in the moment when the self is contested or disturbed by difference as a moment that holds the creativity they are seeking in the development of their own subjectivity. Multiplicity and the other must be recognised as integral to the notion of self (Garlick, 2002b, p. 301). The self, then, is constituted through the relation to the unknown engendered in an unstable moment of rupture or disturbance. Such a contribution will allow us to propose a new 'singular, not universal' understanding of the subject, 'because it will always be an event that constitutes the subject', Badiou (2004, p. 4).

From Section 5 Travel for Change: Subjectivity and Wonder, what emerged through the research was the need to theoretically integrate the big and the little, the principle and the particular. This is an exploration of thinking and thinking about thinking - which is the essence of philosophy. And there was a position, because of revealing something of the way in which the subject is both active and responsive, from which a contribution to theories of the subject could be attempted.

Employing what the other has offered is the pathway to new ideas and knowledge. Within this process, the other's difference is incorporated into the individual's thinking but the other's alterity remains. The contemporary subject is a dynamic entity within complexity; the proposal that the subject is immanent in the external which is itself immanent in the subject could be made. The individual self 
opens to the world that is external through a process of thinking about that world that has been developed from experiencing that world.

\section{AN ARrival}

Travel, then, has offered something to philosophy in the form of contributing to the conceptualisations of the subject and likewise, as postulated in 1.1, philosophy has offered something to tourism studies in the provision of a framework to further explore the motivations and aspirations of travel.

The unknown as destination, it is concluded, is chosen for the increased opportunity for changing the traveller's individual perception of the world, that is, their subjectivity. This occurs because the nexus of alterity, the event and the responsive self allows fresh combinations of elements of the experience to form new conceptualisations and ideas. The traveller subject then has a changed relationship to the world through the development of new meanings for their being in the world. In understanding the moment where the traveller is faced with difference, in a situation where there is a conjunction of recognised and unknown elements, theory of creativity, Levinas' philosophy of the encounter and Badiou's philosophy of the multiple have been brought together. These provided an understanding of the moment of creative encounter that travel offers, thus granting a new perspective on travel and the travel experience.

Tourism studies needs to continue to consciously expand beyond the existing boundaries of a limited set of underpinning theoretical assumptions. Allowing the traveller's reading of place and interaction to come to the fore can bring alternative, previously silenced, stories into the main arena of tourism studies.

An awareness of tensions within the study of 'making meaning', of the contested and multiple meanings and interpretations of the concept of the 'travel experience' and that tourism studies' primary discourse is based around theoretical understandings of practical problems, has been important in the consideration of the outcomes of this thesis. While hypothesis-based tourism research can produce results that can be formed into a generalised application, exploratory creative research cannot offer a similar direct research 'product'. However, as a methodology to explore the complex phenomenon of tourism and travel, the approach offered in the thesis is seen as a contribution to the ongoing investigation into differing methods of approaching this phenomenon. In doing so, it addresses the call for alternative approaches, an identified need to further the field 
of tourism studies which is noted in both Section 1 and Section 2. It is hoped that the methodology raises debate and expands discussion rather than being seen as applicable across a range of research; this is particularly so as the methodology chose to include a personal narrative, something that may only be available or relevant to certain research topics.

The contribution to tourism theory presented in this thesis is that of Levinas' case for the other being critical to our understanding of self, through meeting the difference of the other in the face-to-face encounter. For tourism theory, this offers another insight into the choice to travel, where seeking the unknown, in whatever form that may be for the individual, can be understood as seeking new understanding through the moment of face-to-face encounter with the other in the development for new meanings of being in the world. This consideration has in turn allowed tourism studies to make a contribution to the philosophy of the subject, one of the core debates in philosophical thought (Badiou, 2003). Examining the travel experience has identified the moment of encounter in travel when a person has to change; they cannot, by virtue of the real space they inhabit at this real-time moment, continue to be what they were up until this instant. The philosophical statement is therefore made that travel choice positions the person for the chance/unpredictable event which only lies in the encounter with the other, for the creative moment that alters subjectivity, thus allowing the Other's face to form me. It is concluded that this is the 'something that affects the individual in some way' noted in tourism literature in both Section 1 and Section 2. This contribution developed through applying critical theory to the unknown and the moment in respect to travel and provides new understandings of the outcomes of travel and therefore one of the reasons we 'go'. I sincerely offer this thesis as demonstrating the effectiveness of incorporating a multivocal methodology that at the same time can contribute a new perspective to tourism research which will offer greater dimension to understanding the nature of the travel experience.

The central situation of this thesis, then, is that travel offers the potential for moments that generate new ideas and therefore new meanings, altering the subjectivity of the traveller. The choice of the unknown as destination in travel is an acknowledgement and eager engagement with the understanding that the other's face forms me.

And, finally, the sailing narrative must also have its conclusion ... 


\section{- NarRative 6: Epilogue - RetUrn to KNOWN •}

Once shapely Double Island Head was well abeam, we could see that the whole coast carried a hovering parallel line of dense atmospheric haze above it and that the pall stretched away past the southern horizon. Oblion, however, steadfastly pushed her way through a calm sea past the long southern Queensland beaches until the sun lowered, turned to fiery gold then vibrant orange by the thickened atmosphere. Each swell of ocean was severed by colour, half silvered blue, half burning copper, colour laid across the ocean in a bold sweep. Mt Coolum's isolated cone lay in direct transit between Oblion and the now bloodred sun, to become an ebony cardboard cut-out holding a brilliant, dying aureole for a long, suspended turn until the world tilted toward night.

We were heading for one of the marinas in Mooloolaba where it had been arranged that Oblion would be put up for sale. Stuart was recovering but our time sailing was at an end. Around Oblion, Noosa's light winked on and the loom of Point Cartwright lighthouse began to flicker on the horizon. The sea and sky fell softly into black and Oblion's engine thumped quietly on. The girls required dinner and practicalities blocked thoughts of endings. The shoals near Mooloolaba, trawling lights to starboard, a possible masthead light off the bow these required unhurried watchfulness. The masthead light belonged to a little catamaran that cut under our bow as it tried to pick up the leads immediately outside the entrance. It found them, slowed down sharply as it turned to follow them in and almost had Oblion slicing its stern in two. I swore at the oblivious and stupid skipper in good solid navvy language before it slipped off toward the river's night-shadowed inner moorings. Oblion had to be delivered to Laurie's Marina, the furthest up river. It was midnight now and Bob agreed we should pick up a berth at the closer Wharf marina with which we are both familiar.

I eased Oblion around the marina arm, skipping the first available berth only to be hailed from the stern of a moored yacht.

'This way, slow down now-' he began. 
'Shut up!' I shouted. The awareness was suddenly there of successfully skippering my yacht more than a thousand miles to a safe ending. 'I know what I'm doing!'

I brought Oblion to a perfectly placed, impeccable berthing. Bob hopped silently onto the pontoon and made fast neatly. I killed the engine. Bob straightened up and grinned. 'Well, what would you like, Skipper?'

Thoughts of champagne, dinner, the pub lights and music ... I looked him straight in the eye.

'A shower.'

I never sailed Oblion again. The next morning I 'did a Stuart' as my diary puts it. Waking very early to a mirror-still river, I cast Oblion off singlehanded while everyone remained asleep below, pushing her out and starting the motor as she drifted, then quietly taking her up river to the agent's mooring in Laurie's Marina. There she was washed, scrubbed, tidied and made shipshape generally, ready for sale.

Stuart, recovering slowly, flew back from Adelaide to a big welcome a few days later. I heard the story of his arrival in Adelaide: 'I had this great line planned. Mum and my twin brother were coming to meet me and I was going to come down the stairs and say 'I've been relieved of my command'. And then, when I did see them, I just burst into tears ... waste of a good line ...'

Many familiar yachts were arriving for a secure berth at Mooloolaba, in preparation for the upcoming cyclone-season, and as we packed our belongings and finished cleaning Oblion, a steady stream of visitors came to hamper our efforts, distract our intentions and fill our hearts with love. The folk from yachts we had shared the ocean with now shared in farewells. We learnt that the smoke was from fires close to the Glasshouse Mountains and that Bribie Island was still ablaze: other people had their own problems in this wide world. 
Three weeks later I held Alison's hand tightly as the plane left the tarmac of Brisbane airport. Stuart and Elizabeth were playing with the headphones. Oblion had been sold, suburban living and high school lay ahead. The plane banked: below, spread out like a coloured chart, were the banks and channels of Moreton Bay. The islands, the white lines of beaches and, beyond, the infinite stretch of blue Pacific, beckoning, beckoning, silently, insistently, calling to me in the voices of all those who had woven their lives into ours.

Wait for me. 


\section{- Bibliography •}

Alston, K. 2001, 'Re/Thinking Critical Thinking: The Seductions of Everyday Life', Studies in Philosophy and Education, vol. 20, pp. 27-40.

Arnould, E.J. \& Price, L.L. 1993, 'River Magic: Extraordinary Experience and the Extended Service Encounter', The Journal of Consumer Research, vol. 20, no. 1, pp. 24-45.

Badiou, A. 2003, Infinite Thought: Truth and the Return to Philosophy, trans. O. Feltham \& J. Clemens, Continuum, London.

Badiou, A. 2004, Theoretical Writings, trans. R. Brassier \& A. Toscano, Continuum, London.

Bauman, Z. 1996, 'From Pilgrim to Tourist - or a Short History of Identity', in S. Hall (ed.), Questions of Cultural Identity, Sage, London.

Bayles, D. \& Orland, T. 1993, Art \& Fear: Observations on the Perils (and Rewards) of Artmaking, Image Continuum Press, Santa Cruz.

Bernstein, R. 1991, The New Constellation: The Ethical/Political Horizons of Modernity/Postmodernity, MIT Press, Cambridge, Massachusetts.

Beverley, J. 2003, 'Testimonio, subalternity and narrative authority', in N. Denzin \& Y. Lincoln (eds), Strategies of Qualitative Inquiry, Sage, California, USA.

Bhabha, H.K. 1994, The Location of Culture, Routledge, London.

Bindeman, S. 1998, 'Echoes of Silence: A Phenomenological Study of the Creative Process', Creativity Research Journal, vol. 11, no. 1, pp. 69-77.

Borrie, W.T. \& Roggenbuck, J.W. 2001, 'The Dynamic, Emergent, and Multi-Phasic Nature of On-Site Wilderness Experiences', Journal of Leisure Research, vol. 33, no. 2, pp. 202-228.

Bourdieu, P. 1984, Distinction: A Social Critique of the Judgement of Taste, trans. R. Nice, Routledge \& Kegan Paul, London.

Bourdieu, P. 1990, In Other Words: Essays Toward a Reflexive Sociology, trans. M. Adamson, Stanford University Press, Stanford, California.

Bourdieu, P. 1991, Language and Symbolic Power, trans. M. Adamson \& G. Raymond, Harvard University Press, Cambridge, Massachusetts.

Braidotti, R. 1994, Nomadic subjects: embodiment and sexual difference in contemporary feminist theory, Columbia University Press, New York.

Braidotti, R. 2006, Transpositions: on nomadic ethics, Polity Press, Cambridge, UK. 
Brandt, K. 2006, 'Intelligent Bodies: Embodied Subjectivity Human-Horse Communication', in D. Waskul \& P. Vannini (eds), Body/embodiment: symbolic interaction and the sociology of the body, Ashgate Publishing Limited, Aldershot, England.

Brook, S. 2002, 'Does anybody know what happened to "fictocriticism"?' Cultural Studies Review, vol. 8, no. 2, pp. 104-118.

Brown, J., Collins, A. \& Duguid, P. 1989, 'Situated cognition and the culture of learning', Educational Researcher, vol. 18, no. 1, pp. 32-42.

Bruner, E.M. 1991, 'Transformation of Self in Tourism', Annals of Tourism Research, vol. 18 , pp. $238-250$.

Butler, J. 1990, Gender trouble: feminism and the subversion of identity, Routledge, New York.

Butler, J. 1997, The Psychic Life of Power, Stanford University Press, Stanford.

Carter, P. 1992, Living in a new country: history, travelling and language, Faber, London.

Cary, S. 2004, 'The Tourist Moment', Annals of Tourism Research, vol. 31, no. 1, pp. 61-77.

Chadwick, R. 1994, 'Concepts, Definitions, and Measures Used in Travel and Tourism Research', in J.R. Ritchie \& C.R. Goeldner (eds), Travel, tourism and hospitality researchers, 2nd edn, Wiley, New York, pp. 65-77.

Chessel, D. 2009, Chessel Adventures: Himalayas - Everest Expedition 2010, viewed 10 September 2009 <http://www.dcxp.com/aspx/himalayas-trips>.

Clifford, J. 1997, Routes: Travel and Translation in the Late Twentieth Century, Harvard University Press, Cambridge, Massachusetts.

Cohen, E. 1973, 'Nomads from Affluence: Notes on the Phenomenon of DrifterTourism', International Journal of Comparative Sociology, vol. 14, pp. 89-103.

Collier, G. 1972, Art and the Creative Consciousness, Prentice-Hall, Engelwood Cliffs, NJ.

Crick, M. 1991, 'Tourists, locals and anthropologists: quizzical reflections on 'Otherness' in tourist encounters and in tourism research', Australian Cultural History vol. 10, pp. 6-18.

Csikszentmihalyi, M. 1990, 'The domain of creativity', in M.A. Runco \& R.S. Albert (eds), Theories of Creativity, Sage, Newbury Park, CA. 
Dann, G. 1996, The language of tourism: A sociolinguistic perspective, CAB International, Wallingford UK.

Davidson, K. 2005, 'Alternative India: Transgressive Spaces', in A. Jaworski \& A. Pritchard (eds), Discourse, Communication and Tourism, Channel View Publications, Clevedon, UK.

Davies, P. 1993, 'The Face and the Caress', in D.M. Levin (ed.), Modernity and the Hegemony of Vision, University of California Press, California, USA.

De Botton, A. 2002, The art of travel, Hamish Hamilton, London.

Dean, J. 2005, 'The politics of avoidance: the limits of weak ontology (1)', The Hedgehog Review, vol. 7, no. 2, pp. 55-66.

Deleuze, G. \& Guattari, F. 1987, A Thousand Plateaus: capitalism and schizophrenia, trans. B. Massumi, University of Minnesota Press, Minneapolis.

Denzin, N. 1997, Interpretive Ethnogrpahy: Practices for the twenty-first century, Sage Publications., Thousand Oaks, CA.

Denzin, N. \& Lincoln, Y. 2003, Strategies of Qualitative Inquiry, Sage, California, USA.

Desforges, L. 2000, 'Travelling the World: Identity and Travel Biography', Annals of Tourism Research, vol. 27, no. 4, pp. 926-945.

Diprose, R. 2002, Corporeal Generosity, State University of New York Press, Albany, NY.

Dodgson, M. 2007, 'The Language of Innovation', in R. Williams (ed.), Lies, Deep Fries \& Statistics, ABC Books, Sydney, NSW.

Doron, A. 2005, 'Encountering the "other": pilgrims, tourists and boatmen in the city of Varanasi', The Australian Journal of Anthropology, vol. 16, no. 2, pp. 157-179.

Droit, R. 2005, How Are Things? A philosophical experiment, trans. T. Cuffe, Faber \& Faber, London.

Dutch, R. (ed.) 1966, Roget's Thesaurus of English words and phrases, Penguin Books Ltd, Harmondsworth, England.

Eisner, E.W. 1983, 'On the relationship of conception to representation', Art Education, vol. March, pp. 22- 27.

Feifer, M. 1985, Going Places, Macmillan, London.

Fenner, F. (ed.) 2008, Handle with Care: 2008 Adelaide Biennial of Australian Art, Art Gallery of South Australia, Adelaide, South Australia. 
Fife, W. 2004, 'Penetrating Types: Conflating Modernist and Postmodernist Tourism on the Great Northern Peninsula of Newfoundland', Journal of American Folklore, vol. 117 , no. 464 , pp. 147-167.

Fleming, C. \& Fullagar, S. 2007, 'Reflexive methodologies: An autoethnography of the gendered performance of sport/management', Annals of Leisure Research, vol. 10, no. 3-4.

Fløistad, G. (ed.) 1986, Contemporary philosophy, Martinus Nijhoff Publishers, Dordrecht.

Foucault, M. 1992, The History of Sexuality, trans. R. Hurley, Penguin, London.

Foucault, M. 1981, 'The order of discourse', in R. Young (ed.), Untying the Text: A Poststructuralist Reader, Routledge \& Kegan Paul, London.

Foucault, M. 1988, The Care of the Self, trans. R. Hurley, Vintage Books, New York.

Foucault, M. 1997, 'On the Geneaology of Ethics: An Overview of Work in Progress', in P. Rabinow (ed.), Ethics: Subjectivity and Truth, The New Press, New York.

Gablik, S. 1991, The Re-enchantment of Art, Thames \& Hudson, New York, N.Y.

Garlick, S. 2002a, 'The beauty of friendship: Foucault, masculinity and the work of art ', Philosophy \& Social Criticism, vol. 28, no. 5, pp. 558-577.

Garlick, S. 2002b, 'Revealing the Unseen: tourism, art and photography', Cultural Studies Review, vol. 16, no. 2, pp. 289-305.

Garoian, C. \& Mathews, J. 1996, 'A common impulse in art and science' Leonardo, vol. 23 , no. $2 / 3$, pp. $209-214$.

Getzels, J.W. \& Csikszentmihalyi, M. 1988, 'Creativity and problem finding in art', in F.H. Farley \& R.W. Neperud (eds), Foundations of Aesthetics, Art and Art Education, Praeger, New York.

Gibbs, A. 1997, 'Bodies of Words: Feminism and Fictocriticism - explanation and demonstration ', Text, vol. 1, no. 2.

Gieryn, T.F. 2000, 'A Space for Place in Sociology', Annual Review of Sociology, vol. Annual 2000.

Gilmore, R. 2005, Doing Philosophy at the Movies, State University of New York Press, Albany, NY.

Gruber, H.E. 1989, 'The evolving systems approach to creative work', in D.B. Wallace \& H. Gruber (eds), Creative People at Work: Twelve Cognitive Case Studies, Oxford University Press, New York. 
Gubrium, J., \& Holstein, J. 2003, 'Analysing Interpretive Practice', in N. Denzin \& Y. Lincoln (eds), Strategies of Qualitative Inquiry, Sage, California, USA.

Gurevitch, Z. 1999, 'The Tongue's Break Dance: Theory, Poetry, and the Critical Body', The Sociological Quarterly, vol. 40, no. 3, pp. 525-540

Hall, C. M. 2003, Introduction to tourism: dimensions and issues, Hospitality Press, Frenchs Forest, NSW.

Holland, P. \& Huggan, G. 1998, Tourists with Typewriters, University of Michigan Press, Michigan.

Hollinshead, K. 2004, 'Tourism and new sense; Worldmaking and the enunciative value of tourism', in C.M. Hall \& H. Tucker (eds), Tourism and Postcolonialism: Contested Discourses, Identities and Representations, Routledge, London, UK.

Horne, D. 1992, The Intelligent Tourist, Margaret Gee Publishing, McMahon's Point, NSW.

Huggan, G. 2001, The postcolonial exotic: marketing the margins, Routledge, London, UK.

Hutchinson, S. \& Samdahl, D. 2000, 'Reflections on the "voice of authority" in leisure research and practice', Society and Leisure, vol. 23, no. 1, pp. 237-250.

Islam, S.M. 1996, The ethics of travel: from Marco Polo to Kafka, Manchester University Press, Manchester, UK.

Jamal, T. \& Everett, J. 2004, 'Resisting Rationalism in the Natural and Academic LifeWorld: Critical Tourism Research or Hermeneutic Charity?' Current Issues in Tourism, vol. 7, no. 1, pp. 1-19.

Jamal, T. \& Hollinshead, K. 2001, 'Tourism and the forbidden zone: the undeserved power of qualitative enquiry', Tourism Management, no. 22, pp. 63-82.

Janesick, V. 2003, 'The Choreography of Qualitative Research Design: Minuets, Improvisation, and Crystallisation', in N. Denzin \& Y. Lincoln (eds), Strategies of Qualitative Inquiry, Sage, California, USA.

Jaworski, A. \& Pritchard, A. (eds) 2005, Discourse, Communication and Tourism, Channel View Publications, Clevedon, UK.

Jensen, S. 2005, 'Promoting the Known and the Unknown of Cities and City regions', in T. O’Dell \& P. Billing (eds), Experiencescapes: Tourism, Culture and Economy, Copenhagen Business School Press, Copenhagen, Denmark.

Johnson, M. 1987, The Body in the Mind: The Bodily Basis of Meaning, Imagination and Reason, University of Chicago Press, Chicago. 
Khair, T., Leer, M., Edwards, J.D. \& Ziadeh, H. (eds) 2006, Other Routes: 1500 years of African and Asian travel writing, Signal Books Limited, Oxford, UK.

Krippendorf, J. 1989, The holiday makers: understanding the impact of leisure and travel, trans. V. Andrassy, Butterworth-Heinemann, Oxford.

Lechte, J. 1995, '(Not) Belonging In Postmodern Space', in S. Watson \& K. Gibson (eds), Postmodern Cities and Spaces, Blackwell Publishers, Cambridge, Massechusetts.

Lefebvre, H. 1991, The Production of Space, Blackwell, Oxford.

Leith, V.B. (ed.) 2001, The Norton Anthology of Theory and Criticism, W W Norton \& Company Inc, New York.

Levinas, E. 1969, Totality and infinity: an essay on exteriority, trans. A. Lingis, Duquesne University Press, Pittsburgh, Pennsylvania.

Levinas, E. 1987, Time and the other and additional essays, trans. R.A. Cohen, Duquesne University Press, Pittsburgh, Pennsylvania.

Levinas, E. 1998, Otherwise than Being, or Beyond Essence, trans. A. Lingis, Duquesne University Press, Pittsburgh, Pennsylvania.

Lincoln, Y.S. \& Guba, E.G. 2005, 'Paradigmatic controversies, contradictions, and emerging confluences', in N.K. Denzin \& Y.S. Lincoln (eds), Handbook of Qualitative Research, Sage Public, Thousand Oaks, CA.

Lubart, T.I. \& Sternberg, R.J. 1995, 'An investment approach to creativity: Theory and data', in S.M. Smith, T.B. Ward \& R.A. Finke (eds), The Creative Cognition Approach, MIT Press, Cambridge.

MacCannell, D. 1979, The Tourist: a new theory of the Leisure Class, University of California Press, Los Angeles, California.

MacCannell, D. 1989, 'Semiotics of Tourism', Annals of Tourism Research, vol. 16, pp. $1-6$.

MacCannell, D. 1992, Empty Meeting Grounds; the tourist papers, Routledge, London.

MacCannell, D. 2000, 'Symbolic capital: urban design for tourism', Journeys, vol. JuneDec, pp. 157-183.

MacCannell, D. 2002, 'The Ego Factor in Tourism', Journal of Consumer Research, vol. 29, iss. June, pp. 146-151.

Mace, M. 1997, 'Toward an understanding of creativity through a qualitative analysis of contemporary art making', Creativity Research Journal, vol. 10, no. 2-3, pp. 265278. 
Mandler, G. 1995, 'Origins and consequences of novelty', in S.M. Smith, T.B. Ward \& R.A. Finke (eds), The Creative Cognition Approach, MIT Press, Cambridge.

Martindale, C. 1989, 'Personality, situation and creativity', in J.A. Glover, R.R. Ronning \& C.R. Reynolds (eds), Handbook of Creativity, Plenum Press, New York. Maslow, A. 1962, Toward a psychology of being, D Van Nostrand, Princeton, NJ. Meinig, D.W. 1979, The Beholding Eye: Ten Versions of the Same Scene, in D.W. Meinig (ed.), The Interpretation of Ordinary Landscapes, Oxford University Press, Oxford.

Morris, M. 1995, 'Life as a Tourist Object in Australia', in M. Lanfant, J. Allcock \& E. Bruner (eds), International Tourism: Identity and Change, Sage Publications Ltd, London, UK.

Muecke, S. 1997, No Road (Bitumen All The Way), Fremantle Arts Centre Press, Perth, W.A.

Nozick, R. 1981, The examined life: philosophical meditations, Simon and Schuster, New York.

O’Dell, T. \& Billing, P. (eds) 2005, Experiencescapes: Tourism, Culture and Economy, Copenhagen Business School Press, Copenhagen, Denmark.

Olkowski, D. 1999, Gilles Deleuze and the Ruin of Representation, University of California Press, Berkeley.

Orians, G. 1986, 'An ecological and evolutionary approach', in D. Lowenthal (ed.), Landscape meanings and values, Allen \& Unwin, London.

Page, S. 2003, Tourism management: managing for change, Butterworth-Heinemann, Boston, MA.

Parry, D. \& Johnson, C. 2007, 'Contextualizing Leisure Research to Encompass Complexity in Lived Leisure Experience: The Need for Creative Analytic Practice', Leisure Sciences, vol. 29, pp. 119-130.

Patrick, N. 1990, Curtis Coast, Riverston's Holdings, Gladstone, Australia.

Pearce, P.L. 1982, The social psychology of tourist behaviour, Pergamon Press, Oxford, UK.

Pezzullo, P. 2007, Toxic tourism: rhetorics of pollution, travel and environmental justice, The University of Alabama Press, Alabama.

Phillips, M. 2008, 'Creativity's crossing forces: a danced interplay', viewed 18 Aug 2008 $<$ www.cci.edu.au/publications > 
Pinder, D. 2005, 'Arts of Urban Exploration', Cultural Geographies, vol. 12, no. 4, pp. 383-396.

Plog, S. 1994, 'Developing and using psychographics in Tourism Research', in J.R.B. Ritchie \& C.R. Goeldner (eds), Travel, tourism, and hospitality research: a handbook for managers and researchers, Wiley, New York.

Pratt, M.L. 1992, Imperial Eyes: studies in travel writing, Routledge, London.

Richards, G. \& Wilson, J. 2006, 'Developing creativity in tourist experiences: A solution to the serial reproduction of culture?' Tourism Management, no. 27, pp. 12091223.

Richardson, L. 2000, 'Evaluating Ethnography', Qualitative Inquiry, no. 6, pp. 253-255.

Robb, S. 2001, 'Fictocritical sentences', PhD thesis, University of Adelaide, Adelaide, South Australia.

Rose, G. 1997, 'Situating knowledges: positionality, reflexivities and other tactics', Progress in Human Geography, vol. 21, no. 3, pp. 305-320.

Ryan, S. 1996, The Cartographic Eye, Cambridge University Press, Cambridge, UK.

Ryan, C 1997, The tourist experience: A new introduction, Cassell, London.

Said, E. 1978, Orientalism, Pantheon Books, New York.

Sallis, E. 1998, Hiam, Allen \& Unwin, St Leonards, N.S.W.

Shapiro, R. 1996, 'Ethics, the literary Imagination, and the Other', Journal of Australian Studies, vol. 50/51, iss. 'Fabrications'.

Simms, K. (ed.) 1997, Ethics and the Subject, Rodopi, Amsterdam, Atlanta.

Soja, E.W. 1996, Thirdspace: Journeys to Los Angeles and Other Real-and-Imagined Places, Blackwell, Cambridge, MA.

Spanos, W. 2000, 'The Question of Philosophy and Poiesis in the Posthistorical Age: Thinking/Imagining the Shadow of Metaphysics', boundary 2, vol. 27, no. 1, pp. 151-168.

Starkey, K. \& Hatchuel, A. 2002, 'The Long Detour: Foucault's History of Desire and Pleasure', Organization, vol. 9, no. 4, pp. 641-657.

Suvantola, J. 2002, Tourist's experience of place, Ashgate, Hampshire, England

Symons, S. 2006, 'Deleuze and the Various Faces of the Outside', Theory \& Event, vol. 9, no. 3 .

Tedlock, B. 2003, 'Ethnography and Ethnological Representation', in N. Denzin \& Y. Lincoln (eds), Strategies of Qualitative Inquiry, Sage, California, USA. 
Tenhouten, W.D. 1996, 'Introduction: sociology of emotions', International Journal of Sociology and Social Policy, vol. 16, no. 9/10, pp. 1-20.

Tierny, W. 2003, 'Undaunted courage; life history and the postmodern challenge', in N.

Denzin \& Y. Lincoln (eds), Strategies of Qualitative Inquiry, Sage, California, USA.

Tobin, J. 2004, Creativity and the poetic mind, Peter Lang, New York.

Todd, J. 2005, 'Social transformation, collective categories, and identity change', Theory and Society, vol. 34, pp. 429-463.

Tribe, J. 2006, 'The Truth about Tourism', Annals of Tourism Research, vol. 33, no. 2, pp. 360-381.

Tribe, J. 2008, 'The Art of Tourism', Annals of Tourism Research, vol. 35, no. 4, pp. 924-944.

Trinh, T.M.-H. 1994, 'Other than myself/my other self', in G. Robertson, M. Mash, L. Tickner, J. Bird, B. Curtis \& T. Putnam (eds), Travellers tales: narratives of home and displacement, Routledge, London.

Uriely, N. 2005, 'The Tourist Experience: Conceptual Developments', Annals of Tourism Research, vol. 32, no. 1, pp. 199-216.

Urry, J. 1990, Tourist gaze: leisure and travel in contemporary societies, Sage, London UK.

Veijola, S. \& Jokinen, E. 1994, 'The body in tourism', Theory, Culture and Society, vol. 11, pp. 125-151.

Ventegodt, S., Merrick, J. \& Andersen, N.J. 2003, 'Quality of Life Theory III. Maslow Revisited', The Scientific World, vol. 3, pp. 1050-1057.

Voase, R. 2007, 'Individualism and the "new tourism": a perspective on emulation, personal control and choice', International Journal of Consumer Studies, vol. 31, pp. 541-547.

Wearing, B., and Wearing, S. 1996, 'Refocussing the tourist experience: the flaneur and the chorister', Leisure Studies, no. 15, pp. 229-243.

Wearing, B. 1998, Leisure and Feminist Theory, Sage, London.

Wearing, S., Stevenson, D. \& Young, T. in press 2009, Tourist Cultures:Identity, Place and the Traveller, Sydney, Australia.

Weaver, D. \& Oppermann, M. 2000, Tourism Management, John Wiley \& Sons, Milton, Australia. 
White, N. \& White, P. 2004, 'Travel as Transition: Identity and Place', Annals of Tourism Research, vol. 31, no. 1, pp. 200-218.

Williams, R. 1976, Keywords: a vocabulary of culture and society, Croom Helm, London.

Woods, T. 1997, 'The Ethical Subject: The Philosophy of Emmanuel Levinas', in K. Simms (ed.), Ethics and the Subject, Rodopi, Amsterdam, Atlanta.

Wyndham, J. 1951, The Day of the Triffids, Penguin Books in association with M.Joseph, Harmondsworth, England.

Zajonc, A. 1993, Catching the light: the entwined history of light and mind, Bantam Books, New York, New York. 